\title{
PHYSICS-BASED RELIABLITY ASSESSMENT OF EMBEDDED PASSIVES
}

\author{
A Dissertation \\ Presented to \\ The Academic Faculty \\ By \\ Manoj Kumar Damani \\ In Partial Fulfillment \\ Of the Requirements for the Degree \\ Masters of Science in Mechanical Engineering
}

Georgia Institute of Technology

July 2004

Copyright $\odot 2004$ by Manoj Kumar Damani 


\section{PHYSICS-BASED RELIABLITY ASSESSMENT OF EMBEDDED PASSIVES}

Approved by:

Dr. Suresh K. Sitaraman, Chair

Dr. Peter Hesketh

Dr. Manos Tentzeris

Dr. Swapan Bhattacharya.

July 12, 2004 


\section{ACKNOWLEDGEMENTS}

I would like to thank my advisor Dr. Suresh K. Sitaraman for his encouragement and support throughout my Master's program. His advice has helped me advance both academically and professionally. I would also like to thank Dr. Tentzeris, Dr. Hesketh and Dr. Bhattacharya for agreeing to be on my thesis committee.

I would like to thank Dr. Bhattacharya for his support and his insight throughout the project. His knowledge of passives was very helpful in helping me complete this project. In addition, I would like to thank Dr. Pucha for helping me on various aspects of my project. Some other CASPaR members I would like to thank are Jamie Ahmad, Andy Perkins, Krishna Tunga and Shashikant Hegde. Their detailed knowledge in many subjects helped me learn a lot about packaging. I would also like to thank PRC for their support in this project.

Finally I would like to thank my Dad and Mom for believing in me and encouraging me throughout the project. I would also like to thank my Sister, Pallavi and Brother-in-Law Nishant for their good wishes. I would like to dedicate this thesis to them. 


\section{TABLE OF CONTENTS}

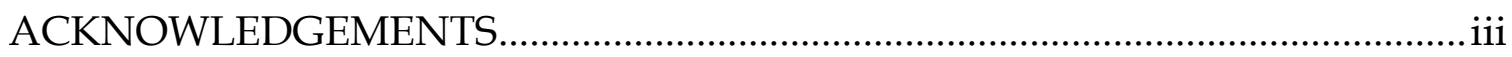

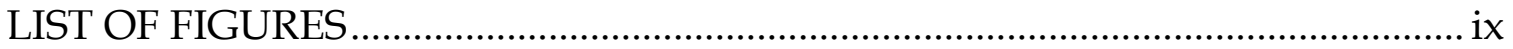

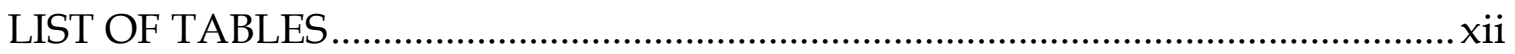

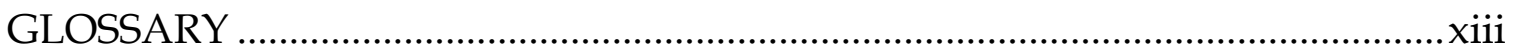

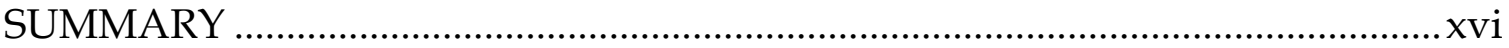

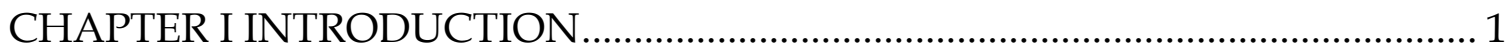

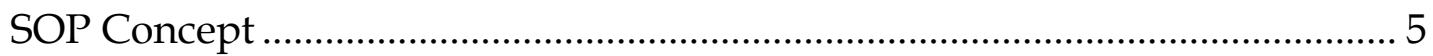

Thermo-Mechanical Reliability of Integral Passives............................................ 6

CHAPTER II BACKGROUND ON PERFORMANCE AND RELIABILITY ........... 8

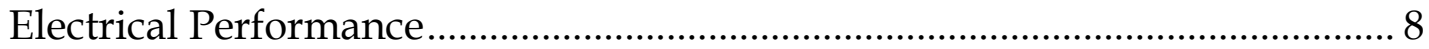

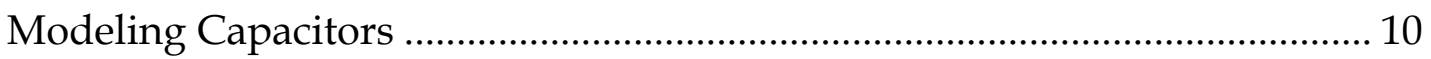

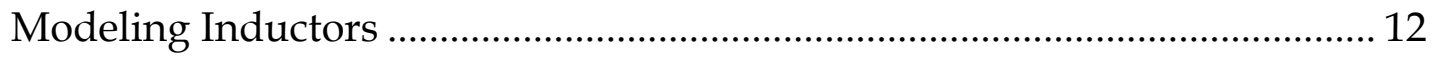

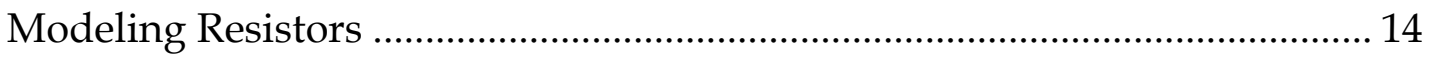

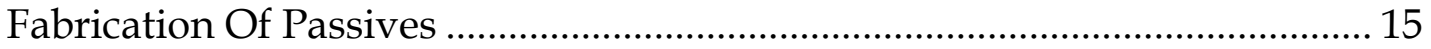

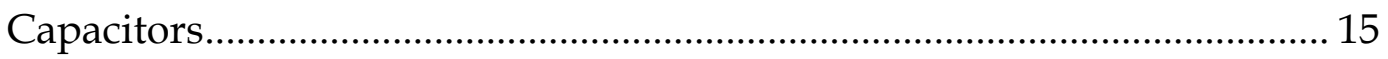

Physical Vapor deposition (PVD) ............................................................. 16

Chemical Vapor Deposition (CVD) .......................................................... 17

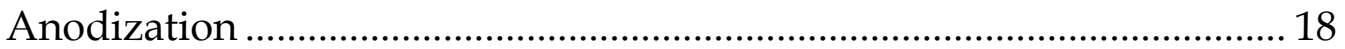

Solution-Based: Physical ........................................................................... 20

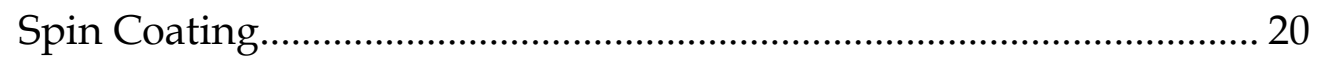




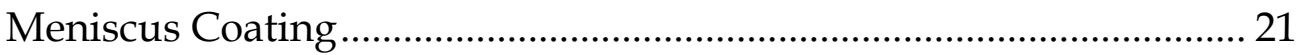

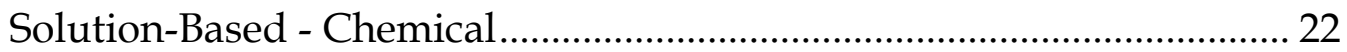

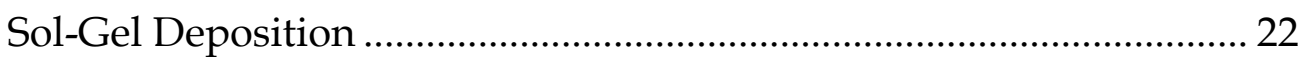

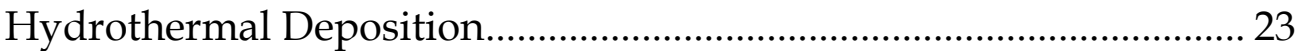

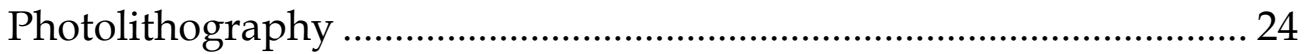

Commercialized Dielectric Materials for Capacitors.................................. 25

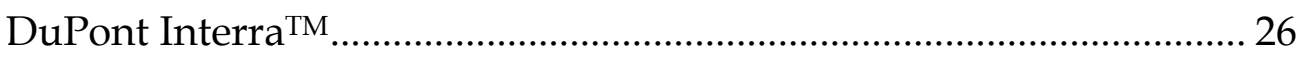

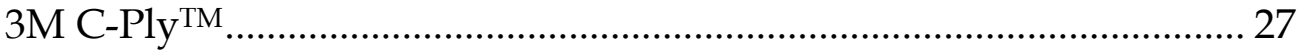

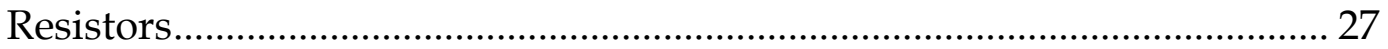

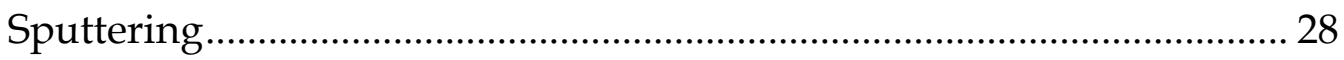

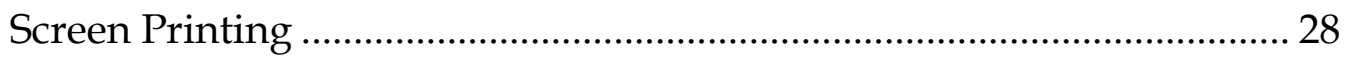

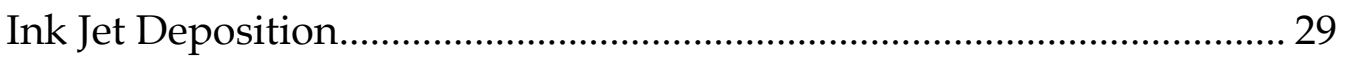

Commercialized Processes for Resistors .................................................... 30

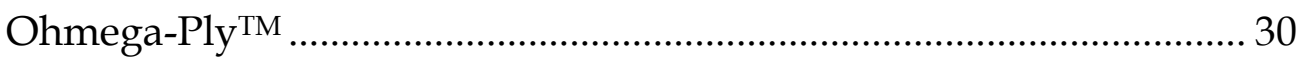

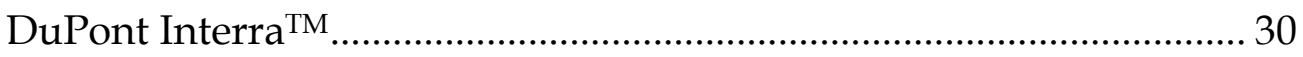

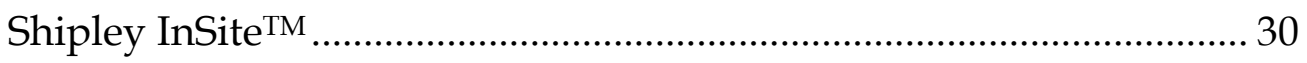

Reliability Experiments ............................................................................... 31

Literature Review on passing qualifications for Embedded Passives ............ 33

Literature Review on Qualification Tests of Embedded Passives ................... 35

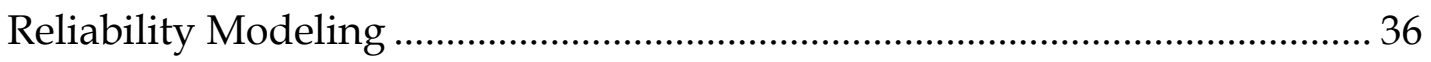

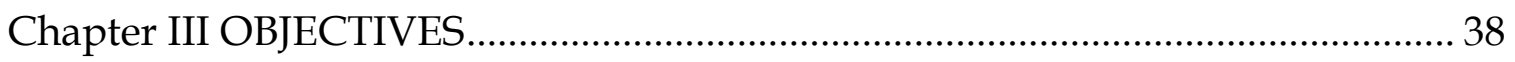

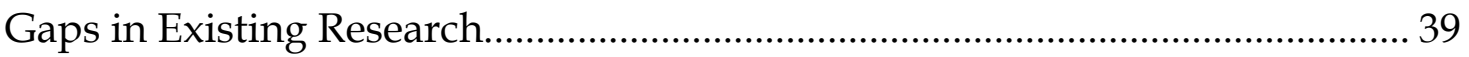


Chapter IV DESCRIPTION OF TEST VEHICLE ....................................................... 41

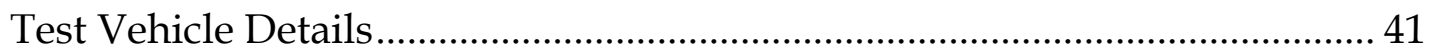

Fabrication Steps and Processing Conditions .................................................... 43

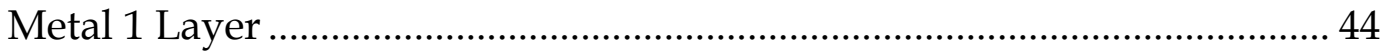

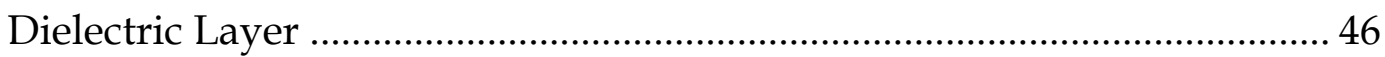

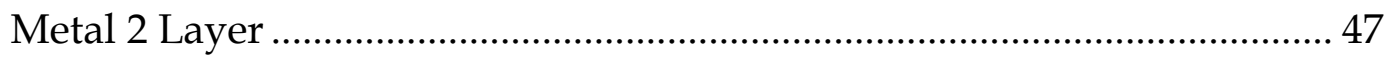

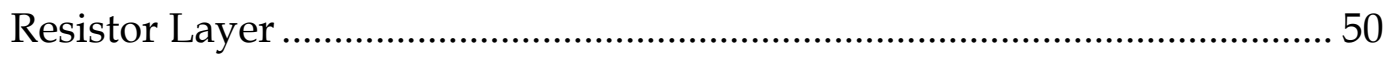

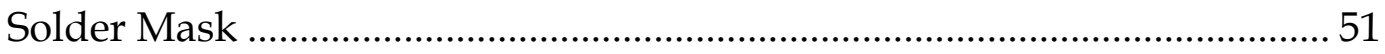

CHAPTER V MODELING OF INTEGRAL PASSIVES …………………………...... 54

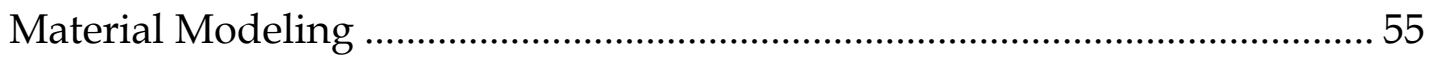

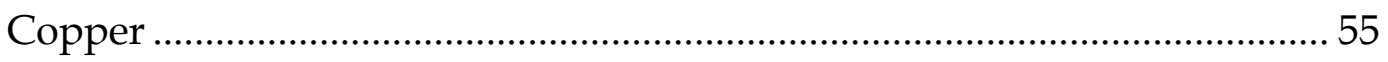

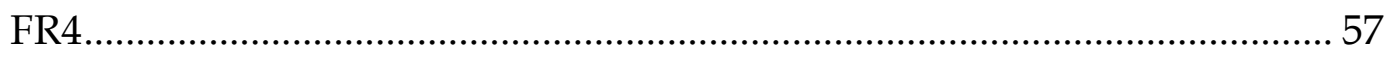

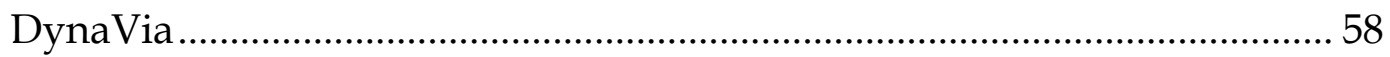

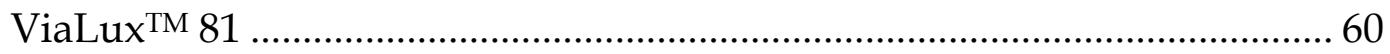

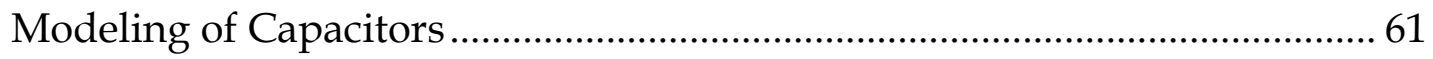

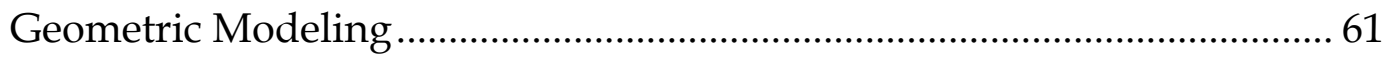

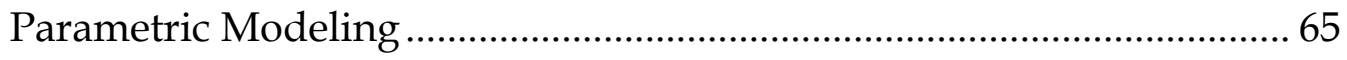

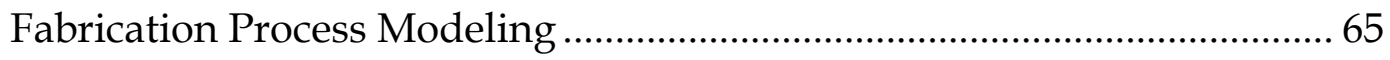

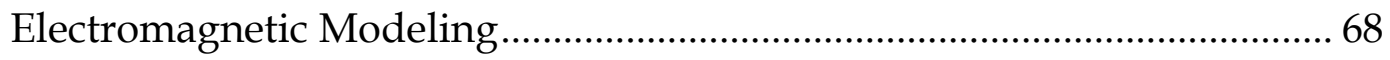

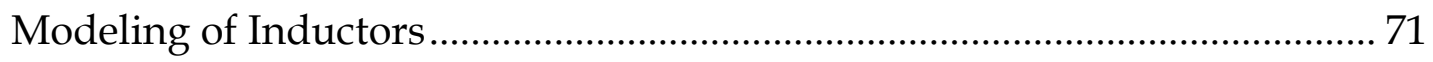

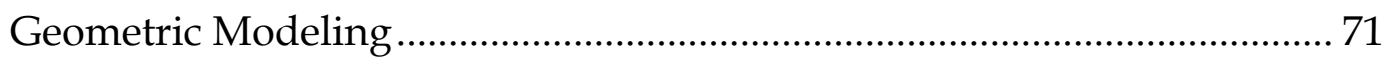

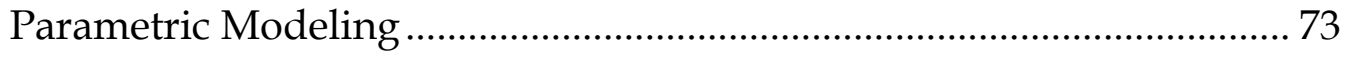


Electromagnetic Model

\section{CHAPTER VI THERMO-MECHANICAL MODELING OF INTEGRAL}

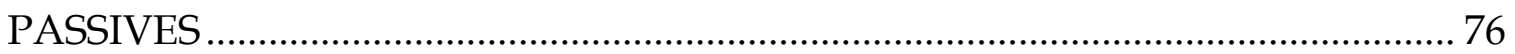

Thermo-Mechanical Loading Conditions............................................................ 76

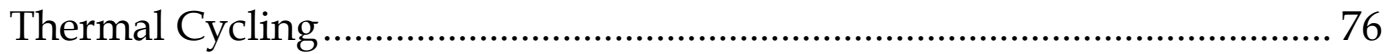

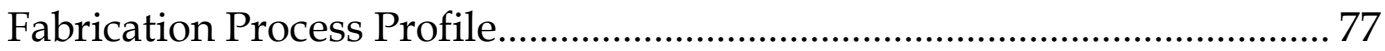

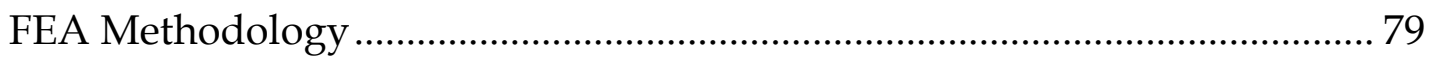

Fabrication Process Methodology ……………............................................ 79

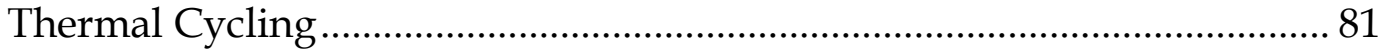

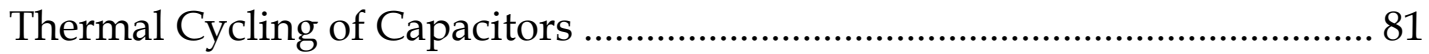

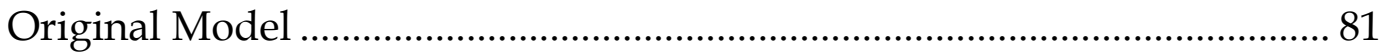

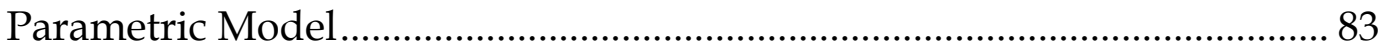

Fabrication Process Deformation In Capacitors ................................................ 84

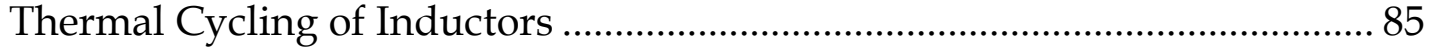

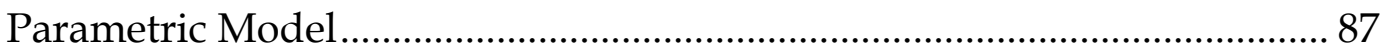

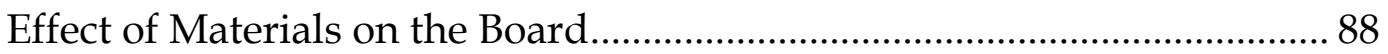

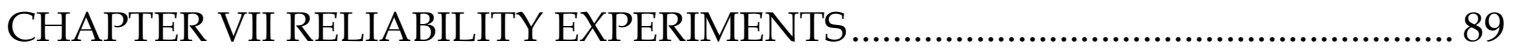

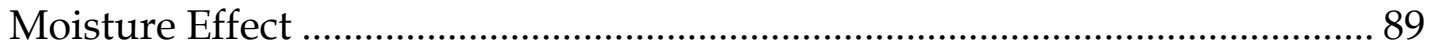

Air-to-Air Thermal Cycling ............................................................................... 92

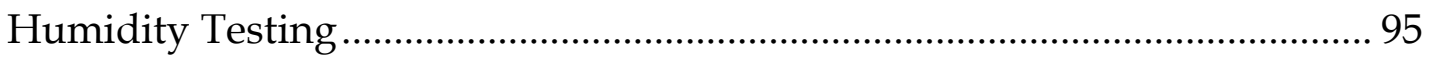

CHAPTER VIII PERFORMANCE OF INTEGRAL PASSIVES DURING FIELD

USE 98 


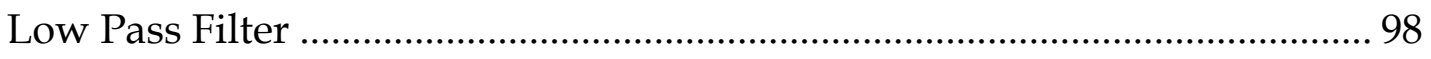

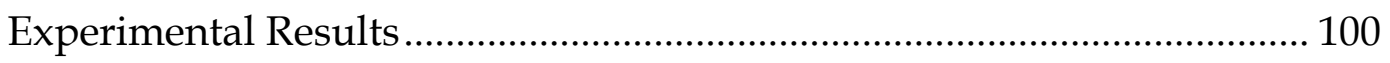

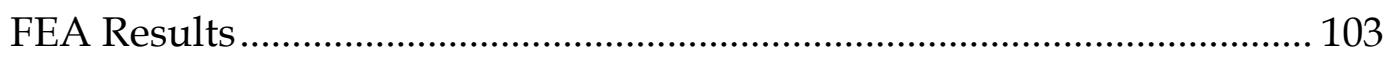

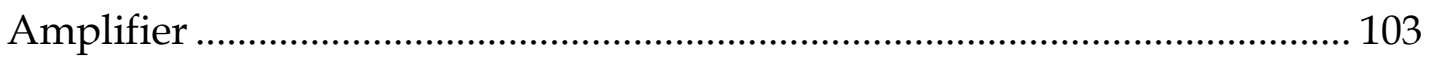

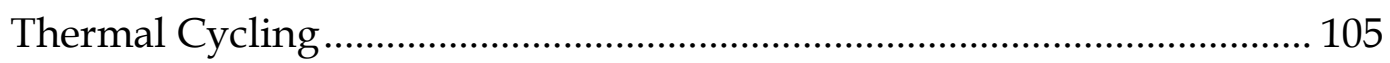

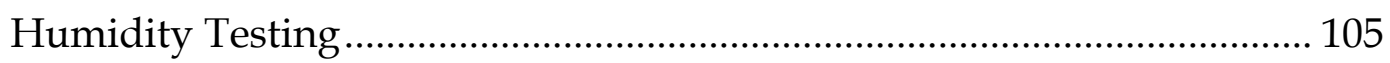

CHAPTER IX CONCLUSIONS AND FUTURE WORK …................................... 106

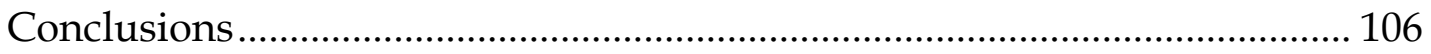

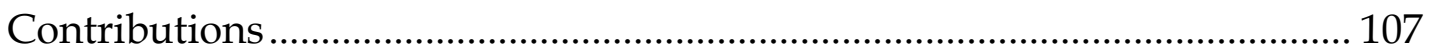

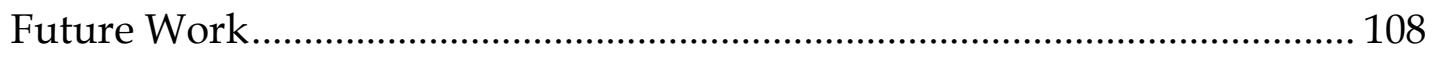

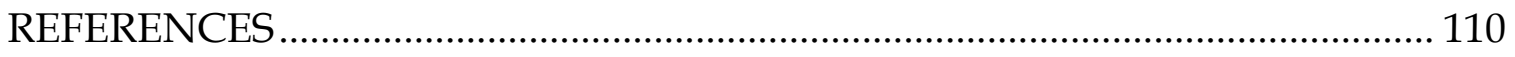




\section{LIST OF FIGURES}

Figure 1.1 Number of passives on PC motherboards

$\begin{array}{lr}\text { Figure 1.2. PRC's SOP Test vehicle } & 6\end{array}$

Figure 2.1. Impedance variance of Ideal Passives with frequency 9

$\begin{array}{ll}\text { Figure 2.2. Behavior of a real capacitor } & 12\end{array}$

$\begin{array}{ll}\text { Figure 2.3. Schematic of CCVD } & 18\end{array}$

$\begin{array}{lr}\text { Figure 2.4. Schematic of Meniscus coating } & 21\end{array}$

$\begin{array}{ll}\text { Figure 2.5. Dupont Interra } & \mathrm{TM} \\ \text { process } & 27\end{array}$

Figure 2.6. Droplets on Demand Ink Jet deposition 29

Figure 2.8. Shipley InSite ${ }^{\mathrm{TM}}$ process $\quad 31$

Figure 4.1. Picture of the Test Board 42

Figure 4.2. Bottom Metal Mask 45

$\begin{array}{ll}\text { Figure 4.3. Via Mask } & 46\end{array}$

$\begin{array}{ll}\text { Figure 4.4. Top Metal Mask } & 49\end{array}$

Figure 4.5. Resistor Mask

Figure 4.6. Solder Mask mask

Figure 4.7. Fabrication process of passives

Figure 5.1. Kinematic Hardening of Copper $\quad 57$

$\begin{array}{ll}\text { Figure 5.2. Co-ordinate axis in ANSYS } & 57\end{array}$

Figure 5.3 Schematic of the board and an explanation of layered shell 62

$\begin{array}{ll}\text { Figure 5.4 FEA representations of capacitors } & 63\end{array}$

Figure 5.5 Symmetry boundary conditions applied on the board. 63 
$\begin{array}{ll}\text { Figure 5.6. Close up on the capacitors } & 64\end{array}$

Figure 5.7. Capacitor mesh moved through parameters 65

$\begin{array}{ll}\text { Figure } 5.8 \text { (a). Etching away of copper during fabrication } & 67\end{array}$

$\begin{array}{ll}\text { Figure } 5.8 \text { (b). Etching away of copper represented in ANSYSTM } & 67\end{array}$

Figure 5.8. Capacitance Convergence for $330 \mathrm{mils}(8.25 \mathrm{~mm})$

Figure 5.9. Capacitance Convergence for 580 mils (14.5mm) 70

Figure 5.10. FEA representation of inductors 72

Figure 5.11. Zoomed view of the inductors on the board 72

Figure 5.12. Inductors as present on the board $\quad 72$

$\begin{array}{ll}\text { Figure 5.13. Boundary Conditions on inductor model } & 73\end{array}$

$\begin{array}{ll}\text { Figure 5.14. Parametric models for inductors } & 74\end{array}$

Figure 5.15. Model of the Inductor in ANSYS ${ }^{\mathrm{TM}}$

$\begin{array}{ll}\text { Figure 6.1. Load step used in thermal cycling of passives } & 77\end{array}$

Figure 6.2. Schematic of a part of the fabrication process in capacitors $\quad 78$

Figure 6.3. Thermal profile between the curing of the dielectric and plating of $\begin{array}{ll}\text { top metal layer } & 79\end{array}$

Figure 6.4. Deformation in board after thermal cycling with capacitors $\quad 82$

Figure 6.5. Deformed capacitor furthest from the neutral point 82

Figure 6.6. Deformed Inductor after thermal cycling 86

Figure 7.1. Capacitance values after baking the board 90

Figure 7.2. Inductance values after baking the board 91

Figure 7.3. Resistance values after baking the board 91 
Figure 7.3. Picture of the Thermal Chamber used

Figure 7.5. Change in capacitance after 1000 thermal cycles

Figure 7.6. Change in inductance after 1000 thermal cycles

Figure 7.7. Change in resistance after 1000 thermal cycles

Figure 7.7. Humidity Chamber used

Figure 7.9. Capacitance change after humidity testing 96

Figure 7.10. Inductance change after humidity testing $\quad 97$

$\begin{array}{ll}\text { Figure 7.11. Resistance change after humidity testing } & 97\end{array}$

$\begin{array}{lr}\text { Figure 8.1. Schematic of a low pass filter } & 99\end{array}$

$\begin{array}{ll}\text { Figure 8.2. Low pass filter characteristics } & 100\end{array}$

Figure 8.3. Change in Attenuation constant after thermal cycling of the filter

Figure 8.4. Change in Attenuation constant after humidity testing 102

Figure 8.5. GaAs FET in the common source configuration 


\section{LIST OF TABLES}

Table 2.1. EIA temperature codes for dielectrics........................................................ 34

Table 4.1. Materials used in the test board ......................................................... 42

Table 4.2. Details of the capacitors ............................................................................... 43

Table 5.1 Dependence of modulus on temperature [31].......................................... 56

Table 5.2 Kinematic Behavior of copper.................................................................... 56

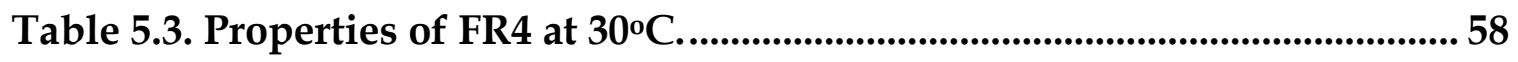

Table 5.4. Viscoelastic Prony Parameters for DynaVia 2000 ................................. 59

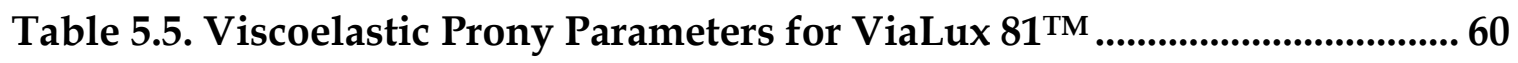

Table 5.6. Capacitance Convergence for 330 mils $(8.25 \mathrm{~mm})$................................... 69

Table 5.7. Comparison with simulated, actual and theoretical values of

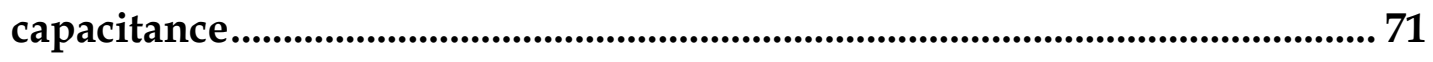

Table 6.1. Results from thermal cycling of capacitors ............................................... 83

Table 6.2. Change in parametrically further capacitors............................................. 84

Table 6.3. Results from the fabrication process simulation..................................... 85

Table 6.4. Results from the thermal cycling of inductors ........................................ 87

Table 6.5. Results from the parametric modeling of inductors.............................. 87 


\section{GLOSSARY}

Abbreviations

CTE - Coefficient of Thermal Expansion

CVD -Chemical Vapor Deposition

DIP- Dual In line Package

DNP - Distance From Neutral Point

FEA- Finite Element Analysis

FEM - Finite Element Model

HDW - High Density Wiring

IC - Integrated Circuits

LTCC - Low Temperature Co-fired Ceramic

MCM - Multi-chip module

PC - Personal Computer

RF - Radio Frequency

RH - Relative Humidity

SMT - Surface Mount Technology

SOP - System On Package

TCC - Temperature Coefficient of Capacitance

TCR - Temperature Coefficient of Resistance

WLP - Wafer Level Package 
Symbols

${ }^{\circ} \mathrm{C}$ - Degrees Celsius

C-Capacitance

E - Elastic Modulus

$f$ - frequency

F - Farad (unit of capacitance)

$\mathrm{nF}$ - Nano Farad (10-9 Farad)

pF - Pico Farad (10-12 Farad)

G - Shear Modulus

GPa - Giga Pascals (unit of stress)

$\mathrm{H}$ - Henry (unit of inductance)

$\mu \mathrm{H}$ - Micro Henry $\left(10^{-6} \mathrm{H}\right)$

$\mathrm{k}$ - dielectric constant

$\mathrm{L}$ - Inductance

$\mathrm{mm}$ - millimeter

MPa - Mega Pascal (unit of stress)

$\mu$ - micro meter $\left(10^{-6} \mathrm{~m}\right)$

$\Omega$ - Ohm (unit of resistance)

k $\Omega$ - Kilo Ohm (103 Ohms)

Q factor - Quality Factor

$\mathrm{R}$ - Resistance

$\mu_{\mathrm{r}}$ - Relative Permeability 
$\mathrm{T}_{\mathrm{g}}$ - Glass Transition Temperature 


\section{SUMMARY}

Multilayer embedded passives (resistors, inductors, and capacitors)

on a printed wiring board can help to meet high performance requirements at a low cost and at a smaller size. Such an integration of embedded passives has new challenges with respect to design, materials, manufacturing, thermal management and reliability. As the area of integral passives on printed circuit boards is relatively new, there is inadequate literature on the thermo-mechanical reliability of integral passives. Therefore, there is a compelling need to understand the thermo-mechanical reliability of integral passives through the development of physics-based models as well as through experiments, and this thesis aims to develop such an experimental and theoretical program to study the thermo-mechanical reliability of integral passives..

As integral passives are often composite layers with dissimilar material properties compared to the other layers in the integral substrate, it is essential to ensure that RLC characteristics of the embedded passives do not deteriorate with thermal cycling due to thermo-mechanical deformations. This thesis aims to study the changes in the passive characteristics due to the thermally-induced deformations. Embedded capacitors and inductors have been looked at specifically in this research. Multi-field physics-based models have been constructed to determine the change in electrical parameters after thermal cycling. The thermo-mechanical models assume direction-dependent material 
properties for the board substrate and interconnect copper layers and temperature-dependent properties for interlayer dielectric and passive layers. Using the deformed geometry, the electrical characteristics have been determined at low frequency. In parallel to the models, test vehicle substrates have been subjected to 1000 thermal cycles between $-55^{\circ} \mathrm{C}$ to $125^{\circ} \mathrm{C}$ and high humidity and temperature conditions at $85^{\circ} \mathrm{C} / 85 \mathrm{RH}$ for 500 hours, and it has been observed that there are significant changes in the electrical parameters. The results obtained from the physics-based simulations have been validated against the measured electrical characteristics from the fabricated functional test boards that have been thermal cycled. 


\section{CHAPTER I}

\section{INTRODUCTION}

The past four decades have seen tremendous progress in the field of system level packaging with IC packaging technology progressing from the dualin-line package (DIPs) to the wafer-level-package (WLPs). However, there is another area in packaging that has not received that much attention as IC's. This is the group of passive elements and the advancements have been comparatively marginal in size and density. As a result, the passive elements occupy more space and make up most of the weight in electronic packages. Passive

elements are very important to the functioning of the microelectronic circuit and perform functions like filtering, decoupling, bias etc. The number of passive components in hand-held devices and computers have been growing through the years and now stand at $80 \%$ of the total part counts [1]. Figure 1.1 shows the growth of passives in PC motherboards over the years [2]. The worldwide market of passives is $\$ 1.1$ Billion with the increased use of cell phones and wireless technologies, passive components are going to play an important role in the development of next generation microlectronics devices. 


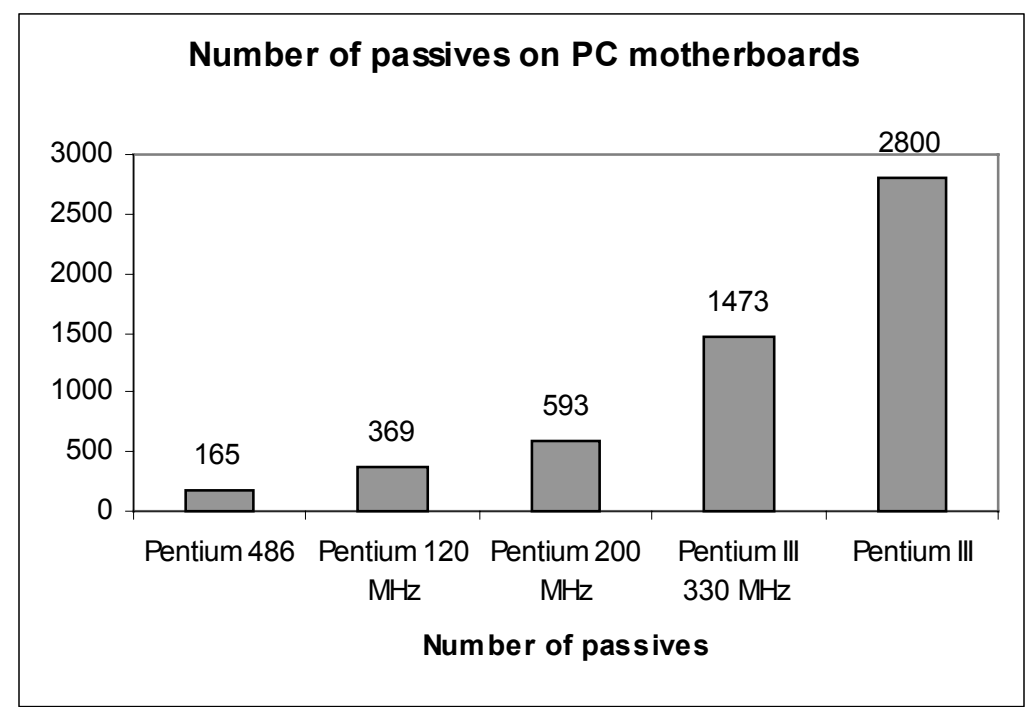

Figure 1.1 Number of passives on PC motherboards

Passives can be categorized into three distinct categories:

1) Discrete Passive: A single passive element in its own leaded or surface mount technology (SMT) package. The most commonly used size is 0402 $(1 \times 0.5 \mathrm{~mm}), 0201(0.5 \times 0.25 \mathrm{~mm})$ is the smallest size available. [3]

2) Integrated Passive: This applies to many passive components grouped together into one package.

3) Embedded Passive: This type of passive is embedded in the interconnect substrate.

Discrete and Integrated passives have been used in the industry for many years now. Up until 1995, almost all passive components were discrete. However, in 1998, 55 Billion SMT Capacitors and Resistors were replaced by Integrated passives devices. 95\% of the current 900 billion passive components 
are Discrete and integrated passives and about 3\% are used in the embedded form [4].

Even with its wide use, Discrete passives have an inherent number of disadvantages associated with them. They are:

i) Real Estate Consumption: Discrete passives take up a large amount of real estate area. Since the IC's have been reducing in size much faster than the passives, the total IC package including the discrete passives is typically 6-8 times the size of the IC itself [5].

ii) Poor Electrical Performance: Discrete passives have high parasitics due to the presence of solder joints in the package, particularly the parasitic inductance in capacitors.

iii) Low Reliability: The presence of solder joints results in reliability problems as the solder joints fail through thermo-mechanical fatigue after prolonged use. In a typical board, passives account for $25 \%$ of the solder joints.

iv) Inflexible Design: Discrete passives are available in limited sizes and ranges making them difficult for customization according to the customer's needs.

Given these shortcomings, there is a need to overcome these problems to improve the overall performance of the microelectronics system. Integral Passives can overcome these limitations due to the following aspects: 
i) Reduced footprint, mass and volume: Since the passives are integrated in the interconnecting substrate, the Integral passives will have lower mass and occupy less real estate area than the corresponding Discrete passive.

ii) Better Electrical Performance: The elimination of solder joints improves the parasitics of the Integral passives.

iii) Increased Design Flexibility: The Integral Passives can be designed with respect to electrical characteristics to any value.

iv) Improved Reliability: The elimination of solder joints leads to improved reliability. A detailed discussion is presented after this subsection.

v) Better Yield: Integral Passives are fabricated with the interconnecting substrate and no additional work is required on the substrate after fabrication. In contrast, discrete passives have to be assembled on the substrate after fabrication resulting in lower yield and higher costs.

However, there are many concerns with Integral passives related to manufacturing and materials that will be addressed in the next section. 


\section{$\underline{\text { SOP Concept }}$}

The SOP (System On Package) paradigm integrates various functionalities such as RF, Optical and Digital into one module. This module promises to provide low cost, reliable and faster to market approach to Microsystems packaging. This is in sharp contrast to the System on Chip (SOC) approach, which will be severely limited by expense and lithography technology by the year 2007. Integral passives form an important part of the SOP package and play an important part in the RF module of the SOP. The RF passives will be critical in the miniaturization and cost effectiveness of the SOP approach. There has been tremendous demand for mobile and wireless applications such as RF Identification, local multipoint distribution systems (LMDS) and wireless Local Area Networks (WLAN) operating at frequencies in the millimeter range. This has been implemented by the SOP approach that integrates antennas, filters, resonators, baluns and other RF components in an advanced LTCC based MCM module. In addition, high Quality factor inductors have been integrated in the multiplayer organic package [6]. Decoupling capacitors will also be essential in providing noise free supply to the different modules in the SOP package. Figure 1.2 shows the SOP test vehicle currently being implemented in the Packaging Research Center (PRC) [7]. 


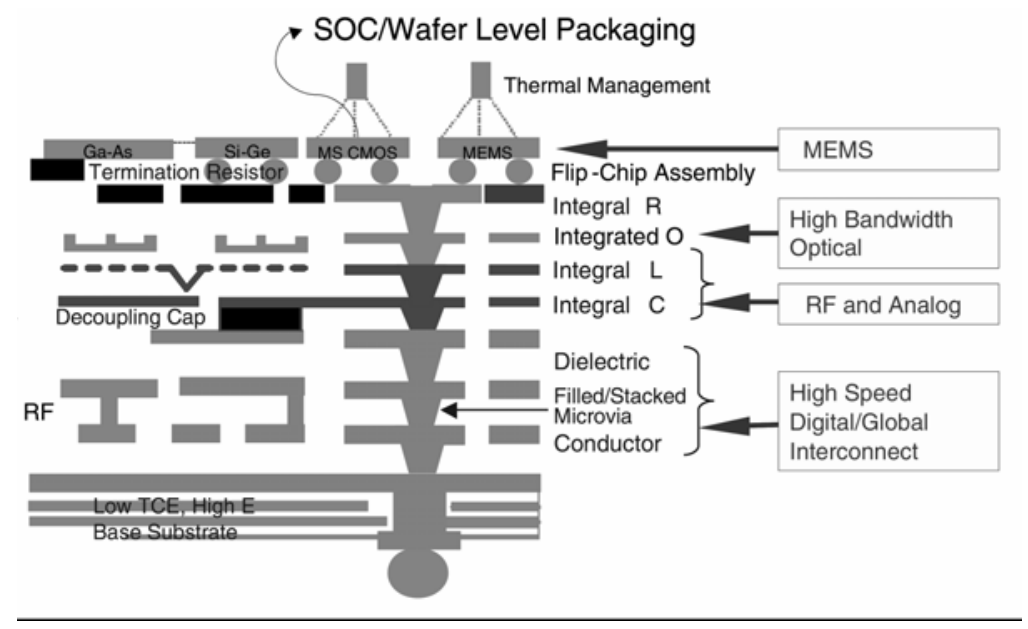

Figure 1.2. PRC's SOP Test vehicle

\section{Thermo-Mechanical Reliability of Integral Passives}

The elimination of solder joints in Integral passives means that Integral passives will have higher reliability than the Discrete passives. However integration into the substrate can give rise to new concerns with respect to reliability of the Integral passives. The primary concern arises from the use of new materials and new fabrication processes. With respect to reliability, the two failure modes are:

1) Mechanical Failure: This failure is characterized by the delamination of the different layers in the interconnecting substrate containing the Integral passives, or cracks propagating in the passive. Also cracking of the traces could lead to electrical opens.

2) Electrical Failure: This failure stems from the change in electrical parameters above a certain tolerance value. The tolerance value 
depends on the application of the passive component. The change occurs due to the thermo-mechanical deformation of the passive component and with the change in the electrical properties of the dielectric material with time/temperature/age/bias. The change in the electrical parameters influences the functioning of the module or the system level functionality of the device.

With the use of different materials in a High Density Substrate (HDW), the difference in Coefficient of Thermal Expansion (CTE) between the different layers in the substrate can give rise to interlaminar stresses that can cause deformation, delamination or crack propagation. The induced stresses depend on the thickness of the layers, the difference in properties of the layers, the curing temperature and the reliability tests conducted. However, it is important to note that electrical failure may occur prior to mechanical failure making it important to analyze the potential for electrical failure before determining the mechanical integrity of the system. In short, just because the system does not exhibit signs of mechanical failure doesn't imply that it has full electrical functionality.

This thesis looks at the change in the electrical parameters of embedded passives with thermal cycling and its impact on the performance of the passive. Test vehicles have been fabricated and subjected to thermal cycles and extreme temperature and humidity conditions. These results will be validated against Finite Element Analysis to determine the change in electrical parameters with adverse conditions. 


\section{CHAPTER II}

\section{BACKGROUND ON PERFORMANCE AND}

\section{RELIABILITY}

\section{Electrical Performance}

In order to accurately represent the electrical performance of embedded passives, the electrical model needs to consider the pure value of the ideal component and the parasitics associated with the passive. For example, this would mean considering the inductive and resistive effects of an embedded capacitor. Currently the discrete passives manufactured have specification sheets detailing its electrical performance. The parasitics of passives should always be taken into account while modeling the electrical performance. Ideal passives are represented by a single number and are characteristic of the passive being used. The impedance of an ideal resistor is a flat line with frequency whereas the impedance of an ideal capacitor decreases linearly with frequency and the impedance of an ideal inductor increases linearly with frequency. In an ideal capacitor, the voltage lags the current by $90^{\circ}$ and in an inductor, the current lags the voltage by $90^{\circ}$. In an ideal resistor, both the current and the voltage are perfectly in phase.

The impedance or reactance of each passive is given by,

$$
\text { Resistor - R }
$$




$$
\begin{aligned}
& \text { Capacitance }-\frac{1}{2 \pi f C} \\
& \text { Inductance - } 2 \pi f L
\end{aligned}
$$

where $\mathrm{R}=$ resistance

$$
\begin{aligned}
& \mathrm{C}=\text { Capacitance } \\
& \mathrm{L}=\text { Inductance }
\end{aligned}
$$

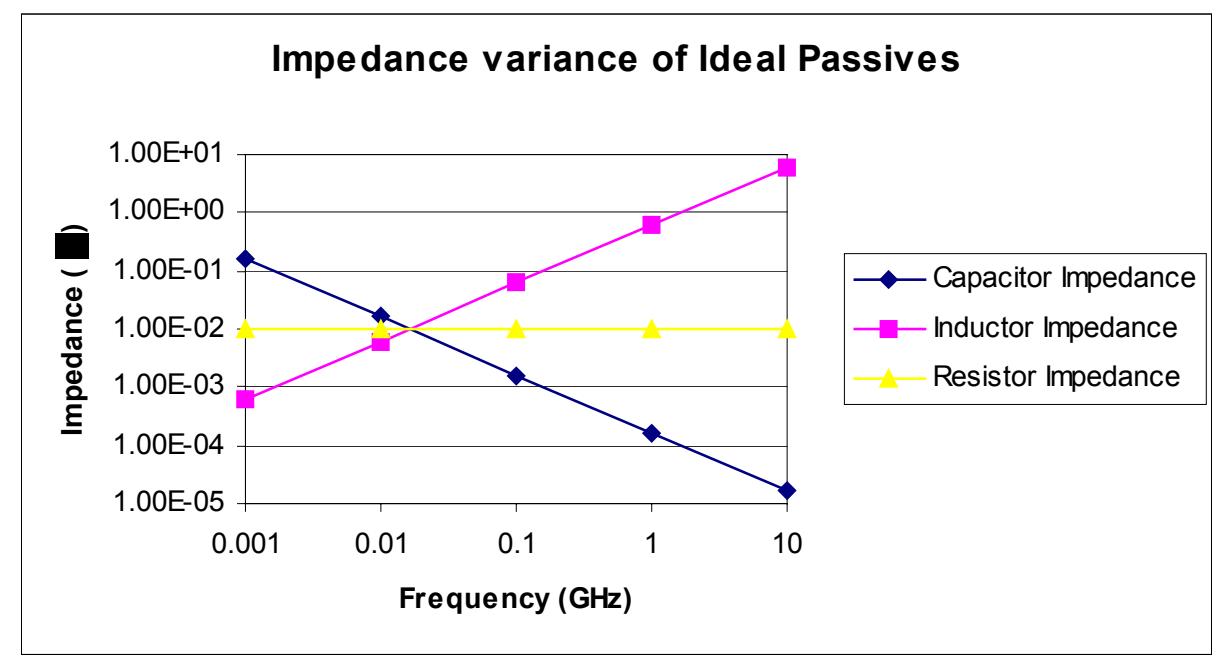

Figure 2.1. Impedance variance of Ideal Passives with frequency

The following sections talk about different electrical parameters used to describe the electrical performance of embedded passives and the modeling of real passives. 


\section{Modeling Capacitors}

A capacitor stores energy in the form of an electric field. The most important constant of the capacitor is the dielectric constant. Another way of representing the dielectric property of a capacitor is to use the capacitance density or specific capacitance. This is the capacitance per unit area and higher values mean higher dielectric constant. The capacitance density can be calculated by the dielectric constant and the dielectric thickness by

$$
\text { Capacitance density }\left(\frac{\mathrm{nF}}{\mathrm{cm}^{2}}\right)=0.885 \frac{\mathrm{k}}{\mathrm{d}}
$$

Where $\mathrm{k}=$ dielectric constant

$\mathrm{d}=$ distance between the plates in $\mu \mathrm{m}$.

Another important parameter is the dissipation factor. This is the measure of how much energy is lost in the dielectric during the AC operation. The inability of the mobile charges to respond to changes in the electric field or the inductive and resistive losses in the capacitor can cause the dissipation factor to increase. The reciprocal of the dissipation factor is known as the quality factor. A dissipation factor of $0.1 \%$ is considered very good and is generally hard to obtain for high $\mathrm{k}$ dielectrics.

The dependence of capacitance on temperature is called the Temperature Coefficient of Capacitance (TCC). It is calculated by

$$
T C C=\frac{1}{C} \frac{\partial C}{\partial T}=\frac{1}{C_{T_{1}}} \frac{C_{T_{2}}-C_{T_{1}}}{T_{2}-T_{1}}
$$


A TCC of around $200 \mathrm{ppm} /{ }^{\circ} \mathrm{C}$ (parts per million) is considered low and the dielectric is very stable with temperature. Thus in order to find the change in capacitance from $-55{ }^{\circ} \mathrm{C}$ to $125{ }^{\circ} \mathrm{C}$, the change will be the TCC times the temperature change $\left(180^{\circ} \mathrm{C}\right)$. For a TCC of $200 \mathrm{ppm} /{ }^{\circ} \mathrm{C}$, this will mean a change of $3.6 \%$ over this temperature range.

A capacitor has two parasitics associated with it called the ESR (Equivalent Series Resistance) and the ESL (Equivalent Series Inductance). The ESR is due to the inherent resistivity of the conductor plates and the leads of the capacitors. The ESL is due to the coupling between the conductor plates and the ground plane. Ideally both the ESR and the ESL should be zero. As mentioned in the section before, the capacitive reactance decreases with frequency and the inductive reactance increases with frequency. In the case of a capacitor, the inductive reactance or the ESL increases with frequency and at a particular frequency balances out the capacitive reactance. At this frequency, the current and voltage are in phase and the only impedance present is due to the resistive reactance. This point is known as the self-resonating frequency or simply the resonance frequency. Beyond the resonating frequency, the capacitor turns into an inductor and the impedance increases with frequency. Figure 2.2 shows the behavior of an actual capacitor and the lowest point is the resonance frequency where the only impedance comes form the resistive reactance. 


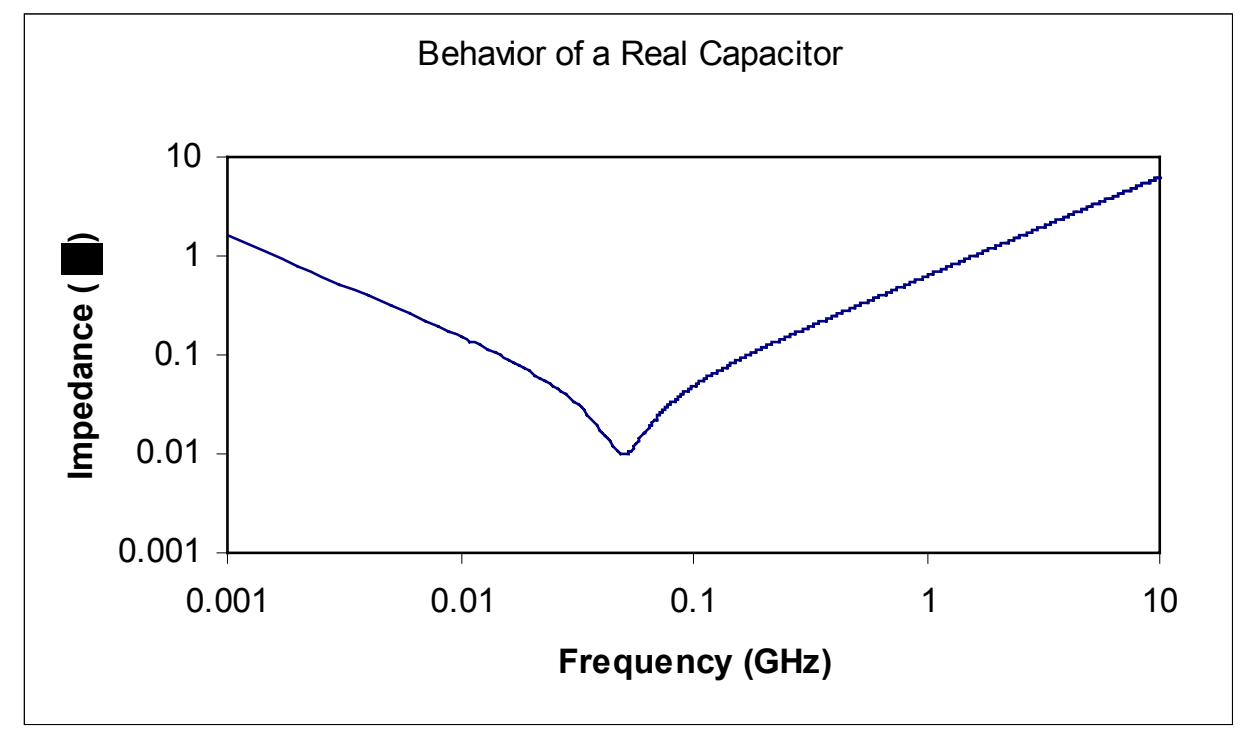

Figure 2.2. Behavior of a real capacitor

The parasitic inductance of a capacitor is proportional to the distance between the plates. Closer plates mean higher capacitance and lower parasitic inductance but difficult manufacturability and distant plates mean lower capacitance with higher parasitic inductance but easier manufacturability. Embedded capacitors don't suffer from the high parasitic inductance as discrete passives do due to the absence of leads and the lower height difference between the interconnects and the embedded capacitor.

\section{Modeling Inductors}

Inductors store energy in the form of magnetic energy. The most important property is that of magnetic permeability. Magnetic permeability is defined in terms of the magnetic field 


$$
\vec{B}=\mu \vec{H}
$$

where $B$ is the magnetic flux density vector, $\mathrm{m}$ is the magnetic permeability and $\mathrm{H}$ is the auxiliary magnetic field or the magnetic field vector. In addition,

$$
\mu=\mu_{0}\left(1+\chi_{m}\right)
$$

where $\mu_{0}$ is the magnetic permeability of free space and $\chi_{\mathrm{m}}$ is the magnetic susceptibility. The relative permeability is given by the ratio of the magnetic permeability of the material to the free space permeability.

A very common parameter used to measure the performance of an inductor is the Quality factor. This is the ratio of the Imaginary impedance to Real Impedance. The Quality factor in inductors can be improved by a variety of methods. This includes reducing the ESR, using high resistivity and low k substrates.

$$
Q=\frac{Z_{\text {im }}}{Z_{r e}}=2 \pi \frac{\text { peak magnetic energy }- \text { peak electric energy }}{\text { energyloss in one cycle }}
$$

Magnetic fields generated in the inductors interact with other materials in the substrate which gives rise to eddy currents. These eddy currents oppose the original change in magnetic field and cause loss in the inductors. The most important factor related to eddy current effects is skin depth. The skin depth measures the level of penetration of the electric current and magnetic flux into the conductor. The skin depth is given by 


$$
\delta=\sqrt{\frac{1}{\pi \mu \sigma f}}
$$

where $\delta$ is the skin depth, $\mu$ is the permeability and $\sigma$ is the conductivity of the material and $\mathrm{f}$ is the frequency. At high frequencies, the skin effect goes up and hence the current only flows on the surface of the conductor. The eddy current losses are minimal if the skin depth is greater than the thickness of the conductor.

\section{Modeling Resistors}

Resistors dissipate electrical energy in the form of heat. For a perfect resistor, the resistance is given by

$$
R=\frac{\rho L}{W t}
$$

where $\mathrm{R}$ is the resistance in $\mathrm{W}$

$\rho=$ resistivity of the material

$\mathrm{L}=$ length of the strip

$\mathrm{W}=$ width of the strip

$\mathrm{t}=$ thickness of the strip

Another way of describing the resistance is by sheet resistance. The sheet resistance is equal to the resistance of a square of the material. The resistance of a resistor can be broken down into little squares and by knowledge of the resistance of each square and the number of squares, the resistance of the entire resistor can be calculated. The sheet resistance is given by 


$$
R=\left(\frac{\rho}{W}\right)\left(\frac{L}{W}\right)=R_{s} N_{s}
$$

where $R_{s}$ is the sheet resistance

$\mathrm{N}_{\mathrm{s}}$ is the number of squares $=\mathrm{L} / \mathrm{W}$

Like the capacitors, the dependence of resistors on temperature is determined by Temperature Coefficient of Resistance (TCR). In some applications like thermistors, resistors with large TCR's can be used to measure changes in temperature. In addition, a positive TCC for the capacitor can be countered with a negative TCR for the resistor to maintain a constant RC time constant.

\section{$\underline{\text { Fabrication Of Passives }}$}

\section{Capacitors}

This section deals with the various methods of fabricating integrated capacitors. Given the wide variety of processing options for fabricating integrated capacitors, only the most commonly used are considered in this section. It is important to note that certain processes have inherent disadvantages over others and can be used only for specific materials. Most of these processes are applicable to organic boards and hence the maximum processing temperature is $250^{\circ} \mathrm{C}$. All the processes may be divided into four basic categories. They are 
Physical Vapor deposition (PVD), Chemical Vapor Deposition (CVD), solution based physical methods and photolithography.

\section{Physical Vapor deposition (PVD)}

Sputtering: Sputtering involves bombing a secondary object with energetic positive ions. The positive ions on hitting the secondary object lose their energy ejecting particles towards the substrate to be coated [8]. Sputtering is used usually to deposit thin films of metals but is also used to deposit resistor materials and dielectrics such as Tantalum Oxide, Titanium Oxide, Barium Titanate, Alumina etc. Sputtering can be performed at low temperatures which makes it a favorable process for temperature sensitive materials but its requirement of a vacuum and its uneven material deposition can be disadvantageous. In addition, thin sputtered films can show high dispersion loss at low frequencies [9]. It is also very important that the bottom electrode of the capacitor on which the deposition is taking place be smooth or the coating will not be even on the steep slopes of the bottom metal plate [10]. As a result obtaining high yields on rough substrate materials such as Kapton and Alumina is very hard [11][12]. In addition, many ferroelectrics such as Barium Titanate have to be annealed at $300^{\circ} \mathrm{C}$ to obtain a higher dielectric constant than obtained from direct sputtering [13]. Some materials such as Tantalum Oxide may require temperatures as high as $550^{\circ} \mathrm{C}$. Such annealing requirements for ferroelectrics 
have limited the commercialization of sputtering in industry. In addition, the slow deposition rate of the dielectric can limit formation of thick films in paraelectrics. The maximum film thickness that can be obtained from sputtering is limited to a few micrometers.

\section{Chemical Vapor Deposition (CVD)}

In Chemical Vapor Deposition, the substance to be deposited is introduced as a vapor in a chamber containing the substrate. In order to deposit the dielectric on the surface, energy needs to be supplied for this endothermic reaction. This is done by either heating the substrate or using the electron energy of plasma. However the difficulty of vaporizing metallic dielectrics has led to use of metallo - organic CVD's (MOCVD) which can be used at low temperatures. CVD can be used to deposit specific dielectrics that cannot be deposited with many other processes. One such example is Diamond-like carbon (DLC), which has high hardness and low friction coefficient [14]. The MOCVD is a promising technology but is limited by its cost and rigid processing conditions.

One emerging chemical vapor deposition process is Combustion Chemical Vapor Deposition (CCVD). Figure 2.3 shows a schematic of the process [15]. 


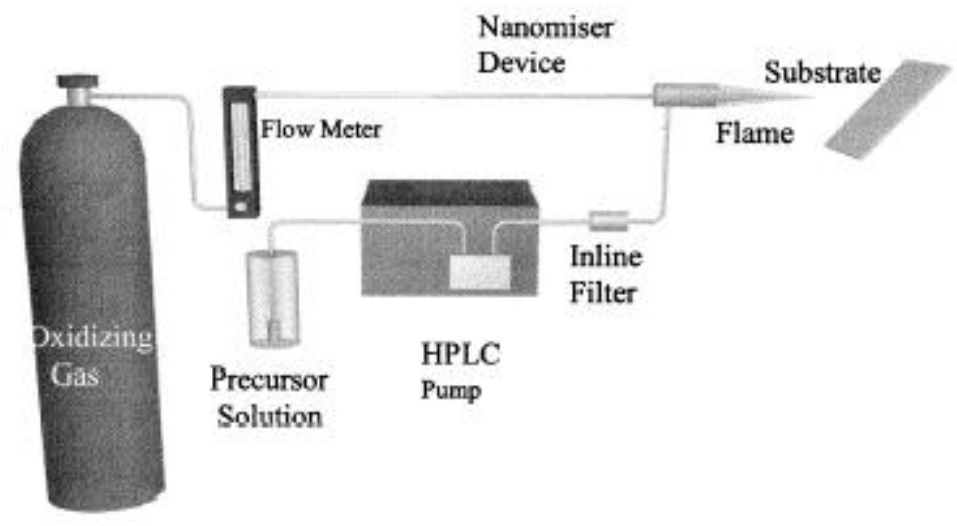

Figure 2.3. Schematic of CCVD

This process entails mixing the dielectric with a combustible solvent and atomizing it to submicron droplets. The combustion of these droplets provides the energy required to evaporate the droplets and cause the dielectric to react and vapor deposit on the substrate. This process doesn't require a vacuum to be realized and can be done in ambient conditions and temperature with appropriate filters [16]. All these features combine to make CCVD a lower cost process than sputtering. CCVD can be used with a variety of materials such as cerium oxide, yttria stabilized zirconia, strontium titanate, Tantalum, Hf oxide, Shipley ${ }^{\mathrm{TM}}$ Insite etc.

\section{Anodization}

Anodization refers to electrochemical process used in forming dielectric oxides on the metal surface. The tendency of metals to form a metal oxide when 
exposed to moisture or oxygen can be exploited to form an oxide on the metal surface. The resultant oxide will have residual compressive stresses giving it excellent mechanical properties and stability. The primary materials used in anodization are Tantalum and Aluminum. Barium Titanate has also been made but the process requires an alkaline solution and the resultant film comparatively poor dielectric properties [17].

The procedure for anodization is quite similar as a typical electrochemical cell. The anode is the metal to be oxidized and the cathode is a noble metal (metal such as gold which is highly resistant to oxidation and corrosion). One of the typical electrolytes used is that of tartaric acid and ammonium hydroxide [18]. The anode and cathode are connected by a DC power source, which should be capable of providing around $150 \mathrm{~V}$ and $1 \mathrm{~mA}$ per $\mathrm{cm}^{2}$ of area to be anodized. The amount of oxide formed on the anode can be determined by Faraday's law:

$$
\begin{aligned}
& \frac{d z_{o x}}{d t}=\frac{i}{n F} \frac{M_{o x}}{\rho_{o x}} \\
& z_{o x}=\text { oxide thickness, } \mathrm{cm} \\
& t=\text { time, sec } \\
& i=\text { current density, A } / \mathrm{cm}^{2} \\
& n=\text { number of electrons given off in the half reaction at the anode } \\
& F=\text { Faraday's constant ( } 96500 \text { coulombs/mole of electrons) } \\
& M_{o x}=\text { molecular weight of the oxide, gms/mole } \\
& \rho_{o x}=\text { density of the oxide, gms } / \mathrm{cm}^{3}
\end{aligned}
$$


Anodization is an excellent process for making capacitor dielectrics for a multitude of reasons. It is very easy to achieve uniform defect free films with this process and in addition the final thickness is a function of cell voltage and not affected by processing time, electrolyte used, temperature and current. Also anodization is not affected by the thickness of the bottom electrode since the amount of dielectric grown can be easily determined by the above equation. The apparatus is inexpensive, easy to use and is non-toxic.

\section{Solution-Based: Physical}

Spin Coating

In spin coating, the liquid dielectric to be coated is put in the middle of the substrate and the substrate is rotated at a high speed. The dielectric then spreads over the substrate due to centrifugal force. The thickness of the dielectric depends on the angular velocity at which the substrate is rotated, the viscosity of the dielectric and surface tension of the dielectric. Hence it is very easy to control the thickness of the films produced by determining the required angular speed. However spin coating has its inherent disadvantages as well, the biggest being the wastage of material, which can drive up the costs. In addition, the ability to form thick films is limited in spin coating as the uniformity is not constant.

Polyimide is the most commonly used material in spin coating. Thickness of $0.95 \mu \mathrm{m}$ in polyimide has been achieved using spin coating. The dielectric 
showed changes within a range of $10 \%$ with increasing frequency and decreased with decreasing thickness [19].

\section{Meniscus Coating}

In Meniscus coating, the dielectric to be coated is pumped through an applicator tube from one end. When the horizontally held tube is full, the material pours out from the slot back into the reservoir. The meniscus that is formed on the upper surface of the tube is made in contact with the substrate held upside down by a vacuum. The tube traverses the entire length of the substrate depositing a thin layer of dielectric on the substrate surface. The thickness of the dielectric deposited is a function of the viscosity of the dielectric, the applicator speed and environmental conditions. Figure 2.4 shows a schematic of the process [20].

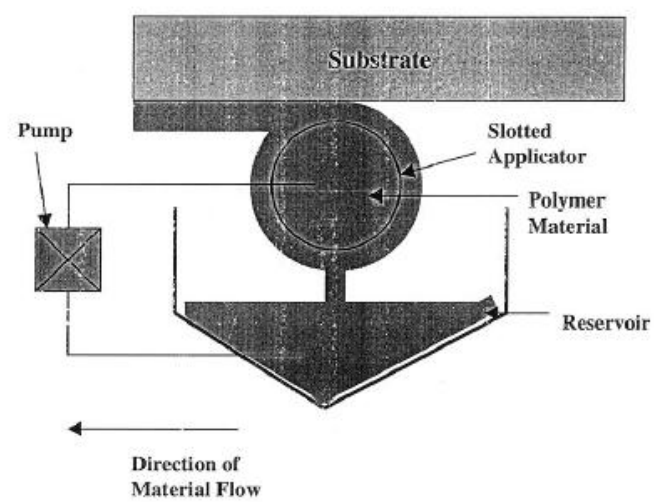

Figure 2.4. Schematic of Meniscus coating 
At PRC at Georgia Tech, Meniscus coating has been successfully used to coat a variety of dielectrics such as Ciba ${ }^{\mathrm{TM}} 7081$, Shipley ${ }^{\mathrm{TM}}$ XP9500CC, Dupont ${ }^{\mathrm{TM}}$ P12611, Dow ${ }^{\mathrm{TM}}$ Benzocyclobutene etc. Uniform thicknesses of 3-25 $\mu \mathrm{m}$ have been obtained using the meniscus coater. Unlike Spin coating, Meniscus coating has achieved minimal material wastage, high throughput, high planarity, minimal defect density and uniform thickness over a large area. This simple to implement technology is an important aspect of achieving a high density, low cost SOP substrate with excellent mechanical and electrical properties.

\section{$\underline{\text { Solution-Based - Chemical }}$}

\section{Sol-Gel Deposition}

In Sol-Gel deposition, a thin layer of a liquid-phase metallo-organic compound is thermally cured to remove the organic portion forming a metal inorganic oxide. Sol-gel processes allow for deposition of films with high degree of homogeneity at low temperatures.

The process starts by dissolving organometallic compounds such as metal alkoxides in alcohol to give a homogenous solution. This solution or "sol' is then gelated by a hydrolysis reaction with water or by exposure to atmosphere. Important factors affecting the gelation are the $\mathrm{pH}$ and concentration of the catalyst, the amount and composition of the solvent and the sequence of mixing. The gel is amorphous and is mechanically weak because it has continuous pores 
and trapped organics, water and hydroxyl groups. Heat treatment and densification of the film form the final film. The high surface area of the dried gels results in very high reactivity, which results in a relatively low-temperature process as compared to ceramic deposition.

Sol-gel can be used for low cost processing of high $\mathrm{k}$ dielectrics since it requires less equipment and no vacuum. However the temperatures required to form high dielectric crystalline films are around $500^{\circ} \mathrm{C}$. For example, films of Barium Strontium Titanate have to be annealed from $500^{\circ} \mathrm{C}$ to $700^{\circ} \mathrm{C}$ to achieve the crystalline structure and yield high dielectric constants in the range of 100250 but the dielectric constant changes dramatically with the film thickness [21]. One promising material is Lead Zirconate Titanate (PZT), which at a film thickness of $0.5 \mu \mathrm{m}$, gives a capacitance density of $2000 \mathrm{nF} / \mathrm{cm}^{2}$ with a very high breakdown voltage of $1.3 \mathrm{MV} / \mathrm{cm}$. Other materials that can be processed with Sol-Gel are Barium Titanate (formed from Barium Hydroxide), PZT (formed by lead acetate) etc.

Hydrothermal Deposition

Hydrothermal deposition involves the dissolution of reactants and precipitation of crystalline compounds in hot, pressurized water. It is a standard technique to form crystalline powders in hot, pressurized water. The raw materials used are similar to that in the sol-gel process. A subsequent 
hydrothermal treatment of the sol can assist in the formation of thin films at lower temperatures. The reactions are carried out in closed vessels typically under strong alkali conditions. Hydrothermal processing can achieve crystalline ceramics at temperatures lower than $100^{\circ} \mathrm{C}$.

At PRC at Georgia Tech, Barium Titanate has been deposited on Titanium coated glass slides or thin foils laminated on FR4. It was found that the specific capacitance was very high but so was the dielectric loss. By treatment with oxygen plasma, the dielectric loss was reduced but as the same time the specific capacitance went down as well. It is uncertain why the oxygen plasma had a significant effect on the dielectric properties of Barium Titanate. Another post hydrothermal method of improving the properties was to use polymer infiltration. The fabricated Barium Titanate films can be integrated on low cost substrate via standard build up processes.

\section{Photolithography}

Photolithography is the most important process in industry right now that is used to assemble and package PWB's. It can be used to get resolutions of upto $2 \mu \mathrm{m}$, which is far larger than the widths currently used in the semiconductor industry. The pattern to be realized on the substrate is generated on a CAD or a similar system and is transferred to a photographic film or photomask. The pattern is made by a computer-controlled photoplotter or an electron beam. In 
order to transfer the pattern from the photomask to the substrate a thin layer of photosensitive material known as photoresist is applied on the substrate surface. The photoresist is then exposed to UV light or other type of light source with the photomask on top of it. The photoresist can be positive in which light breaks the molecules in the polymer making the photoresist easier to dissolve or negative in which light causes crosslinking in the polymer making the illuminated portion harder to dissolve.

\section{Commercialized Dielectric Materials for Capacitors}

In this section, the different types of dielectrics and commercially used dielectrics are discussed. Given the tremendous amount of development going on in the choice of dielectric materials, there are three mechanisms for polarization in dielectric when an electric field is applied. They are electronic, atomic and ionic polarization. Each occurs by a different mechanism and the dielectric constant produced by each of these mechanisms varies. There are two types of dielectrics that are used in embedded passives. They are paraelectric and ferroelectric dielectrics. They display each of the polarizations but the difference is that when the electric field is removed, ferroelectric materials do not lose all of their ionic polarization unlike paralectrics. An example of a ferroelectric is Barium Titanate which below its Curie temperature a asymmetric tetragonal with unequal side lengths giving the crystal a residual polarization. This residual 
polarization can give the ferroelectric a dielectric constant in the thousands and hence gives ferroelectrics dielectric constants that are quite large as compared to paraelectrics. Also unlike paralectrics, ferroelectrics are heavily influenced by temperature, frequency, bias, thickness of the film and aging. In addition, the process used to fabricate the paraelectric can have a significant effect on the final dielectric constant of the dielectric. Following are some of the commercialized materials:

\section{DuPont Interra ${ }^{\mathrm{TM}}$}

DuPont has developed a high-k integrated capacitor process called Interra ${ }^{\mathrm{TM}}$ that involves the firing of a screen-printed ferroelectric paste on one side of the $\mathrm{Cu}$ foil at $900^{\circ} \mathrm{C}$ and then firing a Cu-based paste on that to form a top plate and flipping the stack onto the FR4. The foil is then patterned to form separate capacitors and the electrical connections to the capacitors. The dielectric is fired two times in order to eliminate pinholes. The dielectric used is doped Barium Titanate plus a glass that is compatible with board-level etching processes. The dielectric has excellent properties with the dielectric constant in excess of a 1000 with a capacitance density of $44 \mathrm{nF} / \mathrm{cm}^{2}$ and a breakdown voltage of $0.8 \mathrm{MV} / \mathrm{cm}$. Figure 2.5 depicts the process flow for the InterraTM integrated capacitor [22]. 


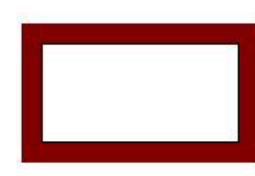

Condition the Copper Foil

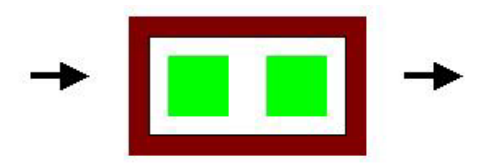

Print and Fire Two layers of Capacitor Paste

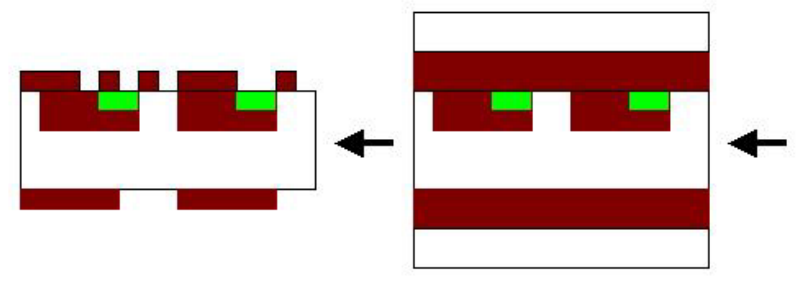

Apply Photoresist

Expose and develop

photoresist, etch copper and strip photoresist

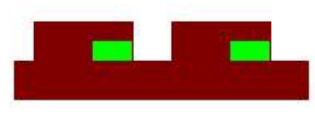

Print and Fire Second Electrode
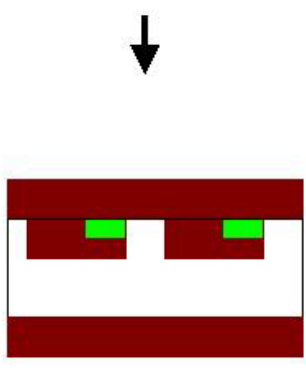

Vacuum Laminate to FR4 using Prepreg

Figure 2.5. Dupont Interra ${ }^{\mathrm{TM}}$ process

$3 \mathrm{M}$ C-Ply ${ }^{\mathrm{TM}}$

This dielectric is a Barium Titanate filled epoxy, which is sandwiched between two layers of $\mathrm{Cu}$ foil. It has a capacitance density of $1.6 \mathrm{nF} / \mathrm{cm}^{2}$ with a very low dissipation factor of $0.45 \%$. Based on these performance parameters, the dielectric has been used for decoupling application and has been found to reduce switching noise by three times [23].

\section{Resistors}

The following section talks about fabrication processes for resistors and materials that are currently being developed for embedded resistors. Some of the 
processes for fabricating resistors have been discussed in the capacitor fabrication section and hence will be only briefly revisited.

Sputtering

Sputtering is the most commonly used process to deposit thin film integrated resistors. Tantalum Nitride $\left(\mathrm{TaN}_{\mathrm{x}}\right)$ has been deposited in a nitrogen rich environment and depending on the concentration of nitrogen, the resistivity increases with increasing nitrogen and the Temperature Coefficient of Resistance (TCR) decreases with increasing nitrogen. Tantalum Nitride films with resistivity of $250 \Omega-\mathrm{cm}$ have been fabricated. Tantalum Oxy-Nitride $\left(\mathrm{TaN}_{\mathrm{x}} \mathrm{O}_{\mathrm{y}}\right)$ is another material that is deposited by sputtering and resistivities of $5000 \Omega$ /square have been demonstrated. Semiconductors like Silicon can be used as resistors but their highly temperature and impurities dependent. Silicon is sputtered on organic substrates.

\section{Screen Printing}

Polymer Thick Film (PTF) materials are primarily processed using screenprinting. These materials consist of epoxy-based polymers that have carbon fillers in the polymer. These are the conducting particles and the conduction mechanism is due to the bridging of these particles. PTF materials have low temperature processing and are usually cured at temperatures below $200^{\circ} \mathrm{C}$. Screen-printing is a very simple and inexpensive process but it suffers from 
tolerance problems, reliability issues and delamination between the resistor material and the copper pad resulting in open circuits. In addition, swelling due to moisture and cracking of the polymer material due to CTE mismatch are causes of failure. Finally Screen-printing may be a little cumbersome process and requires very careful process control for good tolerance. The achievable sheet resistances cover a very wide range of 1 to $10^{7} \Omega$ /square.

\section{$\underline{\text { Ink Jet Deposition }}$}

This process is very similar to ink jet printers and is used to deposit curable resin polymers and solder. Good tolerances, flexibility in resistor values, ease of use and reworkability make ink jet deposition an attractive process. Epoxy resins have been deposited using the above method. Figure 2.6 shows a Figure of the process [24].

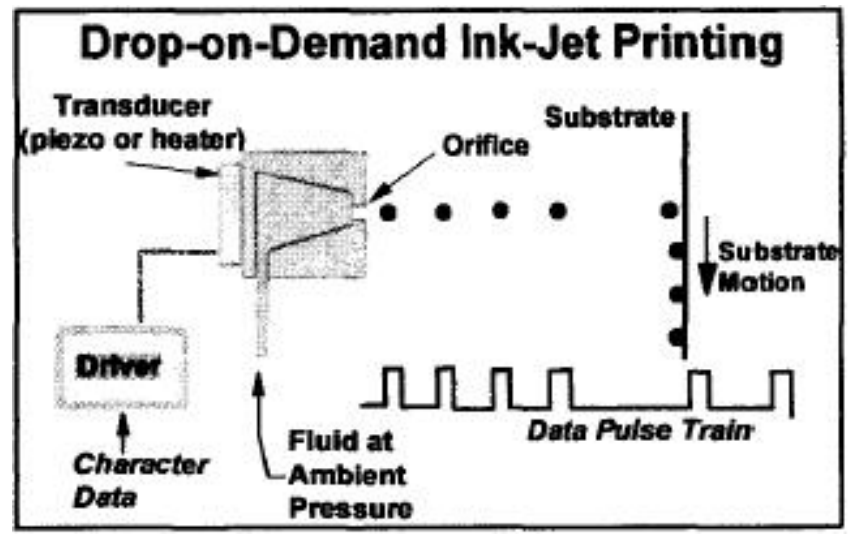

Figure 2.6. Droplets on Demand Ink Jet deposition 


\section{Commercialized Processes for Resistors}

This section discusses some commercialized processes in resistors that are currently being used or show great promise.

\section{Ohmega-Ply ${ }^{\mathrm{TM}}$}

Ohmega-Ply ${ }^{\mathrm{TM}}$ is an embedded resistor technology developed by Ohmega and is meant primarily for organic substrates or laminates. The resistor used is Nickel Phosphide (NiP), which is on one side of a copper foil. Using various process steps, copper interconnects can be formed to define the final resistor structure and value. The thickness of $\mathrm{NiP}$ varies between $0.1 \mu \mathrm{m}$ and $0.4 \mu \mathrm{m}$ and the sheet resistance can be as high as $250 \Omega /$ square.

\section{DuPont Interra ${ }^{\mathrm{TM}}$}

The process is the same as discussed earlier in the capacitor fabrication section with the exception of Lanthanum Boride being used as the resistor material. Lanthanum Boride is stable and highly reliable resistor material. The minimum thickness of the resistor lines is $10 \mu \mathrm{m}$ and issues relating to the separation of the resistor termination interface surfaced.

Shipley InSite ${ }^{\mathrm{TM}}$

The resistor material used in embedded resistor is a thin film of doped platinum deposited on copper foil by CCVD. The process produces high values

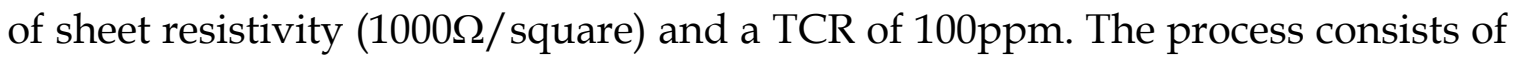


a copper foil of $1 / 2$ oz or 1 oz thickness, which is coated with the InSite resistor material, laminated with the resistor film against the prepreg. Figure 2.8 shows a schematic of the process [25].

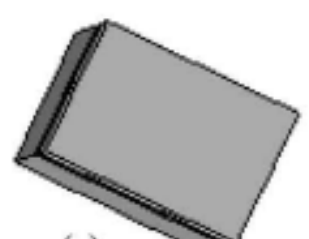

(a)

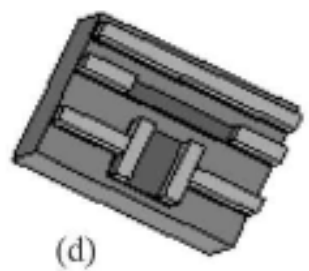

(d)

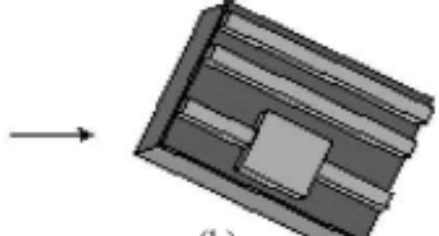

(b)

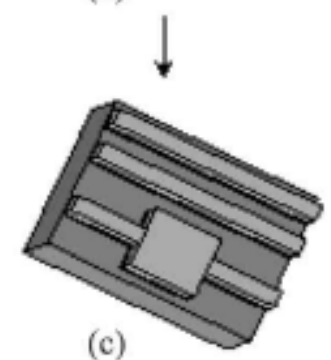

(c)

Figure 2.8. Shipley InSite ${ }^{\mathrm{TM}}$ process

\section{$\underline{\text { Reliability Experiments }}$}

This section addresses the previous research done in the field of reliability of embedded passives. Since embedded passives are still an emerging technology, research in the thermo-mechanical reliability of passives is very limited. Schatzel has studied the thermo-mechanical reliability of capacitors made from Tantalum Oxide $\left(\mathrm{Ta}_{2} \mathrm{O}_{5}\right)$ and Benzocyclobutene (BCB) [26]. The capacitors were fabricated on silicon as compared to industry standard FR4 and the capacitance values were measured at low frequency. The changes in capacitance after assembly process and 20 thermal cycles between $-55^{\circ} \mathrm{C}$ and 
$100^{\circ} \mathrm{C}$ were measured. The mean change in capacitance was $0.61 \%$ but since only 20 thermal cycles were performed, it is inconclusive as far as long-term reliability goes. Borland et al. have reviewed the reliability of the Dupont Interra ${ }^{\mathrm{TM}}$ process as outlined in the capacitor and resistor fabrication section above [27]. The ceramic embedded capacitors and resistors were cycled between $-45^{\circ} \mathrm{C}$ and $125^{\circ} \mathrm{C}$ and kept at $85^{\circ} \mathrm{C} / 85 \% \mathrm{RH}$. The resistors showed an extremely small change $0.3 \%$ and capacitors showed a maximum change of $5 \%$ after 1000 cycles. The change in resistors after the high humidity and temperature conditions are less than $2 \%$. However the resistors and capacitors were ceramic which have a much lower CTE and hence the thermo-mechanical deformation experienced will be much less than the deformation experienced in organic polymer dielectrics. Strydom et al. have looked at the reliability of embedded inductors from a delamination standpoint [28]. The inductors are subjected to thermal cycling and then the interfacial peel strength was measured at the end of subsequent thermal cycles to see the potential site of delamination. In addition, the change in capacitance was measured after 2000 tests. Lots of other literature on reliability of passives was found but they were of discrete passives and generally did not involve any thermal cycling. In addition, the change in electrical parameters was also not considered as a mode of failure. Fairchild et al. have looked at the thermal cycling of flexible thin-film embedded resistors and noticed a change of $2 \%$ after 300 thermal cycles. The resistor material used was Chromium Silicate (CrSi) with copper as the metalization [29]. Zhou et al. have subjected embedded 
resistors and capacitors to 1000 thermal cycles between $-40{ }^{\circ} \mathrm{C}$ and $125^{\circ} \mathrm{C}$ and observed a change of $-0.3 \%$ and $-3.10 \%$ respectively. The resistor used is Dupont $^{\mathrm{TM}}$ ceramic resistor material and the capacitor dielectric is $3 \mathrm{M} \mathrm{C}-\mathrm{Ply} \mathrm{yM}^{\mathrm{TM}}$ [30].

\section{Literature Review on passing qualifications for Embedded Passives}

Failure qualifications in traditional reliability experiments have been very specific and easy to determine. For example, in an IC, the failure of the solder joint occurs when a crack propagates through the entire length of the solder joint and hence current cannot flow through the solder joint. In thermo-mechanical failure of passives however, the failure is not clearly quantified and different applications of passives might carry different ranges of failure. For example, the tolerance in a decoupling capacitor is not extremely important and a change of about $5 \%$ is not considered to be high. On the other hand, analog functions such as filters, $\mathrm{A} / \mathrm{D}$ conversion require tight tolerances and even a change of $5 \%$ is too high.

Though there is no standard for embedded passives, the Electronics Industry Association (EIA) has classified discrete capacitor dielectrics by the change in dielectric constant with temperature. Currently there is no code for embedded passives but a similar system may be implemented in the future. The system consists of a alphanumeric code; the first alphabet is used to describe the 
low temperature, the second number represents the high temperature and the third alphabet is the \%change seen in the dielectric. For example, X7R represents a maximum change of $\pm 15 \%$ between $-55^{\circ} \mathrm{C}$ and $125^{\circ} \mathrm{C}$. Table 2.1 shows the EIA codes used for classifying different dielectric materials.

Table 2.1. EIA temperature codes for dielectrics

\begin{tabular}{|c|c|c|c|c|c|}
\hline \multicolumn{2}{|c|}{ Low Temperature } & \multicolumn{2}{|c|}{ High Temperature } & \multicolumn{2}{|c|}{$\%$ Change } \\
\hline Z & +10 deg. C & 2 & +45 deg. C & A & $1.00 \%$ \\
\hline Y & -30 deg. $C$ & 4 & +65 deg. $C$ & B & $\pm 1.5 \%$ \\
\hline \multirow[t]{10}{*}{$x$} & -55 deg. C & 5 & +85 deg. C & C & $\pm 2.2 \%$ \\
\hline & & 6 & +105 deg. C & $\mathrm{D}$ & $\pm 3.3 \%$ \\
\hline & & 7 & +125 deg. C & E & $\pm 4.7 \%$ \\
\hline & & & & $\mathrm{F}$ & $\pm 7.5 \%$ \\
\hline & & & & $\mathrm{P}$ & $\pm 10.0 \%$ \\
\hline & & & & $\mathrm{R}$ & $\pm 15.0 \%$ \\
\hline & & & & S & $\pm 22.0 \%$ \\
\hline & & & & $\mathrm{T}$ & $+22 \%,-33 \%$ \\
\hline & & & & $\mathrm{U}$ & $+22 \%,-56 \%$ \\
\hline & & & & $\mathrm{V}$ & $+22 \%,-82 \%$ \\
\hline
\end{tabular}

In addition, the EIA has also classified dielectrics according to their dielectric constant and the stability with temperature. The three classes are: 
i) Class 1: These dielectrics usually have a $k$ less than 100 and change no more than $30 \mathrm{ppm}$ between temperature range of $125^{\circ} \mathrm{C}$ and $-55^{\circ} \mathrm{C}$. If adapted for embedded passives, this category would go to paraelectrics for dielectric constant and stability.

ii) Class 2: These dielectrics usually have a $k$ in the range of 2000-5000 and a stability of upto $\pm 15.0 \%$.

iii) Class 3: These dielectrics have a $\mathrm{k}$ in the range of 4000-20000 and stability in the range of $+22 \%$ to $-82 \%$. Both Class 2 and 3 belong to the category of ferroelectrics.

In the near future with the widespread use of embedded passives, some sort of code will be used to describe the changes in electrical parameters in passives with changes in temperature, voltage, bias, aging etc.

\section{Literature Review on Qualification Tests of Embedded Passives}

The reliability of passives has been determined using some of the techniques mentioned below.

Air-to-air accelerated reliability testing: Air to air thermal stress testing is a standard methodology in the electronic packaging industry to assess the reliability of the components. It is also called the MIL-STD-883 Method or IPCSM-785 test. Components are subjected to a temperature range from $-55^{\circ} \mathrm{C}$ to 
$125^{\circ} \mathrm{C}$ in a cycle. Each cycle has a period of 20 minutes with 10 minutes dwell at extreme temperatures.

Standard Steady State Humidity Life Test: Very commonly used to determine the reliability of microelectronics packages, this test places the test substrate at high temperature and relative humidity of $85^{\circ} \mathrm{C} / 85 \% \mathrm{RH}$. Sometimes the substrate is also subjected to a bias to determine the electrical performance of the test vehicle in adverse conditions. The test is also referred sometimes as the HAST test (Highly Accelerated Stress Test).

\section{$\underline{\text { Reliability Modeling }}$}

It is clear that research into the thermo-mechanical reliability of organic dielectrics on FR4 substrates is lacking and more work needs to understand the physics of passive reliability. In addition, very limited literature was found on the Finite Element Analysis validation of the results obtained from various experiments. Most of the research found published the results without any Finite Element Evaluation of the reason behind the changes in electrical parameters. No attempts are made to explain the reason for the changes in electrical parameters and the physics behind the change of the parameters.

Lee et al. have looked at the temperature distribution in integrated passive modules and determined the thermo-mechanical stress distribution in 
the module [31]. The temperature distribution was validated using an Infra Red camera and the Von Mises stress distribution was found to influenced by the in plane stresses. The stress distribution was not validated by any means. 


\section{Chapter III}

\section{OBJECTIVES}

Embedded passives will play a critical role in high performance low cost microelectronics packages of the future. Everything from the fabrication process to the materials to be used is still under research and there is no consensus on each of the issues. In addition, the reliability research in embedded passives is lacking and there is no standard developed right now to qualify the reliability of passives. With the strong consumer drive to wireless applications, it is necessary to have design guidelines to fabricate reliable passives structures.

The primary objective of this research is to see the effect of thermomechanical deformation on the electrical parameters of the embedded passive structures. In order to perform reliability experiments, test boards are fabricated in a class 1000 clean room and then subjected to various reliability tests. The results from the experimental studies are correlated with the results obtained from the Finite Element Simulations.

The specific objectives of this work are:

- Develop theoretical models and to conduct experiments to study the reliability of embedded passives.

- The theoretical program aims: 
- To develop physics based models that simulate the board deformation during thermal cycling.

- To develop electrostatic models that find the electrical parameters of the deformed model.

- Develop parametric models to see the effect of passive distance from neutral point and material selection on passive reliability.

- To develop physics based models to predict the change in electrical parameters based on the thermal loading experienced in fabrication processes.

○ The experimental program aims:

- To fabricate test vehicles with embedded passives using photolithography process on standard FR4 substrate.

- To subject the test vehicles to various reliability tests and observe the change in electrical parameters.

- To validate the results from the theoretical program with the experimental data.

\section{Gaps in Existing Research}

As observed in the literature survey, there is a severe shortage of research performed in thermo-mechanical reliability of embedded passives. Most of the 
research in the reliability of passives has been performed on either discrete passives or ceramic passives. Very limited literature takes a look at the reliability of standard photolithography process on conventional substrates. In addition, no Finite Element Analysis is performed in most of the published work to correlate the results with the experimental results obtained. There has been no attempt to understand the reason for the change in electrical parameters after the reliability experiments. No combined experimental and theoretical program exists for understanding the reliability of embedded passives. While material selection based on cost and electrical performance is widely considered, selection based on mechanical performance is very limited. No design guidelines exist for designing passives for optimal electrical and mechanical performance. Finally, there is limited research in understanding the effect of fabrication process on the change in electrical parameters. It has been generally observed in literature that obtaining a tolerance higher than $5 \%$ after fabrication is difficult. No literature could be found on effects on fabrication process on the performance of passives. In addition, the focus of most of the published work is limited to one type of passive instead of looking at all three. 


\section{Chapter IV}

\section{DESCRIPTION OF TEST VEHICLE}

This chapter focuses on the steps to fabricate a multi-layered substrate with embedded passives. The first section discusses the test vehicle and the various passives structures in it. The next section looks at the processing conditions required to fabricate the test vehicle.

\section{$\underline{\text { Test Vehicle Details }}$}

The test vehicle fabricated has five layers of material on it. It is fabricated using a photolithography process on a FR4 substrate. The different materials used in the substrate and their thickness are listed in table 4.1. Figure 4.1 shows a picture of the test board and the passives embedded in the test board. The test board has 6 parallel circular plate capacitors, 4 spiral inductors and 2 meander resistors. The 6 capacitors have varying electrode diameters but same dielectric thickness between the electrodes. Table 4.2 shows the diameter of the capacitors and the capacitance value. 
Table 4.1. Materials used in the test board

\begin{tabular}{|c|c|c|}
\hline Material & Function & Thickness \\
\hline Copper & Traces, Pads, Inductor traces, \\
Capacitor Plates & $15 \mu \mathrm{m}$ \\
\hline Shipley Dynavia 2000 & Dielectric & $63.5 \mu \mathrm{m}$ \\
\hline Carbon Ink & Resistor & $15 \mu \mathrm{m}$ \\
\hline FR4 & Base material & $700 \mu \mathrm{m}$ \\
\hline Vialux 81 & Solder Mask & $30 \mu \mathrm{m}$ \\
\hline
\end{tabular}

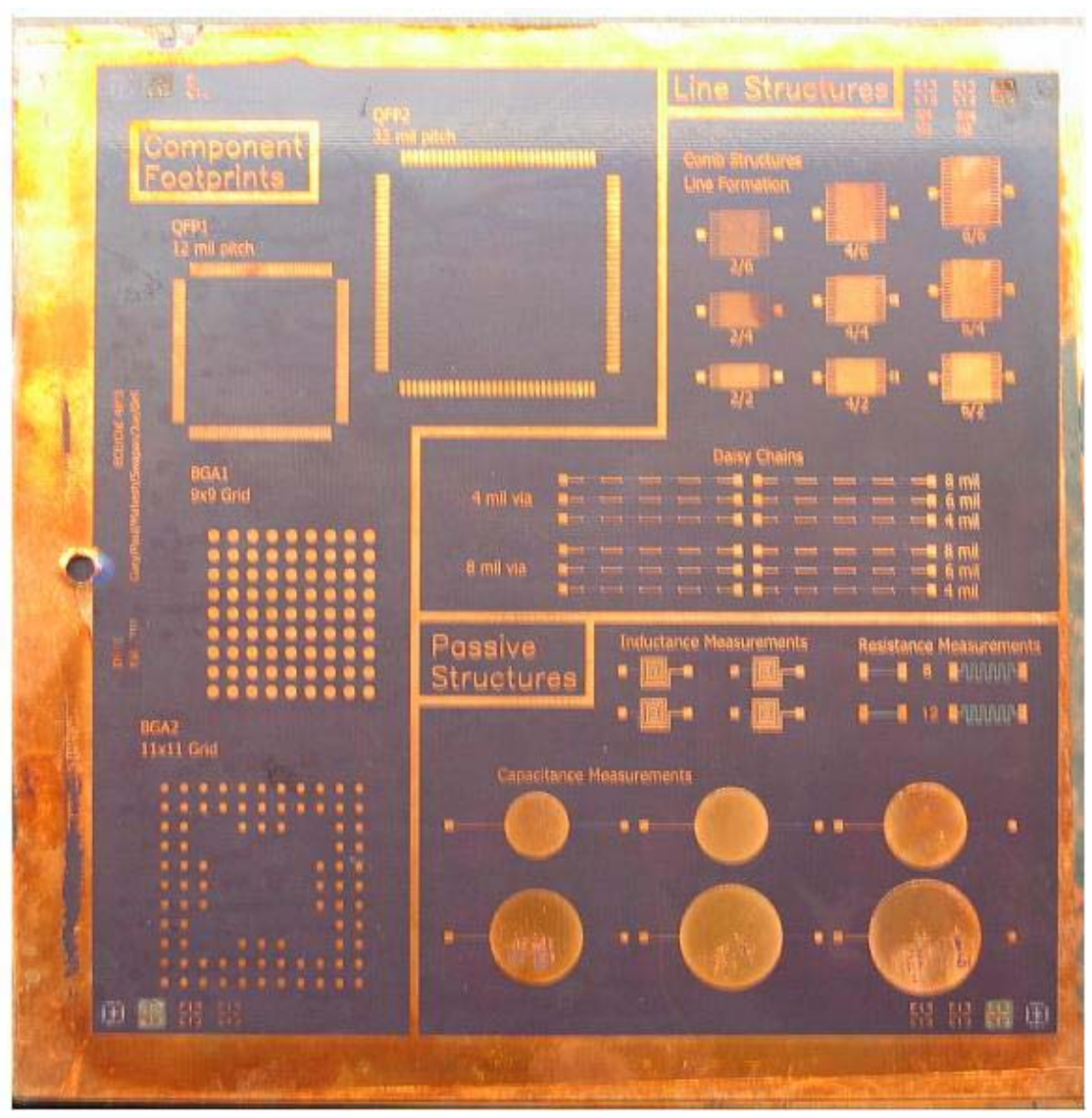

Figure 4.1. Picture of the Test Board 
Table 4.2. Details of the capacitors

\begin{tabular}{|c|c|c|}
\hline Passive & Diameter & Value \\
\hline Capacitor 1 & 330 mils & $29.53 \mathrm{pF}$ \\
\hline Capacitor 2 & 380 mils & $39.16 \mathrm{pF}$ \\
\hline Capacitor 3 & 430 mils & $50.14 \mathrm{pF}$ \\
\hline Capacitor 4 & 480 mils & $62.48 \mathrm{pF}$ \\
\hline Capacitor 5 & 530 mils & $76.18 \mathrm{pF}$ \\
\hline Capacitor 6 & 580 mils & $91.23 \mathrm{pF}$ \\
\hline
\end{tabular}

The other passives on the board are inductors and resistors. The value of inductance for all the inductors is $4.9 \mu \mathrm{H}$ and the resistance for the 8 mil thick resistor is $350 \mathrm{~K} \Omega$ and for the 12 mil thick resistor is $125 \mathrm{~K} \Omega$.

\section{Fabrication Steps and Processing Conditions}

There are five layers in the fabrication. They are metal 1 (or the bottom metal layer), dielectric, metal 2 (or the top metal layer), soldermask and resistor layer. The photoresist used in the process is Dupont ${ }^{\mathrm{TM}}$ Riston 206, which is a negative defined dry film photoresist. The fabrication process starts with a double clad FR4 board. Prior to fabrication, the board is cleaned and the thin oxide formed on the copper is removed. This is done by dipping the board in Acetone, Methanol and Propanol to remove the dirt from the copper. It is then 
dipped in deionized water and placed in sulphuric acid for $1 \mathrm{~min}$. The board is finally baked at the end of the process to remove the accumulated moisture.

\section{Metal 1 Layer}

The photoresist is taken out of the refrigerator and allowed to warm up to room temperature. A 5.375" square is cut out from the photoresist and placed on the board. The protective coating on the side of the substrate is removed prior to the placement on the board. The photoresist is then vacuum laminated at $105^{\circ} \mathrm{C}$ for 60 seconds and at 4 atmospheres for 30 seconds respectively. After the photoresist has been laminated, the laminator drawer is opened and the substrate is cooled down to room temperature.

The photoresist is now exposed for 15 seconds using the under the bottom metal mask shown in Figure 4.2. Photolithography is based on the principle that the exposed region is going to be harder to remove due to cross-linking under UV light. Hence when the photoresist is developed, the unexposed areas will etch away and the exposed areas will prevent the underneath materials from etching or other processes. The exposed photoresist is developed using a much stronger solvent. In case of the negative acting Riston 206, the unexposed photoresist is developed using Sodium Carbonate solution heated upto $35{ }^{\circ} \mathrm{C}$. Before developing, the protective coating on the top side of the photoresist is removed and the substrate is placed in the solution for 60 seconds. The substrate is then rinsed in deionized water and dried with an air gun. The substrate is 
inspected under a microscope to make sure no residue of the exposed photoresist is left on the board.

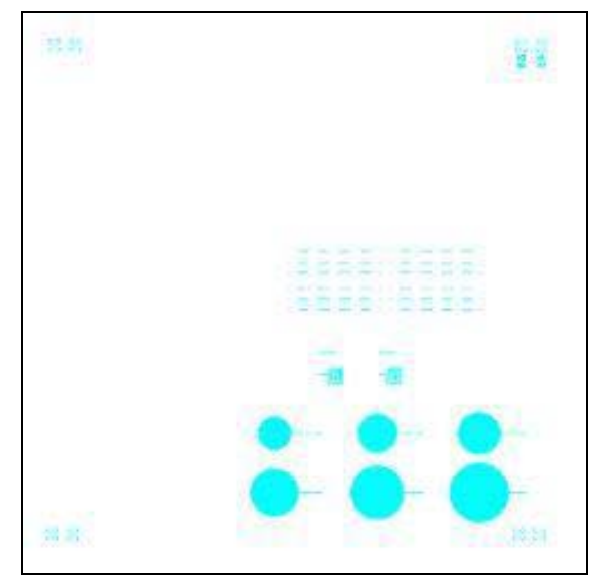

Figure 4.2. Bottom Metal Mask

Now that the photoresist is removed from the board, the exposed copper, which was under the unexposed photoresist, is etched away using a 30\% Ferric Chloride solution. The substrate is rinsed and dried and inspected for any copper residue and feature sharpness. Having formed the bottom metal layer, the remaining developed photoresist is removed using 1\% Sodium Hydroxide solution heated to $53{ }^{\circ} \mathrm{C}$. Any residue of photoresist or copper means that the stripping should go on till no residue is left and all features on the board are visible. Finally the substrate is baked to remove any accumulated moisture in the substrate. After the metal 1 layer, the Dielectric layer is fabricated. 


\section{Dielectric Layer}

Shipley DynaVia $2000^{\mathrm{TM}}$ is the dielectric material used as the dielectric. It is a negative acting dry film dielectric. The dielectric is laminated on the substrate in the same manner as the photoresist. However the lamination takes place at $60{ }^{\circ} \mathrm{C}$ instead of $105{ }^{\circ} \mathrm{C}$. Once the dielectric has been laminated, the substrate is baked at $85{ }^{\circ} \mathrm{C}$ for 45 minutes and allowed to cool down to room temperature. The DynaVia ${ }^{\mathrm{TM}}$ is exposed using the via mask. The vias mask used is shown in Figure 4.3. In order to align the mask properly with the board, orientation structures called fiducials are matched with the fiducials formed on the bottom metal layer. It is important to align the masks properly or the vias will be unable to connect the bottom layer with the top metal layer. This mask allows the formation of vias in the dielectric and connects the bottom metal layer with the top metal layer. The substrate is baked after exposure for 45 minutes at $85^{\circ} \mathrm{C}$.

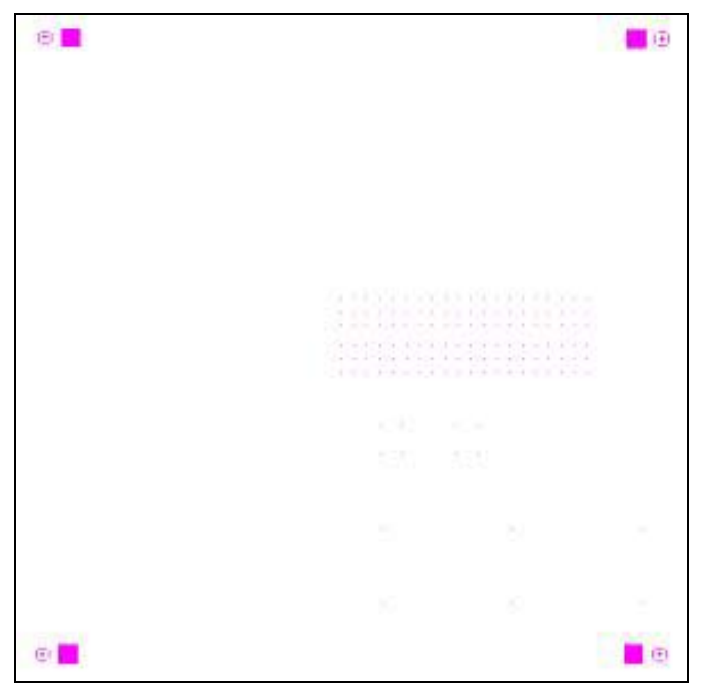

Figure 4.3. Via Mask 
The Dynavia is then developed using a $98 \%$ solution of GBL (Gammabutyroacetone) for 31/2 minutes to form the via holes. Following the developing, the substrate is placed in a solution of propanol for 1-2 minutes and dried with an air gun. The substrate is inspected under a microscope to ensure that the vias have opened up and if that is not the case, the dielectric is developed again. The Dynavia is now exposed without any mask and subsequently cured at $135{ }^{\circ} \mathrm{C}$ for 45 minutes to cross link the dielectric. The substrate is removed from the oven and allowed to cool down to room temperature. Following the fabrication of the dielectric layer, the top metal layer is formed next.

\section{Metal 2 Layer}

In order to form copper on the substrate, copper needs to be electroplated on the substrate. However electroplating requires a conducting medium on the surface of the substrate and Dynavia, being a dielectric, is not one. So a thin seed layer of copper is deposited to electroplate thicker layer of copper later. The seed layer has a thickness of around $5 \mu \mathrm{m}$ and is deposited by electroless plating. Following are the steps followed in order to do electroless plating on the substrate: 
i) The substrate is swelled in order to make etching easier. This is done by using a solution containing the solvents diethylene glycol and nbutyl ether.

ii) The substrate is rinsed in deionized water and put in a permanganate etch solution. This allows for better adhesion of the material.

iii) The board is rinsed in deionized water for 2 minutes and then neutralized for 2 minutes at room temperature using a solution of $\mathrm{p}$ toulene, sulphuric acid and hydrogen peroxide to remove any excess chemicals.

iv) The board is rinsed in deionized water and conditioned using weak sulphuric acid to prepare the board for microetching.

v) The board is then microetched to prepare the substrate for the activator and rinsed for 2 minutes.

vi) The board is pretreated for 1 minute before dipping in the activator. The pretreatment solution consists of sodium bisulfate and carbamidic acid. The activator bath triggers the insulating surface to provide metal seeds and provide better copper deposition. The activator solution consists of hydrochloric acid, palladium chloride and tin chloride.

vii) The board is rinsed and put in a reducer solution for 5 minutes. The reducer allows for reduction of metal cations at the substrate surface, a plating reaction, to occur. The reducing agent used is Formaldehyde. 
viii) The board is rinsed and electroless plating is performed on the board for 6 minutes.

ix) The board is rinsed and microetched for 1 minute.

x) The board is rinsed and dipped in an antitarnish solution to remove any oxide from the freshly formed copper surface.

xi) The board is rinsed and baked at $65{ }^{\circ} \mathrm{C}$ for 2 minutes to remove excess moisture from the board.

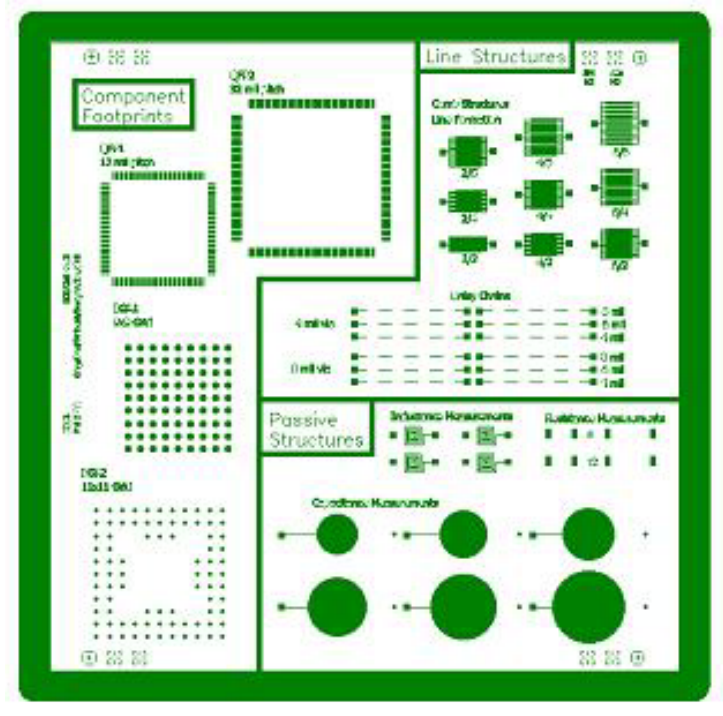

Figure 4.4. Top Metal Mask

With the formation of the seed layer, electroplating can now be carried out. However, in order to pattern the top metal, copper only needs to be deposited in certain areas. Hence in order to develop that pattern, photoresist is laminated on the top surface of the substrate, aligned with the top metal mask and exposed. The photoresist is then developed to expose only the areas that need to be 
electroplated. The board is then microetched to remove the oxide layer on copper before electroplating. The following steps are followed for the electroplating of copper.

i) The board is dipped in sulphuric acid for 1 minute to remove the oxide.

ii) The board is clipped into place and placed in the electroplating bath for 10 minutes.

iii) After 10 minutes, rotate the substrate to perform even coating over the coated surface.

iv) After all 4 sides of the board have been rotated; place the board in a 3\% Sodium Hydroxide solution to remove the remaining photoresist.

v) Rinse the board and dry it.

vi) The board is microetched for 40 seconds and rinsed and dried. The board is inspected to ensure uniform coating.

vii) The board is baked to remove any moisture.

\section{Resistor Layer}

With the completion of the top metal layer, resistors are fabricated by opening gaps between copper pads and depositing resistor material with a squeegee in the gaps. The process starts by laminating photoresist on the substrate and exposing it using the resistor mask. 


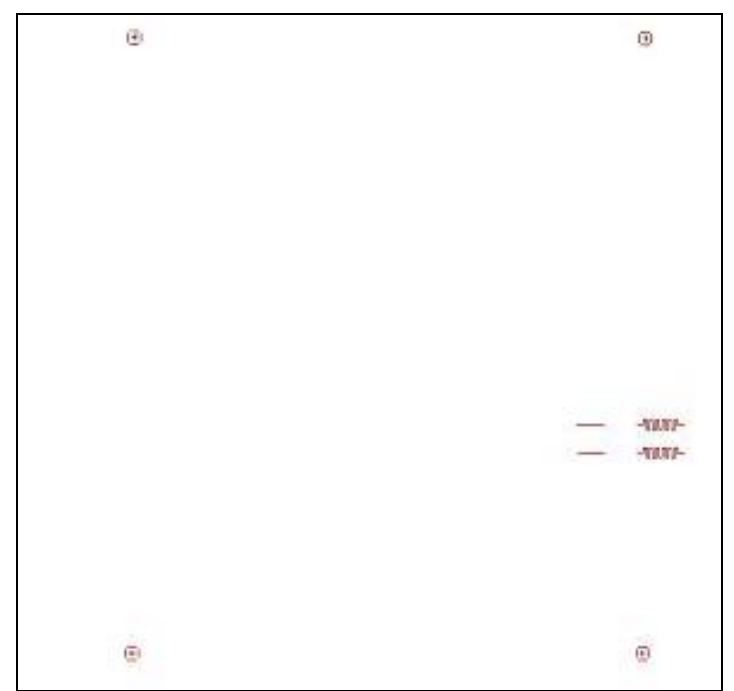

Figure 4.5. Resistor Mask

The photoresist is developed and then rinsed in deionized water. The resistor material is then squeegeed into the gaps in the substrate. The substrate is then baked for 30 minutes at $85^{\circ} \mathrm{C}$ and for 15 minutes at $110^{\circ} \mathrm{C}$. The photoresist then stripped off to complete the liftoff process. The resistor is then cured at $150^{\circ} \mathrm{C}$ for 2 hours to make the resistor permanent. After the resistor layer, the final layer of solder mask is fabricated.

\section{Solder Mask}

The solder mask is fabricated by first making the solder mask. The solder mask consists of a thinner, hardener and thinner. After the mixture is made, the solder mask is spun coat on the substrate by spinning it for 30 seconds at 300 rpm and for 30 seconds at $1200 \mathrm{rpm}$. The substrate is then baked for 15 minutes 
at $60^{\circ} \mathrm{C}$ and for 45 minutes for $85^{\circ} \mathrm{C}$. The solder mask is then exposed using the solder mask mask.

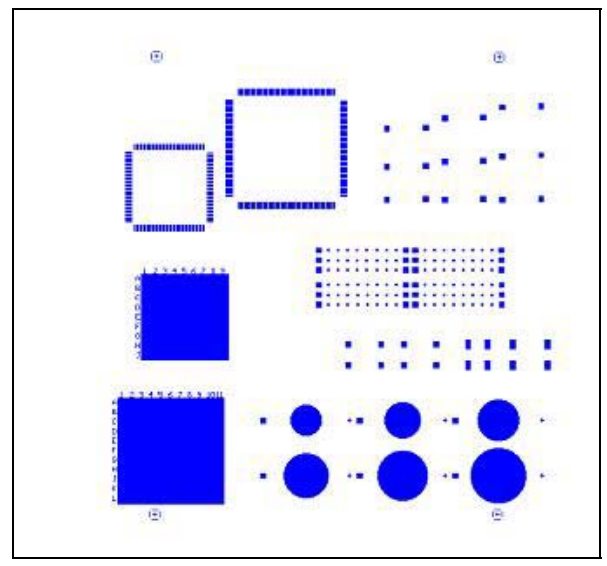

Figure 4.6. Solder Mask mask

The solder mask is then developed in a 1\% Sodium Carbonate solution and cured for 1 hour at $150{ }^{\circ} \mathrm{C}$. With the completion of the solder mask layer, the fabrication of the board is concluded. Figure 4.7 shows a schematic of the fabrication process. 


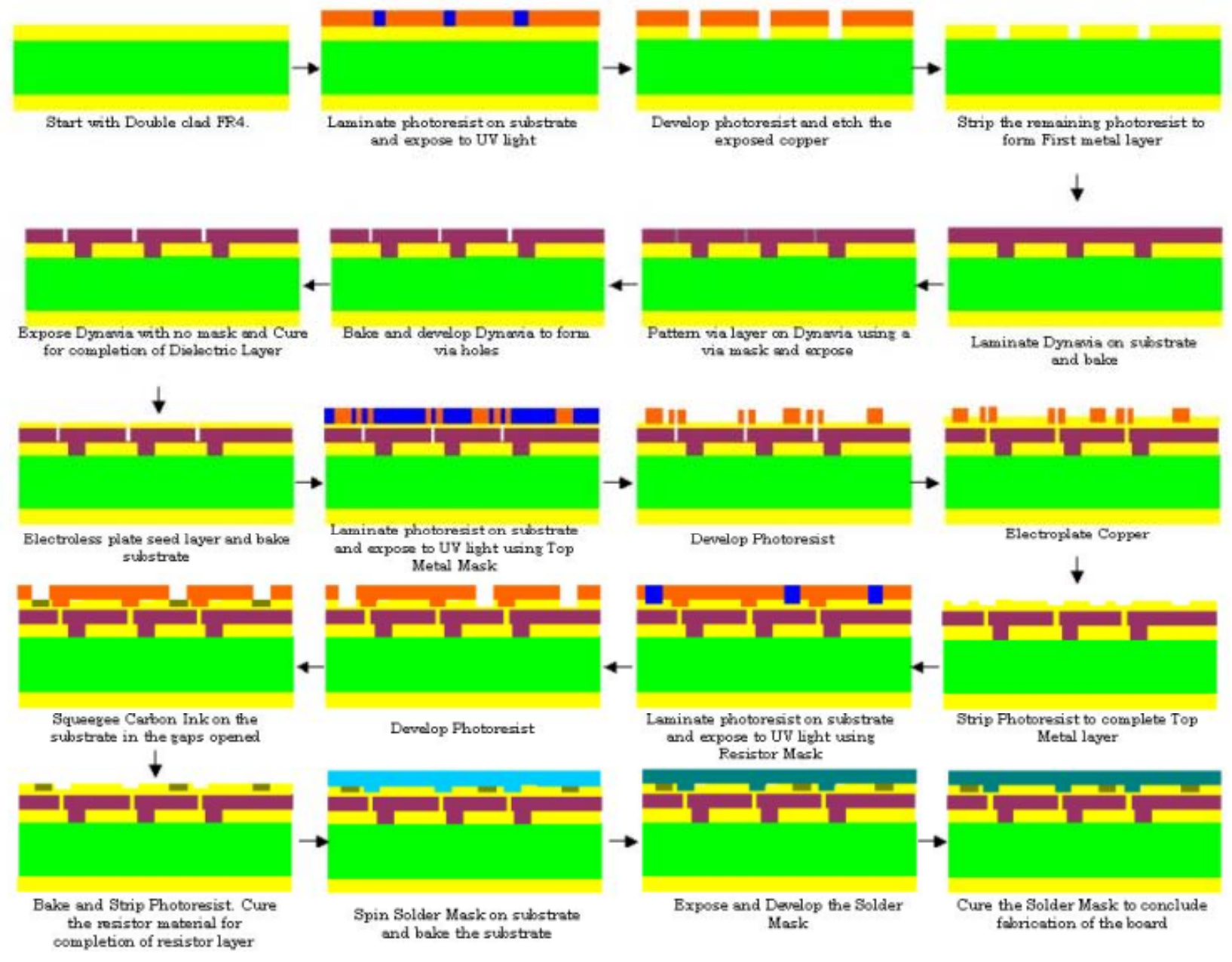

Figure 4.7. Fabrication process of passives 


\section{CHAPTER V}

\section{MODELING OF INTEGRAL PASSIVES}

In this section, the electrical and geometric modeling of passives has been discussed. The FEA models corresponding to thermo-mechanical models have been discussed. In addition, the electrostatic simulation of passives has been discussed in detail. The focus is on capacitors and inductors. All the FEA models constructed are parametric and important parameters such as the material properties, board thickness, distance from the neutral point (DNP), capacitor diameter, inductor length, thickness of the layers can be changed to determine

their effect. It is important to note that the geometric modeling is done using shell elements and electromagnetic modeling was done using solid elements. This difference will play an important role in the thermo-mechanical modeling of passives.

Some assumptions are made during modeling of the FEA modeling of the board. They are:

i) Since mainly electrical failure is of concern here, mechanical failure is not considered here. Only the deformation of the board is the critical parameter that can lead to the failure of passives.

ii) There are many other features on the board that are not modeled. It is assumed that their effect on deformation is minimal. 
iii) During thermal cycling, all the components are assumed to be at same temperature and there is no temperature gradient in the board.

iv) All the thickness of the layers are measured using a profilometer. Any small variations in thickness of the layers across the board are ignored.

\section{Material Modeling}

The test board fabricated has several layers of different materials in it. In order to represent these materials accurately, different material models are used in the FEA. The properties of the dielectric and soldermask are of particular interest since they exhibit viscoelastic behavior. The following section discusses the properties of the materials in the board.

\section{Copper}

Copper is present in the board as the capacitor plates, as inductor traces and on the other side of FR4. The elastic properties are modeled as linear isotropic with temperature dependent material properties. The plastic behavior was modeled as multi-linear kinematic hardening. Unlike isotropic hardening where there is uniform expansion of the yield surface, kinematic hardening leads to translation of the yield surface. The copper laminated on the FR4 and the electroplated copper are both assumed to have same properties. Table 5.1 shows the temperature dependence of Copper modulus. Table 5.2 and Figure 5.1 shows the kinematic hardening behavior of copper. 
Table 5.1 Dependence of modulus on temperature [32]

\begin{tabular}{|c|c|}
\hline Temperature $\left({ }^{\circ} \mathrm{C}\right)$ & $\mathrm{E}(\mathrm{GPa})$ \\
\hline 27 & 121 \\
\hline 38 & 119 \\
\hline 93 & 117 \\
\hline 149 & 115 \\
\hline 204 & 112 \\
\hline 260 & 110 \\
\hline
\end{tabular}

Table 5.2 Kinematic Behavior of copper

\begin{tabular}{|c|c|}
\hline Strain & Stress (MPa) \\
\hline 0.001 & 121 \\
\hline 0.004 & 186 \\
\hline 0.01 & 217 \\
\hline 0.02 & 234 \\
\hline 0.04 & 248 \\
\hline
\end{tabular}




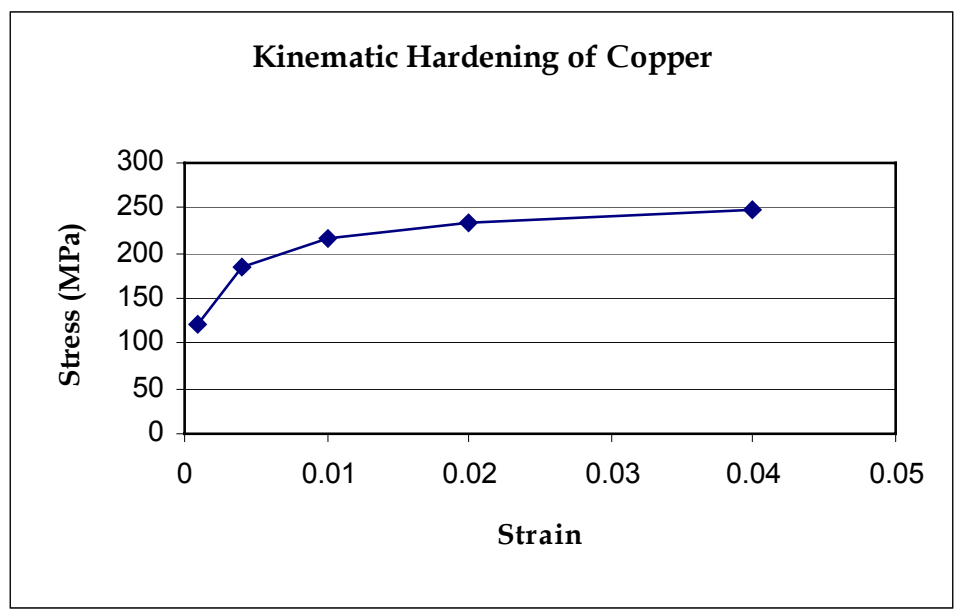

Figure 5.1. Kinematic Hardening of Copper

\section{FR4}

FR4 is the most commonly used material in electronics industry for the base material of Printed Wiring Boards (PWB). Its favorable mechanical and electrical properties combined with its low cost are the primary reasons for its wide spread use. In the FEA model, FR4 is modeled as temperature dependent, linear-elastic material with orthotropic properties. This is due to the fact that FR4 consists of glass fibers in an epoxy matrix. The fabrication of FR4 makes it very orthotropic in the normal or out of plane direction ( $\mathrm{z}$ direction). Table 5.3 presents the properties of FR4 at $30^{\circ} \mathrm{C}$ [33].
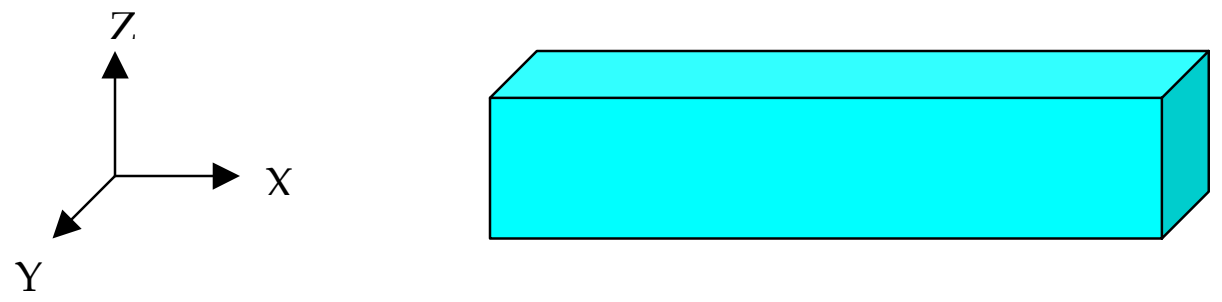

Figure 5.2. Co-ordinate axis in ANSYS ${ }^{\mathrm{TM}}$ 
Table 5.3. Properties of FR4 at $30^{\circ} \mathrm{C}$.

\begin{tabular}{|c|c|}
\hline Property & Value \\
\hline $\mathrm{E}_{\mathrm{X}}, \mathrm{E}_{\mathrm{Z}}$ & $22.4 \mathrm{GPa}$ \\
\hline $\mathrm{E}_{\mathrm{Y}}$ & $1.5 \mathrm{GPa}$ \\
\hline$\alpha_{X}, \alpha_{Z}$ & 16.2 \\
\hline$\alpha_{Y}$ & 54 \\
\hline $\mathrm{G}_{X Y}, \mathrm{G}_{Z}$ & $0.199 \mathrm{GPa}$ \\
\hline $\mathrm{G}_{X Z}$ & $0.63 \mathrm{GPa}$ \\
\hline$v_{X Y}, v_{\mathrm{YZ}}$ & 0.1425 \\
\hline$v_{X Z}$ & 0.2 \\
\hline
\end{tabular}

\section{DynaVia}

Shipley DynaVia $2000^{\mathrm{TM}}$ is the dielectric that is used in the board. It is an epoxy based photo definable, negative acting, dry film dielectric. Unlike copper and FR4, DynaVia exhibits typical linear viscoelastic behavior after curing. DynaVia posses a very high CTE of 72ppm below its Glass transition of 110$120^{\circ} \mathrm{C}$ and a CTE of $200 \mathrm{ppm}$ above that.

Viscoelastic materials can be very simply represented by the Kelvin and the Maxwell model. The Kelvin model consists of a spring and dashpot in series and the Maxwell model consists of a spring and dashpot in parallel. However these models have severe deficiencies and cannot represent the viscoelastic 
behavior of materials satisfactorily [34]. The Maxwell model shows no time dependent recovery and does not show decreasing strain under constant strain rate. Both models show finite initial strain whereas the initial strain rate is very rapid. The approach used to capture the full behavior of the material is to use an array of Kelvin models and Maxwell models together. This model is also called the Prony Series and is represented by:

$$
G(\xi)=G_{0}+\sum_{i=1}^{N} G_{i} e^{\left(-\xi / \tau_{i}\right)}
$$

where $\mathrm{N}$ is the number of Maxwell elements, $\mathrm{G}_{0}$ is the initial glassy modulus, $\xi$ is the reduced time and $\tau$ is the relaxation time. The Viscoelastic Prony series parameters are obtained from Dynamic Mechanical Analysis (DMA). These are displayed in table 5.4 [35].

Table 5.4. Viscoelastic Prony Parameters for DynaVia 2000

\begin{tabular}{|c|c|}
\hline Relaxation time $\tau_{\mathrm{i}}(\mathrm{sec})$ & $\begin{array}{r}\text { Extensional relaxation modulus } \\
\text { weight factors }\left(\mathrm{E}_{\mathrm{i}} \text { in MPa) }\right.\end{array}$ \\
\hline $7.19 \mathrm{E}-03$ & 16.6368 \\
\hline $9.05 \mathrm{E}-02$ & 9.48133 \\
\hline $1.14 \mathrm{E}+00$ & 167.537 \\
\hline $1.43 \mathrm{E}+01$ & 136.641 \\
\hline $1.81 \mathrm{E}+02$ & 312.464 \\
\hline
\end{tabular}




\begin{tabular}{|c|c|}
\hline $2.27 \mathrm{E}+03$ & 330.227 \\
\hline $2.86 \mathrm{E}+04$ & 267.117 \\
\hline $3.60 \mathrm{E}+05$ & 251.494 \\
\hline $4.54 \mathrm{E}+06$ & 9.75963 \\
\hline $5.71 \mathrm{E}+07$ & 38.8723 \\
\hline $7.19 \mathrm{E}+08$ & 21.4291 \\
\hline & $\mathrm{E}(\infty)$ \\
& $($ rubbery $)=7.55$ \\
\hline
\end{tabular}

\section{ViaLux ${ }^{\mathrm{TM}} 81$}

ViaLux is used as the soldermask in the fabricated board. Like DynaVia, it is a viscoelastic material and has to be characterized in order to represent its properties in ANSYS. The properties are obtained from Dynamic Mechanical Analysis (DMA) and Digital Scanning Calorimetry (DSC). Table 5.5 shows the Prony Series obtained for ViaLux 81TM [34].

Table 5.5. Viscoelastic Prony Parameters for ViaLux 81TM

\begin{tabular}{|c|c|c|}
\hline $\begin{array}{c}\text { Relaxation time, } \tau_{\mathrm{i}} \\
(\mathrm{sec})\end{array}$ & $\begin{array}{c}\text { Extensional Relaxation } \\
\text { Modulus Weight factors } \\
\left(\mathrm{E}_{\mathrm{i}} \text { in MPa) }\right.\end{array}$ & $\begin{array}{c}\text { Shear Relaxation } \\
\text { Modulus Weight } \\
\text { factors }\left(\mathrm{g}_{\mathrm{i}}\right)\end{array}$ \\
\hline $1.24793 \mathrm{E}-1$ & 157.684 & 0.05651770 \\
\hline $1.24793 \mathrm{E} 0$ & 1.00629 & 0.00017334 \\
\hline
\end{tabular}




\begin{tabular}{|c|c|c|}
\hline $1.24793 \mathrm{E} 1$ & 74.2163 & 0.02667660 \\
\hline $1.24793 \mathrm{E} 2$ & 293.866 & 0.10383600 \\
\hline $1.24793 \mathrm{E} 3$ & 284.428 & 0.09921200 \\
\hline $1.24793 \mathrm{E} 4$ & 684.306 & 0.23453700 \\
\hline $1.24793 \mathrm{E} 5$ & 863.822 & 0.28453700 \\
\hline $1.24793 \mathrm{E} 6$ & 380.537 & 0.11971700 \\
\hline $1.24793 \mathrm{E} 7$ & 176.611 & 0.05630420 \\
\hline $1.24793 \mathrm{E} 8$ & 45.0753 & 0.01348240 \\
\hline $1.24793 \mathrm{E} 9$ & 10.5792 & 0.00356210 \\
\hline & $\mathrm{E}_{\infty}$ (rubbery) $=12.9836$ & $\mathrm{G}_{0}$ (glassy) \\
& & $1066.61 \mathrm{MPa}$ \\
\hline
\end{tabular}

\section{Modeling of Capacitors}

\section{Geometric Modeling}

Before discussing the modeling of capacitors, the element used to model the entire board is discussed. The element used in ANSYSTM to represent the board is a non-linear layered Shell element. Its number is 181 and it can store data for upto 250 layers. Several layers are combined into one element and this eliminates the need for using solid elements to represent the board. As such, the very small thickness of the layers (some as thin as $15 \mu$ ) compared to the length and breadth of the board (140mm square) means that aspect ratio errors would be obtained while trying to represent the board with solid elements. In addition, the time needed to solve the FEA model would be tremendously large and the 
maximum number of nodes allowed in the educational version of ANSYSTM would be exceeded. One of the important distinctions between shell and solid elements is that there are six degrees of freedom (displacement and rotation) in shell elements as compared to 3 degrees of freedom in solid elements (displacement only). Figure 5.3 shows the schematic cross section of the board. In addition, an example of Shell 181 element is presented by considering a small portion of the board. Figure 5.4 shows the portion of the board containing capacitors and the half model that is used to represent it.
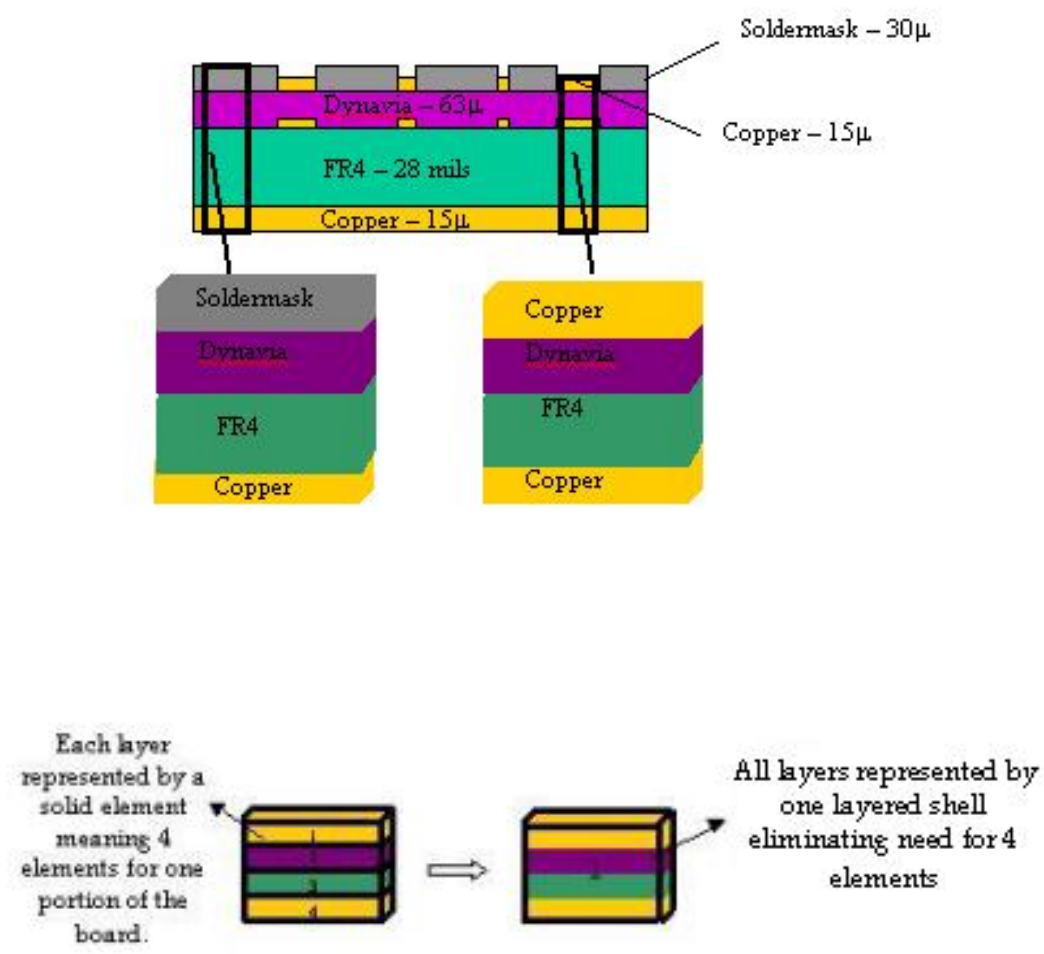

Figure 5.3 Schematic of the board and an explanation of layered shell 

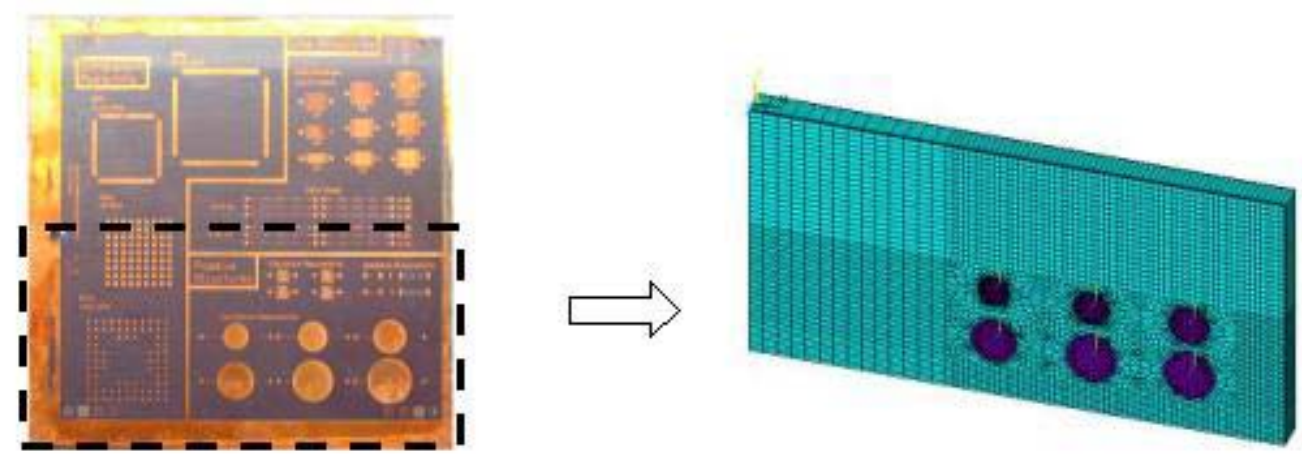

Figure 5.4 FEA representations of capacitors

For capacitors, only half of the board is modeled as the other half is sufficiently far away and will not have an influence on capacitor deformation. The model constructed is a $140 \mathrm{~mm} \times 70 \mathrm{~mm}$. All six capacitors are modeled in the board at once. Constrained y boundary conditions are applied as shown in Figure 5.5. The neutral point lies on the top center of the model and is constrained in all directions.

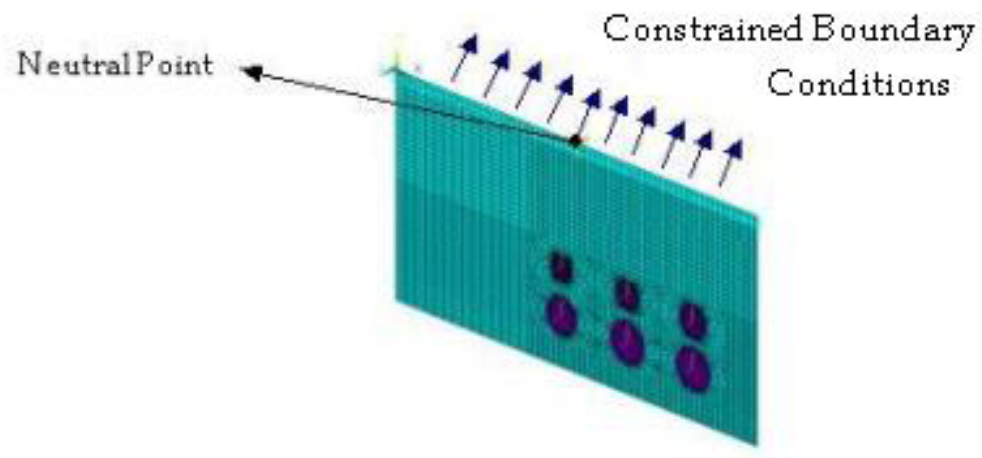

Figure 5.5 Symmetry boundary conditions applied on the board. 
The capacitors are displayed differently in the board because they reference different section identification as compared to the rest of the board. The section identification defines the number of layers in a particular element, the thickness of it, the material used in it and the number of integration points in that particular element. The integration points refer to the points in each layer where the stress is evaluated and more integration points means more accuracy but increased computation time. For example, one integration point means that the layer is infinitely stiff and has only membrane (in plane) stiffness and will not bend. Layers with non-linear properties have five integration points assigned to them whereas the thickest layer (FR4) has eleven integration points assigned to it. Figure 5.6 shows a close up on the capacitors, the soldermask, which is slightly higher than the top metal plate is shown in it.

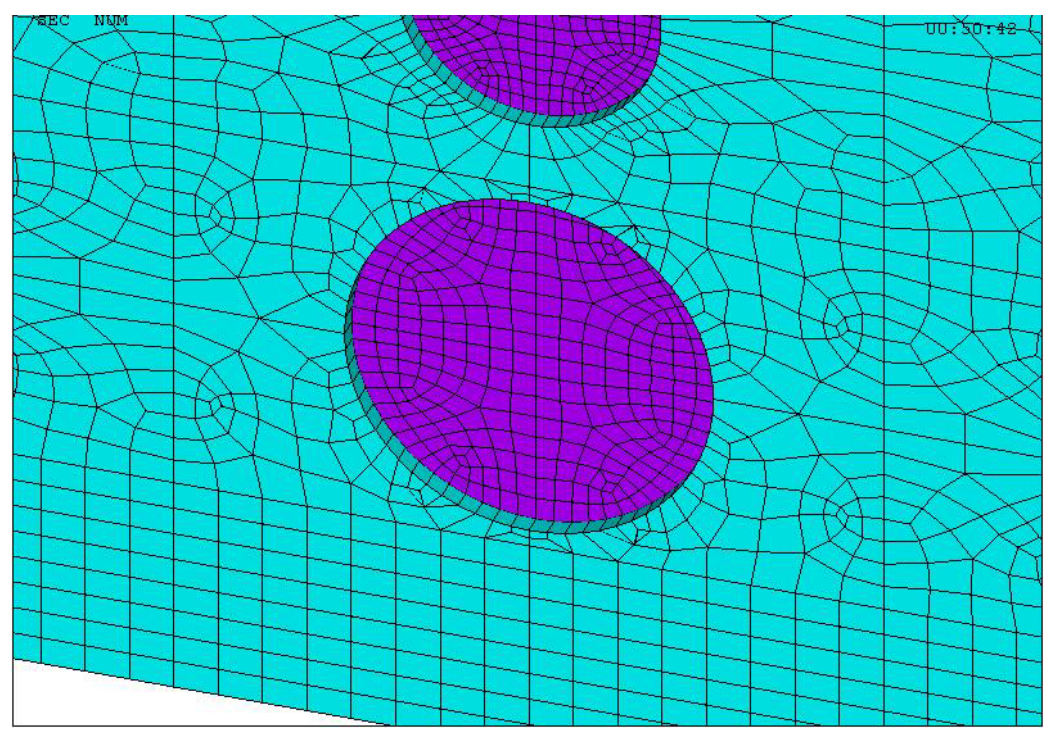

Figure 5.6. Close up on the capacitors 


\section{Parametric Modeling}

In order to determine the effect of the distance from neutral point (DNP) on the change in electrical parameters, parametric models are developed that change the position of the capacitors with respect to the neutral point. The capacitors can be put anywhere on the board both with respect to length and breadth. Figure 5.7 shows the parametric model constructed for the capacitors; each capacitor is moved by a distance of $11 \mathrm{~mm}$ vertically down (y direction on board). The original model is on the left and the parametric model is on the right.
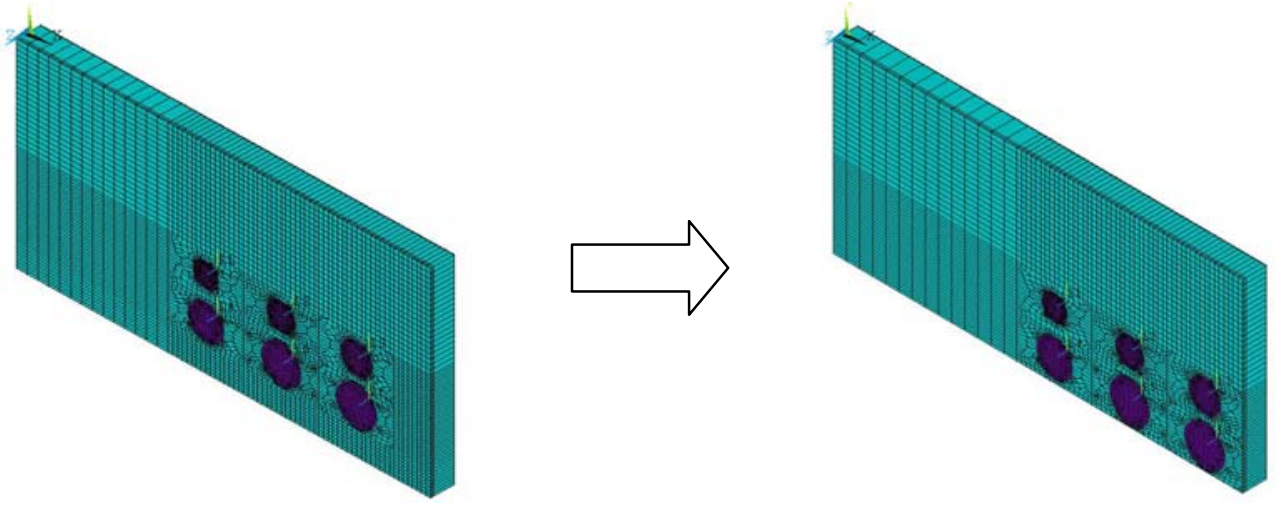

Figure 5.7. Capacitor mesh moved through parameters

\section{Fabrication Process Modeling}

In order to find the effect of the process on the capacitance of the capacitor, a model is constructed that takes into consideration the changing layers of the model as the fabrication process goes on. There are two ways of changing material properties in ANSYSTM. One of them involves the death and 
birth of elements and the other involves changing the pointer to the material. In death and birth, the elements that are "killed" have their stiffness reduced by six orders of magnitude and their stress history deleted as well. While the elements are killed, they do not contribute any stiffness to the model. When the elements are "reborn", they start at a zero strain and stress state and have their stiffness restored to the initial value. In this way, a sequential fabrication process consisting of several layers can be simulated. Starting with only those layres in the first step of the process, the simulation accounts for sequential deposition of layers by stiffening the elements. However Shell 181 does not have death and birth ability and so an alternative approach is needed. The other approach is to use linear layered element Shell 91. This element also does not have birth and death like Shell 181 but it uses a different method for defining the layers. The method being used allows it to reference a different Material for a particular layer between the load steps in ANSYSTM. For example, if copper is etched away during fabrication, its representation is shown in Figure 5.8. Material 1 has the normal modulus of copper whereas Material 2 has the modulus of copper decreased by six orders of magnitude. Hence Material 1 has been etched away to give Material 2. 

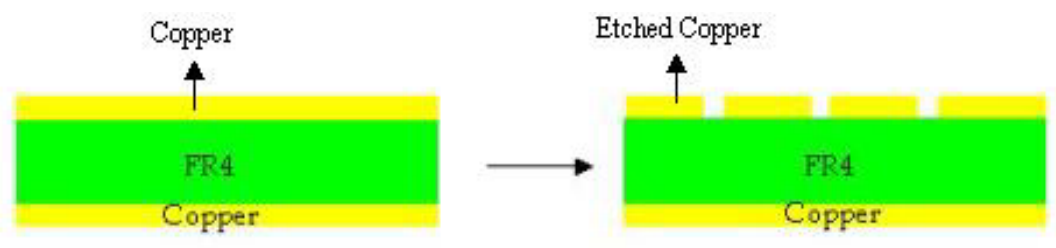

Figure 5.8 (a). Etching away of copper during fabrication
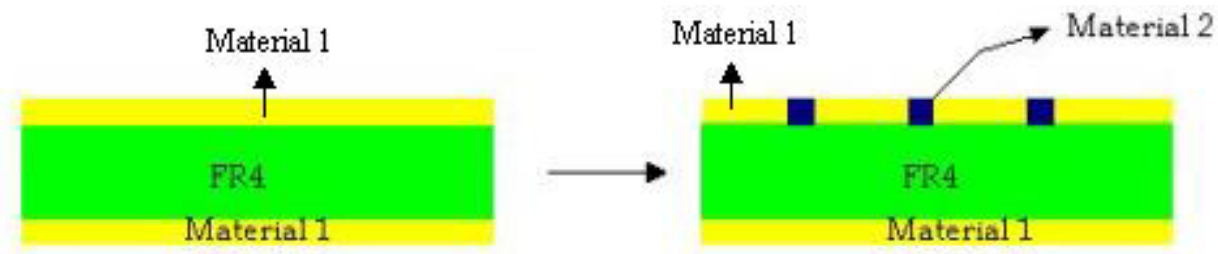

Figure 5.8 (b). Etching away of copper represented in ANSYSTM

However this method has a disadvantage associated with it. Suppose a Material is deposited on the substrate, the above process is reversed and Material 2 will now change to Material 1. So if copper is electroplated onto the substrate, Material 2 will be changed to Material 1. It is necessary to have a layer of Material 2 in the first place because the number of layers cannot be changed between load steps. Hence when Material 2 is changed to Material 1, all the previous strain and stress history gets transferred to Material 1 even though it is supposed to be born strain and stress free. This represents a problem since there is now way to delete the strains or the stresses within a particular layer. However, this does not pose any concerns, as the stresses induced in the layer are very small because of the very low modulus. In addition, the strains are 
elastic and will disappear in other load steps. The fabrication simulation follows the deformation induced in the board from the curing of the dielectric to the end of fabrication of the top metal layer.

\section{Electromagnetic Modeling}

Unlike the geometric model, the electrostatic model of capacitors needs to be made by solid elements only instead of shell elements since there are no electrostatic shell elements in ANSYSTM. The elements used are Electrostatic element Solid 122 and Infinity 111. The electrostatic model consists of only the two copper plates with the dielectric sandwiched in the middle. The dielectric constant of DynaVia $2000^{\mathrm{TM}}$ is 3.72 and its loss tangent is 0.024 . Since ANSYSTM requires the dielectric properties of all materials used in the model, copper is given a very low dielectric constant of $10^{-8}$. The dielectric, which is $63 \mu$ thick, is sandwiched between two $15 \mu$ thick copper plates. Since the thickness of the layers is again much smaller than the diameter (smallest diameter is 330mils or $8250 \mu \mathrm{m})$, the model is constructed with a fine mesh to prevent aspect ratio errors. In order to declare the ground plane on the capacitor, the bottom copper electrode is selected and all the elements are given infinity boundary conditions. With this, the bottom copper plate is now the ground plane.

The top plate nodes are grouped together and given a name to be referenced later. The bottom plate nodes are grouped together as well. The CMATRIX command is then invoked in ANSYSTM to find the capacitance of the 
structure. The grouped nodes are called in this command to declare the top and bottom conductor plates in ANSYSTM. On computation of the capacitance, it was found that the theoretical value was higher than the simulated value. A mesh convergence was then performed to see the effect of number of nodes on the capacitance simulation. As the number of nodes was increased, the capacitance value increased and then did not change more than 5\% a little below 60,000 nodes. Table 5.7 shows the capacitance values for the capacitor of 330 mils diameter $(8.25 \mathrm{~mm})$ and Figure 5.7 shows the capacitance convergence for the same diameter. Figure 5.9 shows the convergence for a diameter 580 mils (14.5mm). Table 5.7 shows the final capacitance values at 60,000 nodes for all the capacitors and compared with the theoretical and experimental values. This concludes the electromagnetic simulation of capacitance.

Table 5.6. Capacitance Convergence for 330 mils (8.25mm)

\begin{tabular}{|c|c|}
\hline \# Nodes & Capacitance \\
\hline 7379 & $24.58 \mathrm{pF}$ \\
\hline 17312 & $26.16 \mathrm{pF}$ \\
\hline 31012 & $26.89 \mathrm{pF}$ \\
\hline 40271 & $27.29 \mathrm{pF}$ \\
\hline 54551 & $27.71 \mathrm{pF}$ \\
\hline 86887 & $27.7 \mathrm{pF}$ \\
\hline
\end{tabular}




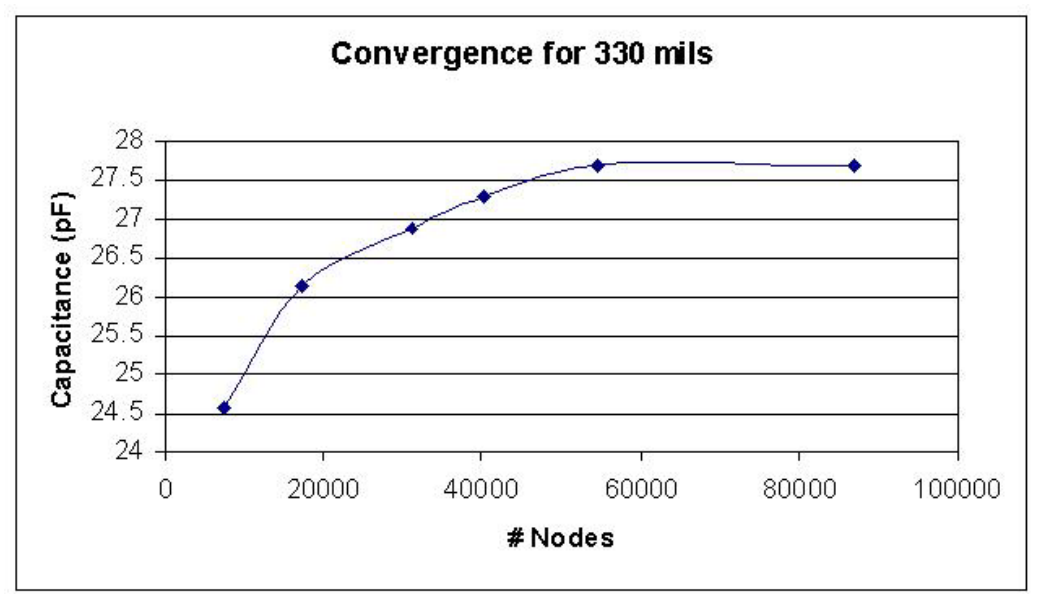

Figure 5.8. Capacitance Convergence for 330 mils (8.25mm)

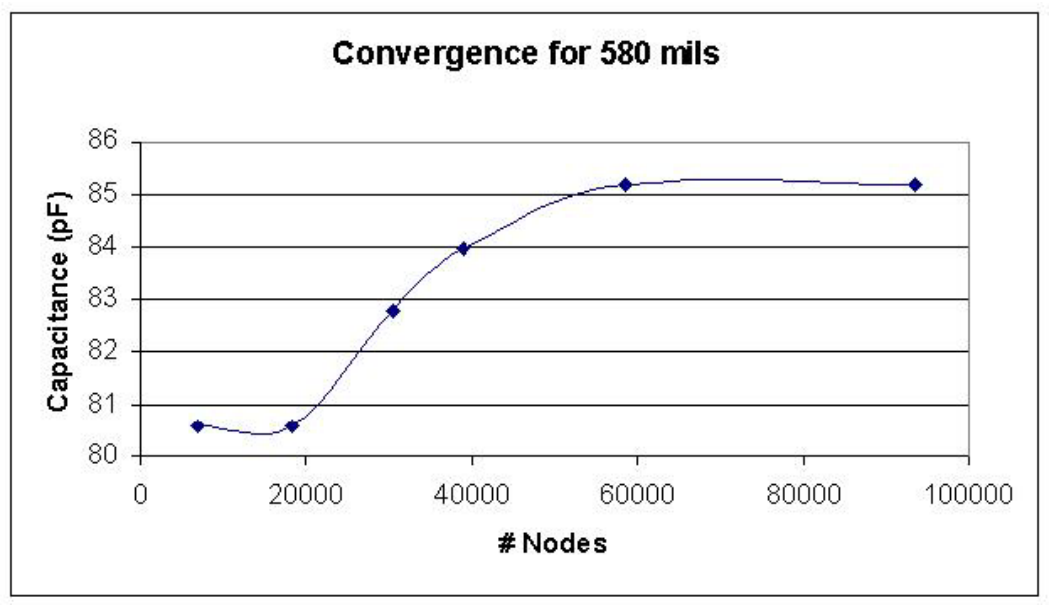

Figure 5.9. Capacitance Convergence for 580 mils (14.5mm) 
Table 5.7. Comparison with simulated, actual and theoretical values of capacitance

\begin{tabular}{|c|c|c|c|}
\hline Capacitor Diameter & ANSYS & $\begin{array}{c}\text { Experimentally } \\
\text { Mesured }\end{array}$ & Analytical Solution \\
\hline $8.25 \mathrm{~mm}$ & $27.70 \mathrm{pF}$ & $28.5 \mathrm{pF}$ & $29.53 \mathrm{pF}$ \\
\hline $9.5 \mathrm{~mm}$ & $36.68 \mathrm{pF}$ & $37.7 \mathrm{pF}$ & $39.16 \mathrm{pF}$ \\
\hline $10.75 \mathrm{~mm}$ & $46.92 \mathrm{pF}$ & $48.0 \mathrm{pF}$ & $50.14 \mathrm{pF}$ \\
\hline $12 \mathrm{~mm}$ & $58.68 \mathrm{pF}$ & $60.3 \mathrm{pF}$ & $62.48 \mathrm{pF}$ \\
\hline $13.25 \mathrm{~mm}$ & $71.18 \mathrm{pF}$ & $73.7 \mathrm{pF}$ & $76.18 \mathrm{pF}$ \\
\hline $14.5 \mathrm{~mm}$ & $85.19 \mathrm{pF}$ & No Data & $91.23 \mathrm{pF}$ \\
\hline
\end{tabular}

\section{Modeling of Inductors}

\section{Geometric Modeling}

Much of the geometric modeling of Inductors follows what has been done in capacitance modeling. However some changes are made to model the inductors in the board. Figure 5.10 shows the portion of the board represented by the inductor model. Figure 5.11 shows the zoomed view on the inductors on the board. Figure 5.12 shows the actual inductors on the board. 

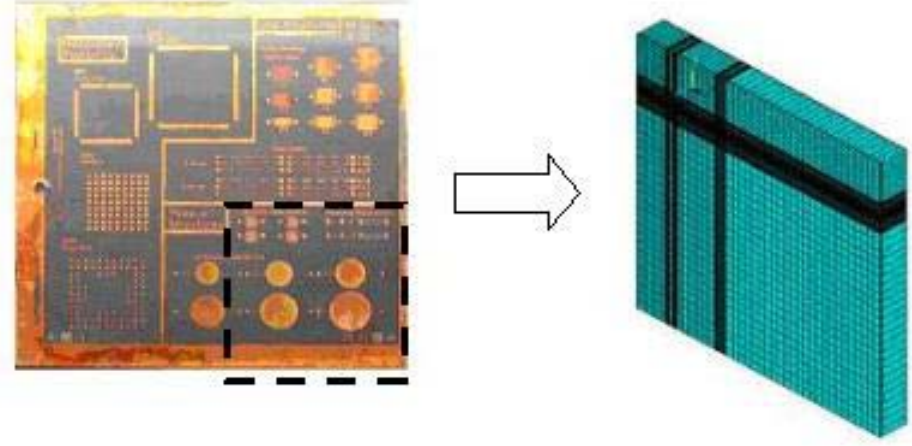

Figure 5.10. FEA representation of inductors

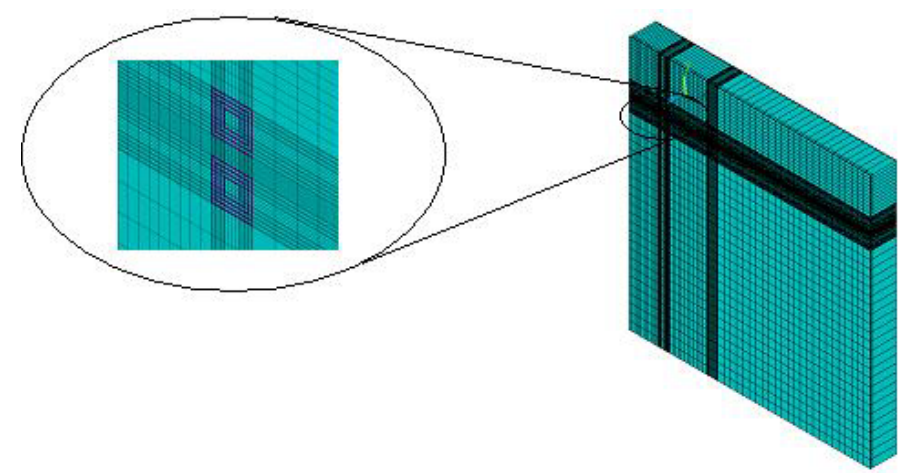

Figure 5.11. Zoomed view of the inductors on the board

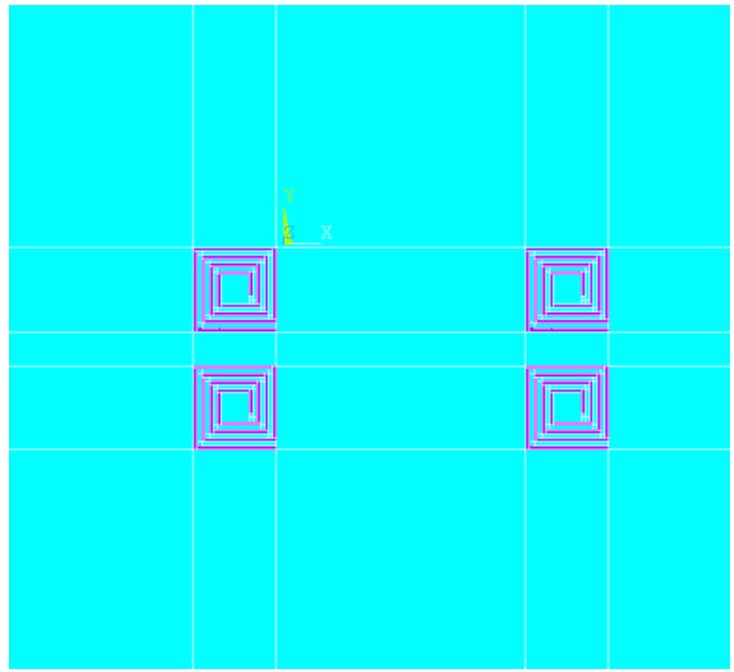

Figure 5.12. Inductors as present on the board 
The above part of the model is constrained in the y direction, the left part in the $\mathrm{x}$ direction and the neutral point in all directions. Figure 5.13 shows the boundary conditions applied on the quarter model.

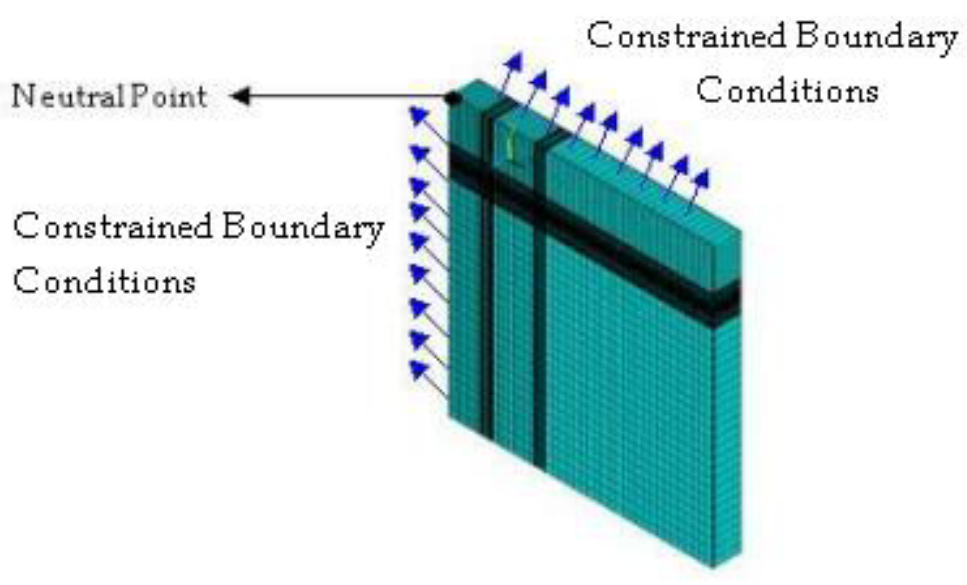

Figure 5.13. Boundary Conditions on inductor model

\section{Parametric Modeling}

Parametric models, similar to those of capacitors are written to determine the effect of DNP on the change in inductance values. Two models are constructed in this effort. In one, the inductors are moved by a distance of $40 \mathrm{~mm}$ horizontally right and 55mm vertically down to the furthest end of the board. In another model, they are put in the center of the board between the neutral point and the furthest point on the board. Figure 5.14 shows the parametric model constructed for the furthest inductors. The parametric model is on the right and the original is on the left. 

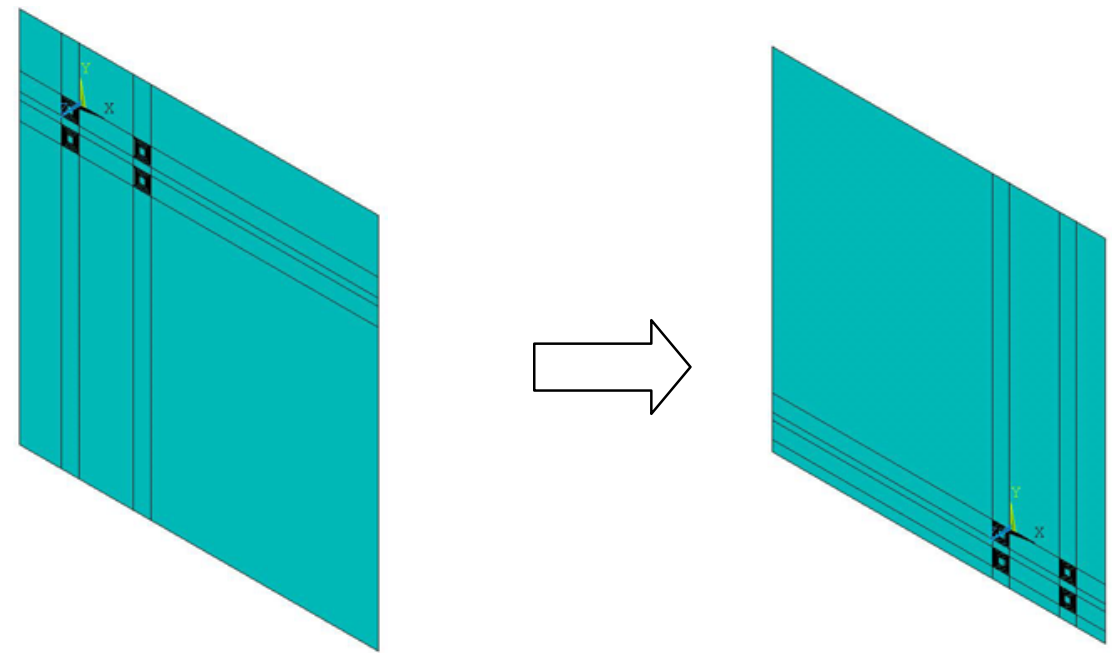

Figure 5.14. Parametric models for inductors

\section{Electromagnetic Model}

The electromagnetic analysis of inductors is performed in Conventor Ware ${ }^{\mathrm{TM}}$ rather than ANSYSTM. The solid model of inductor is constructed in ANSYS $^{\mathrm{TM}}$ and then exported to Conventor Ware ${ }^{\mathrm{TM}}$. Figure 5.15 shows the inductor as constructed in ANSYSTM. The length of the longest inductor is $3.85 \mathrm{~mm}$ with the thickness of the inductor trace as $150 \mu \mathrm{m}$ and the gap between the traces as $0.5 \mu \mathrm{m}$. The material is copper with a relative permeability of 1.02 . The model is then exported to Conventor Ware ${ }^{\mathrm{TM}}$ and the inductance analysis is performed. The inductance value as determined from the above simulation is $4.95 \mu \mathrm{H}$ and matches well with the experimental value of $4.63 \mu \mathrm{H}$. 


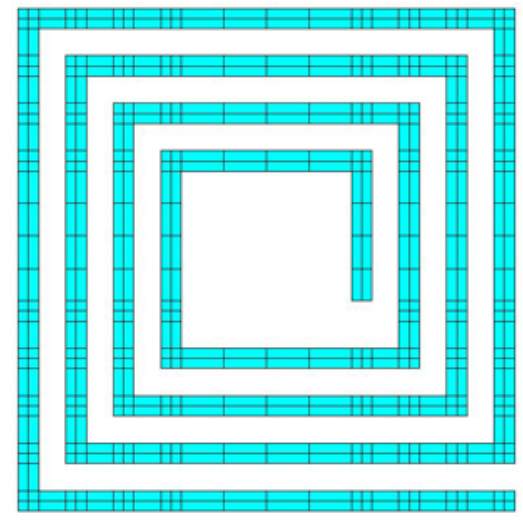

Figure 5.15. Model of the Inductor in ANSYSTM 


\section{CHAPTER VI}

\section{THERMO-MECHANICAL MODELING OF INTEGRAL}

\section{PASSIVES}

This chapter talks about the thermo-mechanical modeling of integral passives and the process followed to implement an electro-thermo-mechanical methodology. The basic aim of the thermo-mechanical modeling in this thesis is to subject the boards containing the passives to thermal cycling and then extract the electrical parameters of the deformed passives. However this is not a trivial task as it involves the interfacing between the shell and solid elements in ANSYSTM and between the different analysis modes in ANSYSTM. Since the final electromagnetic capacitance analysis is done in ANSYSTM and the inductance analysis is done in Conventor Ware ${ }^{\mathrm{TM}}$, the processes followed are slightly different. The first section discusses the thermal loading conditions used in the thermo-mechanical simulation, the FEA methodology used to resolve the above issues is presented, the next section is on the thermal loading of the capacitors and the final section focuses on inductors.

\section{$\underline{\text { Thermo-Mechanical Loading Conditions }}$}

\section{Thermal Cycling}

This section discusses the loading conditions used in the thermal cycling of the board with embedded capacitors and inductors. The thermal cycle used for 
the experimental testing of the boards is MIL-STD-883 Method or IPC-SM-785 test. The test consists of thermal cycling the test vehicles in a thermal chamber from $-55{ }^{\circ} \mathrm{C}$ to $125{ }^{\circ} \mathrm{C}$. Each thermal cycle is for a duration of twenty minutes where the basket containing the test vehicle is moved from a basket of $125^{\circ} \mathrm{C}$ to a basket of $-55{ }^{\circ} \mathrm{C}$. From literature review, it is found that it takes around 3 minutes to achieve steady state temperature after being introduced from the other chamber [32]. Hence the thermal cycle, taking this ramp time into account and with the dwell time as seven minutes, is shown in Figure 6.1.

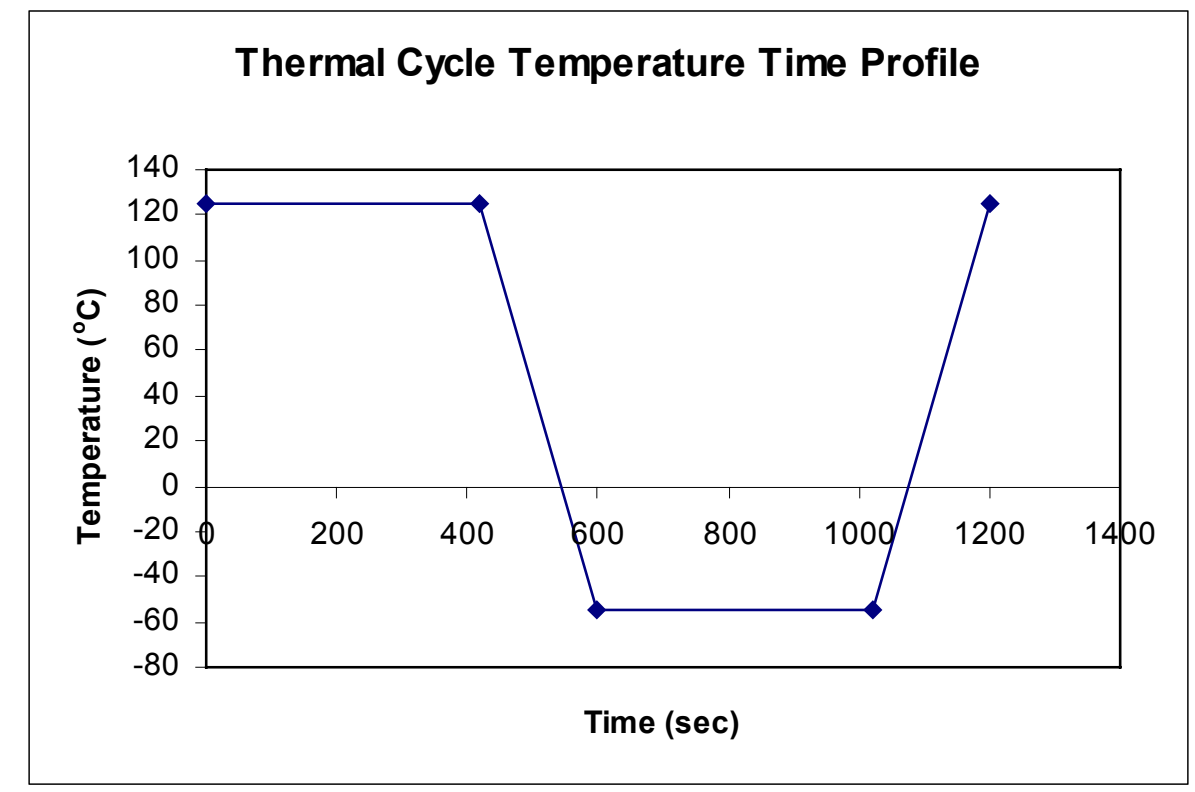

Figure 6.1. Load step used in thermal cycling of passives

\section{Fabrication Process Profile}

The fabrication process, which has been discussed in Chapter 4, involves baking and curing and then processing the board at room temperature. The 
combination of the excursions between the baking or curing temperatures and the room temperature resembles an asymmetric thermal cycle. However given the limitations of ANSYSTM discussed in Chapter 5, only the portion between the curing of DynaVia and electroplating of the top metal layer is modeled. A collapsed version of the thermal cycle between the curing of DynaVia $2000^{\mathrm{TM}}$ and the end of the fabrication of the top metal layer is presented in Figure 6.2. The thermal cycle equivalent to the fabrication process is presented in Figure 6.3. It assumed that the board returns to room temperature after baking in 5 minutes (since the boards are kept on rack to cool off for 5 minutes before further processing).

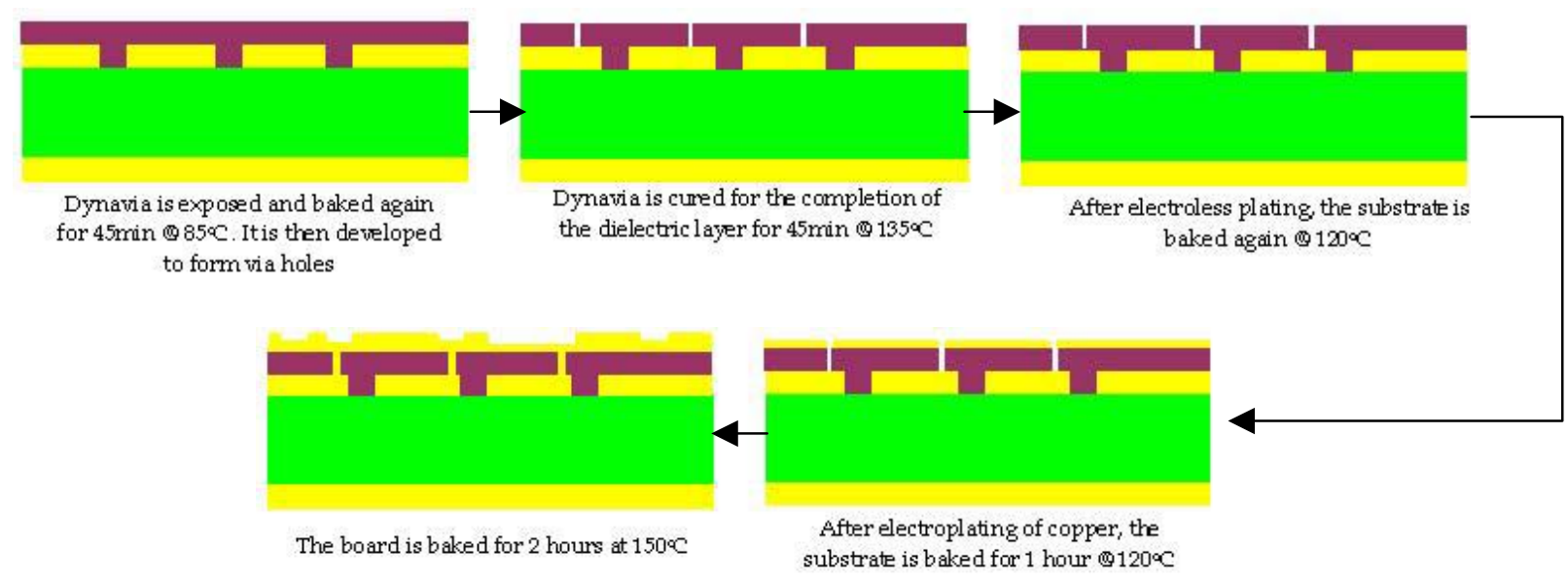

Figure 6.2. Schematic of a part of the fabrication process in capacitors 


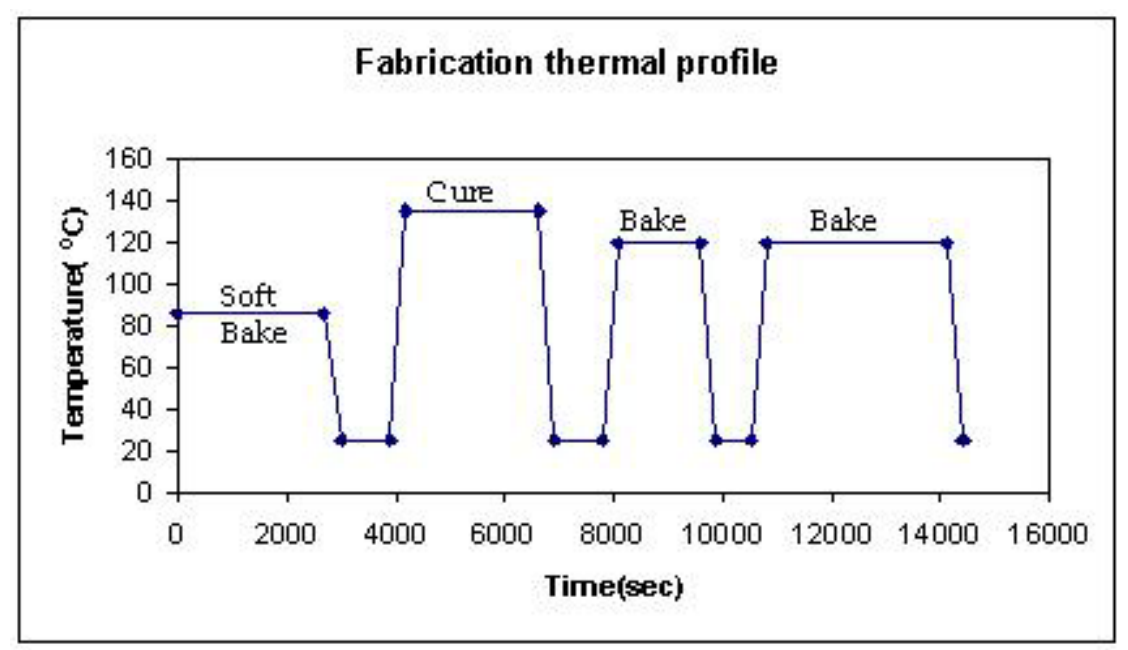

Figure 6.3. Thermal profile between the curing of the dielectric and plating of top metal layer

\section{FEA Methodology}

\section{Fabrication Process Methodology}

Before the thermal cycling is considered, the effect of the fabrication process needs to be considered on the capacitor. Before thermal cycling, it is assumed that the board is stress free at $135{ }^{\circ} \mathrm{C}$ (curing temperature of the dielectric). However, this is not true because the board is subjected to more baking steps after the curing of the dielectric. In order to determine the effect of these baking steps, the fabrication temperature profile between the curing of the dielectric layer and the electroplating of the top metal layer is applied to the model (Figure 6.3). 
As mentioned in the beginning of the chapter, there are issues that have to be resolved for transferring the thermo-mechanical loads from the substrate level into the electrostatic models of the passives. This section discusses the procedure followed to achieve the above objective. Once the geometric model of the passives has been constructed, the thermal profile is applied to the full board model of shell elements and solved. It is important to note that the thermal load is different for thermal cycling and for the fabrication process. The thermomechanical stresses and deformation induced by the thermal loading are saved into the ANSYSTM database. The program is restarted and a solid model corresponding to the passive only is constructed in the same coordinates with respect to the global coordinate system as its corresponding shell representation. Now the method of cut boundary interpolation is used in which the loads from the shell elements of the full board model are transferred to the solid elements of the passive by reading in the nodal loads from the nodes of the full model. These loads are applied as displacement boundary conditions in the solid element model. A load step of small time duration is then applied to the model and the results obtained. The thermo-mechanical deformations obtained for the individual passive (local model) are compared with the deformations in passives embedded in the board (global model). The deformations are found to be within $0.1 \%$ change. Electromagnetic analysis is then performed on the passive by either using ANSYSTM for the capacitors or Conventor Ware ${ }^{\mathrm{TM}}$ for the inductors. This 
concludes the FEA method uses to implement the fabrication process analysis of embedded passives.

\section{Thermal Cycling}

The FEA methodology for determining the effect of the fabrication process is very similar to that of the fabrication process methodology. However, there are two primary differences between two analysis types. One, as discussed earlier, is that the loading conditions are different and another is that the no deformation convergence is required since the thermal profile followed is the one that is experienced by the board in the actual fabrication. The thermal cycles are applied till the deformation in the board converges. This happens after around 8 thermal cycles. Barring these differences, the FEA methodology is the same and the analysis procedure very similar.

\section{Thermal Cycling of Capacitors}

\section{Original Model}

This sections looks at the results obtained from the electro-thermomechanical analysis of capacitors. The procedure mentioned above is followed to obtain the changed electrical parameter from the thermo-mechanically deformed passive. Figure 6.4 presents the deformation in the board after thermal cycling. As seen from the figure, the deformation is symmetric about the $\mathrm{x}$-axis of the 
board. Also the deformation increases with increase in DNP. The deformations in the board converge after 8 thermal cycles. Figure 6.5 shows the deformed capacitor furthest from the neutral point (capacitor 6).

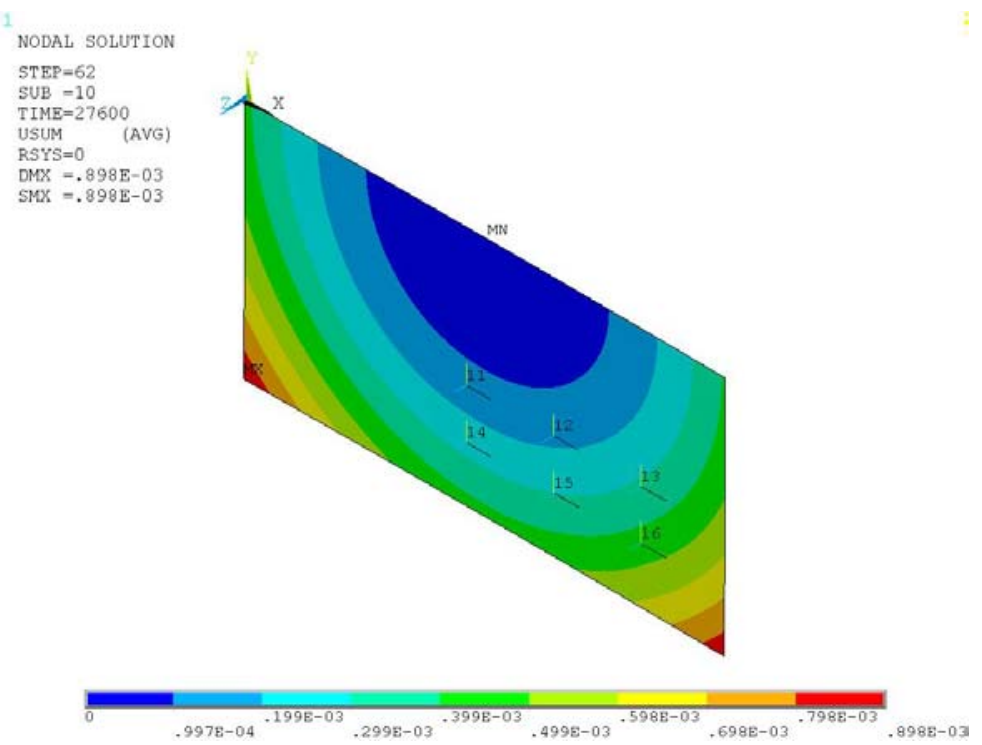

Figure 6.4. Deformation in board after thermal cycling with capacitors

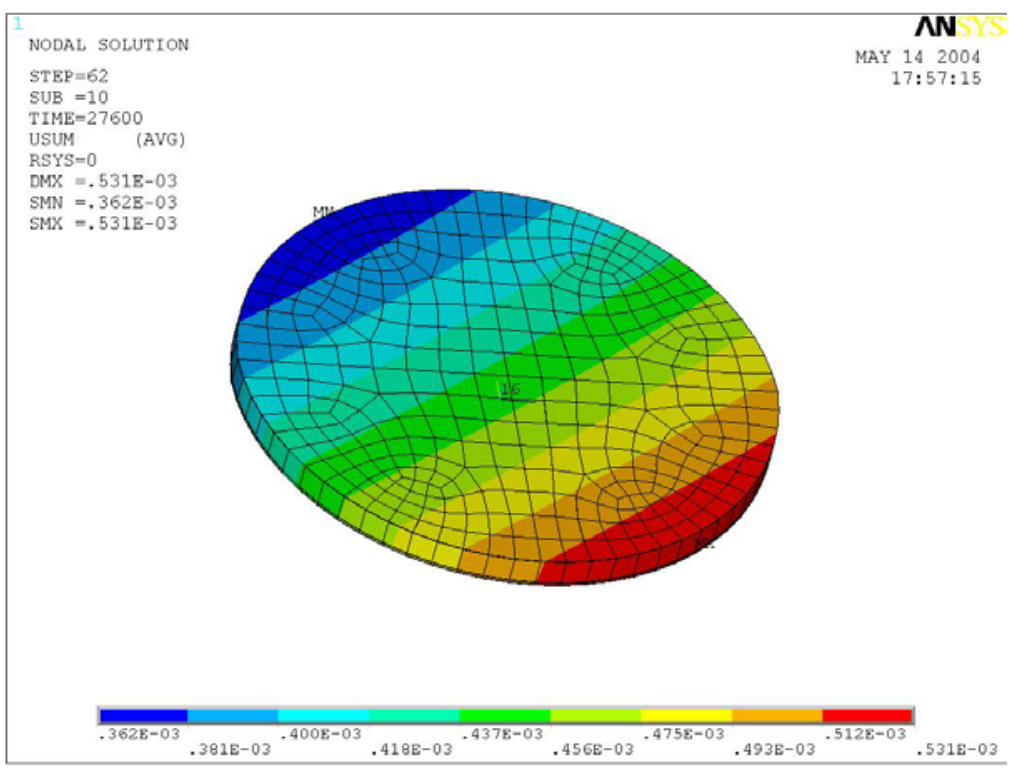

Figure 6.5. Deformed capacitor furthest from the neutral point 
The electrostatic analysis then performed on the capacitors. The first three capacitors in the first row are numbered from 1-3 and the next three in the other row from 4-6. The results are tabulated in Table 6.1. The simulated change is the change obtained from the electro-thermo-mechanical analysis in ANSYSTM and experimental change is the change as measured from the fabricated test boards subjected to thermal cycling. As seen from the table, the results agree well with the experimental changes. The difference between the values is in part due to the change in the dielectric constant during thermal cycling and other factors.

Table 6.1. Results from thermal cycling of capacitors

\begin{tabular}{|c|c|c|c|c|}
\hline & $\begin{array}{c}\text { Before Thermal } \\
\text { Cycling }\end{array}$ & $\begin{array}{c}\text { After Thermal } \\
\text { Cycling }\end{array}$ & $\begin{array}{c}\text { Simulated } \\
\text { Change }\end{array}$ & $\begin{array}{c}\text { Experimental } \\
\text { Change }\end{array}$ \\
\hline Capacitor 1 & $27.72 \mathrm{pF}$ & $27.45 \mathrm{pF}$ & $-1.50 \%$ & $-3.92 \%$ \\
\hline Capacitor 2 & $36.68 \mathrm{pF}$ & $36.02 \mathrm{pF}$ & $-1.78 \%$ & $-4.21 \%$ \\
\hline Capacitor 3 & $46.92 \mathrm{pF}$ & $46.05 \mathrm{pF}$ & $-1.85 \%$ & $6.53 \%$ \\
\hline Capacitor 4 & $58.68 \mathrm{pF}$ & $57.38 \mathrm{pF}$ & $-2.20 \%$ & $-4.33 \%$ \\
\hline Capacitor 5 & $71.18 \mathrm{pF}$ & $69.44 \mathrm{pF}$ & $-2.44 \%$ & $-4.44 \%$ \\
\hline Capacitor 6 & $85.19 \mathrm{pF}$ & $82.91 \mathrm{pF}$ & $-2.67 \%$ & N/A \\
\hline
\end{tabular}

\section{Parametric Model}

The parametric model is run in the same way as the original model and the results obtained are tabulated in Table 6.2. It should be noted that the DNP of the capacitors is increased in the parametric model. As expected, the increased 
deformation in the capacitors leads to higher changes in the capacitance values. It is important to note that the parametric models can be validated with experimental results.

Table 6.2. Change in parametrically further capacitors

\begin{tabular}{|c|c|c|c|}
\hline & Before Cycling & After Cycling & Simulated Change \\
\hline Capacitor 1 & $27.72 \mathrm{pF}$ & $27.17 \mathrm{pF}$ & $-1.98 \%$ \\
\hline Capacitor 2 & $36.68 \mathrm{pF}$ & $35.84 \mathrm{pF}$ & $-2.29 \%$ \\
\hline Capacitor 3 & $46.92 \mathrm{pF}$ & $45.79 \mathrm{pF}$ & $-2.41 \%$ \\
\hline Capacitor 4 & $58.68 \mathrm{pF}$ & $57.12 \mathrm{pF}$ & $-2.66 \%$ \\
\hline Capacitor 5 & $71.18 \mathrm{pF}$ & $69.12 \mathrm{pF}$ & $-2.89 \%$ \\
\hline Capacitor 6 & $85.19 \mathrm{pF}$ & $82.59 \mathrm{pF}$ & $-3.05 \%$ \\
\hline
\end{tabular}

\section{Fabrication Process Deformation In Capacitors}

The fabrication process results are tabulated in table 6.3. The experimental deviation compares the simulated values of the deformed capacitors with the simulated electromagnetic values. The actual change is the deviation of the fabricated capacitors on the test board with the analytical values. As seen from the results, the fabrication process can have a significant impact on the final values of the capacitance. The actual change is a little different with respect to trends, as the experimental values don't follow the pattern of increasing change with increasing DNP. The change in capacitance at the end of the fabrication process means that the fabrication process needs to be modified to reduce the 
temperature of the processes and the dwell times. Changes such as these can lead to more reliable fabrication and more stable values of the final capacitances.

Table 6.3. Results from the fabrication process simulation

\begin{tabular}{|l|c|c|c|c|}
\hline & Theoretical Value & After Processing & $\begin{array}{c}\text { Experimental } \\
\text { Deviation from }\end{array}$ & $\begin{array}{c}\text { Actual Deviation } \\
\text { from theoretical } \\
\text { values }\end{array}$ \\
\hline Capacitor 1 & $27.72 \mathrm{pF}$ & $27.15 \mathrm{pF}$ & $-2.07 \%$ & $-3.49 \%$ \\
\hline Capacitor 2 & $36.68 \mathrm{pF}$ & $35.82 \mathrm{pF}$ & $-2.35 \%$ & $-3.73 \%$ \\
\hline Capacitor 3 & $46.92 \mathrm{pF}$ & $45.76 \mathrm{pF}$ & $-2.48 \%$ & $-4.27 \%$ \\
\hline Capacitor 4 & $58.68 \mathrm{pF}$ & $57.10 \mathrm{pF}$ & $-2.70 \%$ & $-3.49 \%$ \\
\hline Capacitor 5 & $71.18 \mathrm{pF}$ & $69.09 \mathrm{pF}$ & $-2.93 \%$ & $-3.26 \%$ \\
\hline Capacitor 6 & $85.19 \mathrm{pF}$ & $82.53 \mathrm{pF}$ & $-3.12 \%$ & $\mathrm{~N} / \mathrm{A}$ \\
\hline
\end{tabular}

\section{$\underline{\text { Thermal Cycling of Inductors }}$}

This section talks about the changes in inductance with thermal cycling. With the models constructed discussed in chapter $\mathrm{V}$, the main focus of this section is to discuss the results obtained from the analysis of the boards conducted. The deformation of the board is very similar to the deformation obtained in the case of the capacitors. This is because the passives have very little effect on the deformation and hence the deformation in the board containing 
different passives is nearly the same. As seen from the results, the change in inductance is very small and will not even be measurable. The inductance does not undergo a significant change after deformation. This is due to the fact that the inductor is planar and does not have any turns in the $z$ direction (in direction normal to top surface of board). Hence the deformation does not have a significant impact on the inductance. Another important aspect to consider is the change of material properties of copper with thermal cycling. In the simulation, the changes in the properties of copper with thermal cycling or high temperature and humidity conditions are not accounted for. Such changes can also be responsible for the small change in inductance obtained from the model simulations as compared to the experimental results. Figure 6.6 shows the deformed inductor after it has been subjected to thermal cycling. Table 6.4 shows the results of the thermo-mechanical-electro analysis.

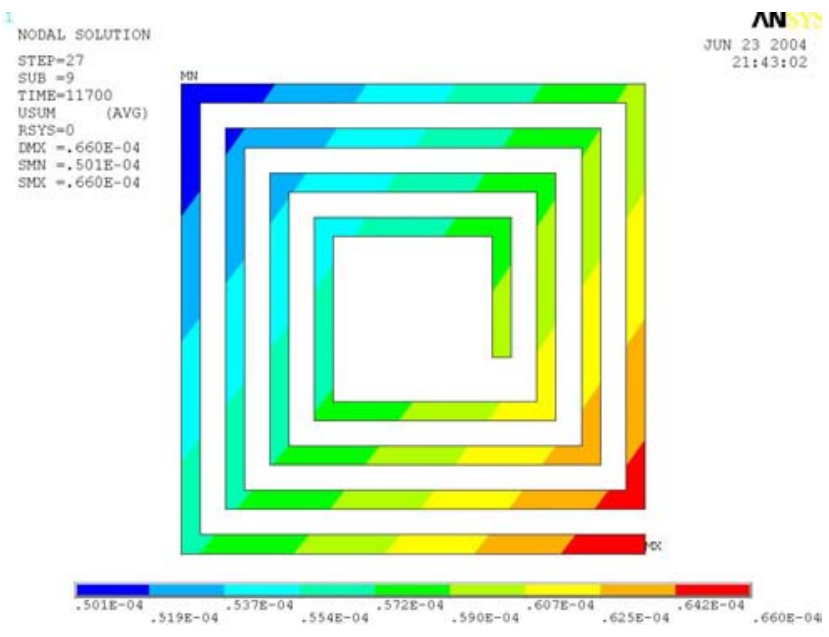

Figure 6.6. Deformed Inductor after thermal cycling 
Table 6.4. Results from the thermal cycling of inductors

\begin{tabular}{|l|c|c|c|c|}
\hline Inductor \# & Data Source & Before & After & \% Change \\
\hline Inductor 1 & Experimental & $4.85 \mu \mathrm{H}$ & $4.63 \mu \mathrm{H}$ & $-4.75 \%$ \\
\hline & FEA & $4.95 \mu \mathrm{H}$ & $4.94 \mu \mathrm{H}$ & $-0.06 \%$ \\
\hline Inductor 2 & Experimental & $4.86 \mu \mathrm{H}$ & $4.64 \mu \mathrm{H}$ & $-4.76 \%$ \\
\hline & FEA & $4.95 \mu \mathrm{H}$ & $4.94 \mu \mathrm{H}$ & $-0.17 \%$ \\
\hline
\end{tabular}

\section{Parametric Model}

The results of both the parametric models are tabulated in table 6.5. The parametric model moves the inductors further away form the DNP. As expected, the changes in the inductance increase with increase in DNP. However the change is still not large enough as compared to capacitors. Hence it can be inferred that inductors are more stable with respect to deformation as compared to capacitors.

Table 6.5. Results from the parametric modeling of inductors

\begin{tabular}{|l|c|c|c|c|c|c|}
\hline & \multicolumn{3}{|c|}{ Middle } & \multicolumn{3}{c|}{ Farthest } \\
\hline & Before & After & \%Change & Before & After & \%Change \\
\hline Inductor 1 & $4.951 \mu \mathrm{H}$ & $4.93 \mu \mathrm{H}$ & $-0.42 \%$ & $4.951 \mu \mathrm{H}$ & $4.91 \mu \mathrm{H}$ & $-0.84 \%$ \\
\hline Inductor 2 & $4.951 \mu \mathrm{H}$ & $4.90 \mu \mathrm{H}$ & $-1.03 \%$ & $4.951 \mu \mathrm{H}$ & $4.88 \mu \mathrm{H}$ & $-1.25 \%$ \\
\hline
\end{tabular}




\section{Effect of Materials on the Board}

The deformation in the board is caused due to the high CTE mismatch between the different materials in the board. Prominent among them is DynaVia $^{\mathrm{TM}}$, which has a very high CTE of $72 \mathrm{ppm}$. If the materials were to be more compatible with respect to the CTE, the deformation obtained in the board would decrease and the change in electrical parameters would follow. Since FR4 is the most commonly used substrate material, the materials used in the board should have very similar CTE's to that of FR4's. 


\section{CHAPTER VII}

\section{RELIABILITY EXPERIMENTS}

This section discusses the reliability experiments conducted on the boards with passives in detail. The equipment used, the type of experiments conducted and the final results obtained are the main goals of this section. The basic principle of reliability experiments is to accelerate the failure of electronic components within a reasonable time frame. Based on the data from previous reliable products or established standards, the new product can be qualified. Given the tremendous variety of reliability tests and standards available, only the most commonly used ones are used. At the end of each reliability test, the change in electrical parameters is measured.

\section{$\underline{\text { Moisture Effect }}$}

Before the boards are put in thermal chamber, measurements of all the electrical parameters are taken. These are then put in a convection oven at $100^{\circ} \mathrm{C}$ to drive out the moisture and see the effect of the moisture absorption on the dielectric. Figures 7.1 shows the effect of moisture absorption on capacitors. As expected, the capacitance decreases because the dielectric material loses all the moisture and the effective dielectric constant goes down decreasing the 
capacitance. On the other hand, the inductance of the embedded inductor goes up which is contrary to expectations. One possible explanation could be that the copper permeability improves due to the annealing of the material. The resistance of the embedded resistor goes down and again this could be because of the favorable change of material properties in copper or the resistor material after baking. The average change in capacitance after baking is around $-0.80 \%$, the change in inductance is around $1.1 \%$ and the resistance change is $-1.4 \%$. Figures 7.2 and 7.3 show the effect of moisture on inductance and resistance.

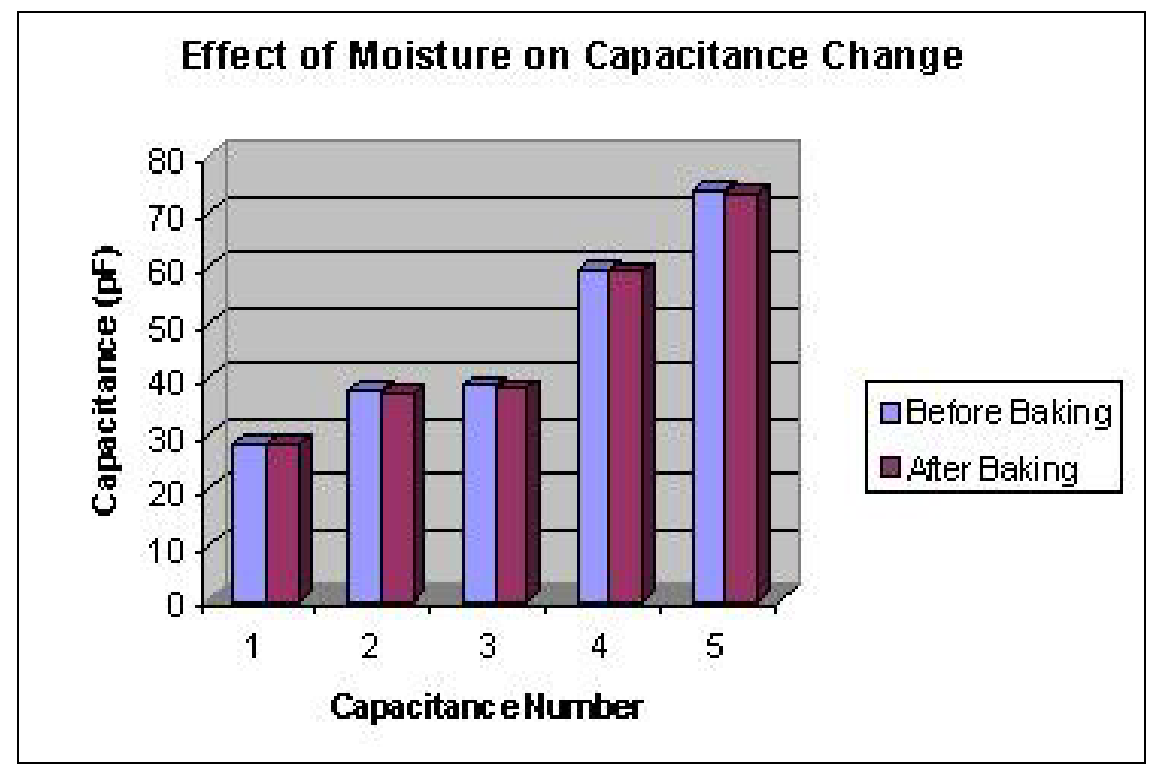

Figure 7.1. Capacitance values after baking the board 


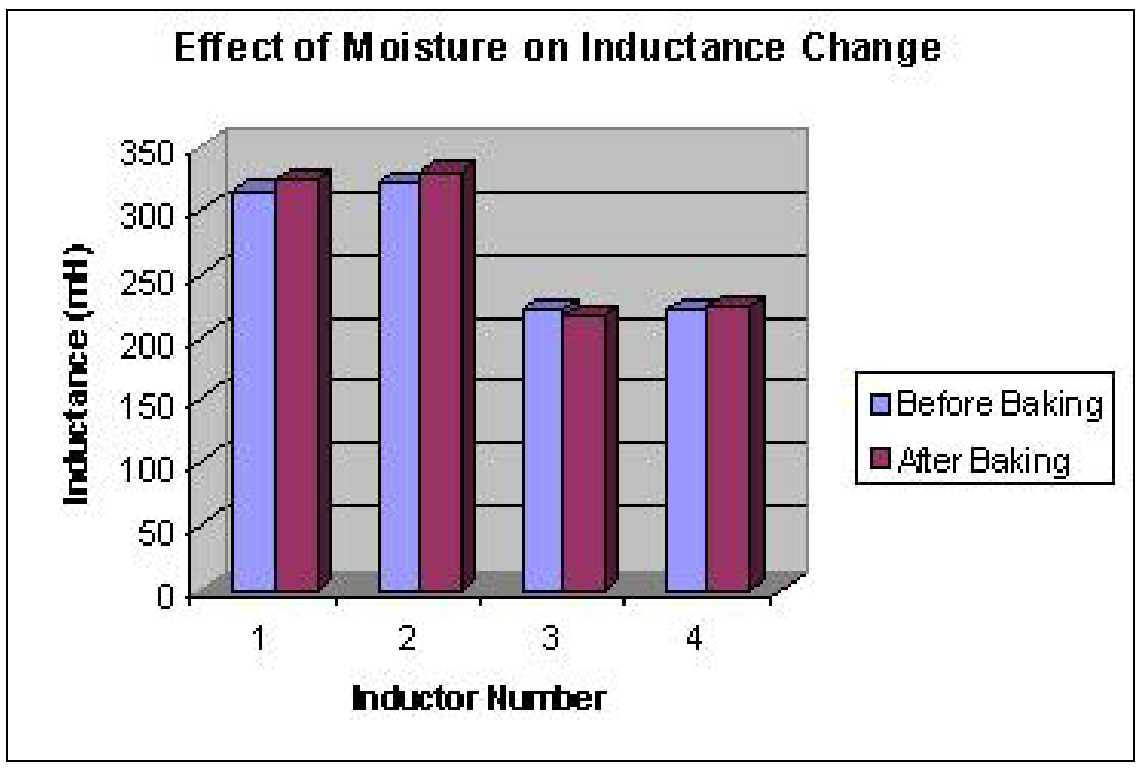

Figure 7.2. Inductance values after baking the board

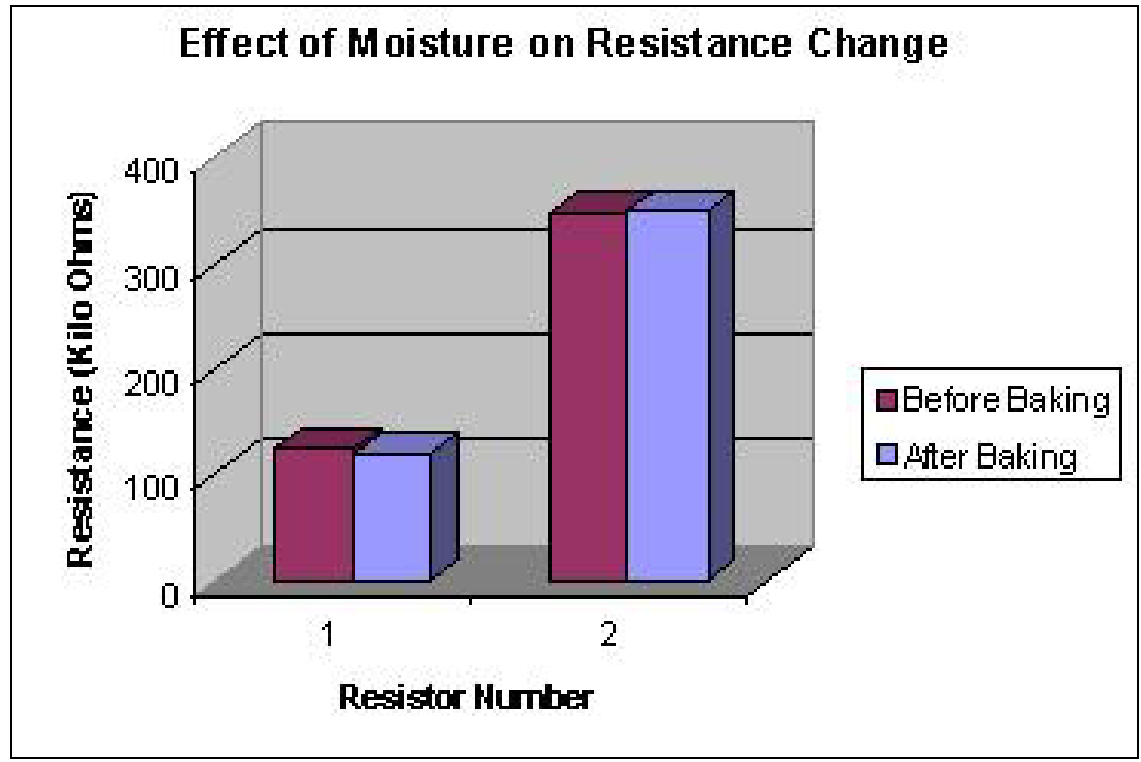

Figure 7.3. Resistance values after baking the board 


\section{Air-to-Air Thermal Cycling}

This reliability test is also called the MIL-STD-883 Method or IPC-SM-785 test. In this test, the boards are thermal cycled between $-55^{\circ} \mathrm{C}$ and $125^{\circ} \mathrm{C}$. Given this $180{ }^{\circ} \mathrm{C}$ temperature range, any board or chip that lasts beyond 1000 thermal cycles is considered reliable. The test entails keeping the board at $125^{\circ} \mathrm{C}$ for 10 minutes and $-55^{\circ} \mathrm{C}$ for 10 minutes taking the whole cycle 20 minutes to complete. In our current set-up, the board is moved from one chamber to another with one chamber being kept at $-55^{\circ} \mathrm{C}$ and the other being kept at $125^{\circ} \mathrm{C}$.

After baking the boards, the boards are then subjected to 100 thermal cycles to see that the passives do not fail prematurely. With the functionality of the passives unaffected, the board is then cycled 1000 times. Figure 7.4 shows the thermal chamber used for thermal cycling. After the cycling, the boards are baked again to remove the moisture. However after thermal cycling, it is noticed that the copper oxidizes which has a significant impact on the passive. Hence etching is performed to remove the copper oxide and the properties are measured after that. Figure 7.5, 7.6 and 7.7 show the change of the electrical parameters after 1000 thermal cycles and etching away the copper oxide.

From the Figures, it can be seen that the capacitance decreases after thermal cycling. This change is expected as the capacitance undergoes thermomechanical deformation resulting in the decreased capacitance. After oxidation, the capacitance goes down by an average of $0.7 \%$. Hence oxidation does not have 
a significant impact on capacitance. The capacitance decreases by an average of $4 \%$ after oxide removal. The inductance drops by an average of $18 \%$ with the maximum drop being $20 \%$. However when the inductor is etched to remove the oxide, the final change after thermal cycling is only $8 \%$. One possible reason for the drop in inductance could be the change in the magnetic permeability of copper with thermal cycling and the thermo-mechanical deformation induced in the inductors. The average resistance change is around $-13 \%$ and the maximum resistance change is $-16 \%$. However when the resistor is etched, the change increases to an average of $-10 \%$ and a maximum of $-12 \%$. This is because the copper oxide on the pads gets etched away decreasing the resistance.

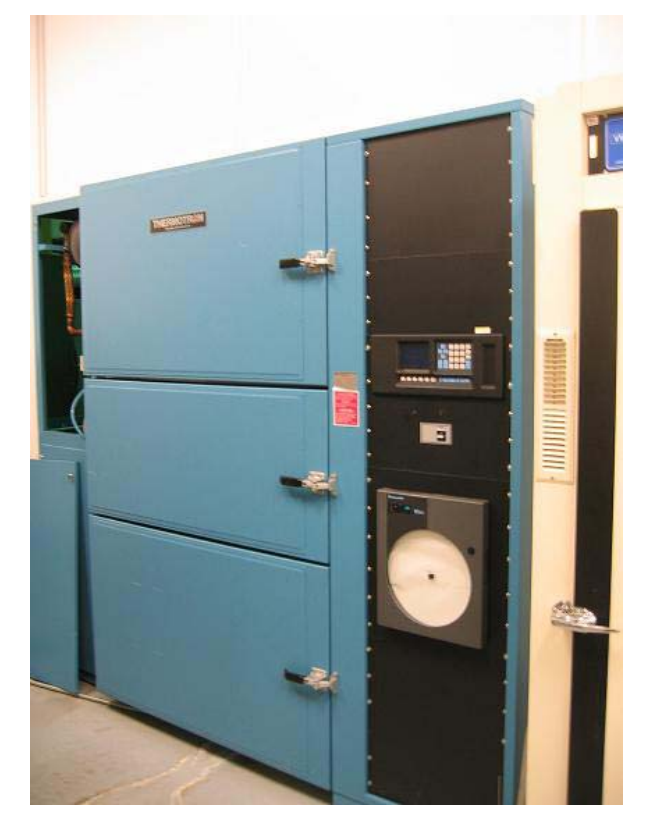

Figure 7.3. Picture of the Thermal Chamber used 


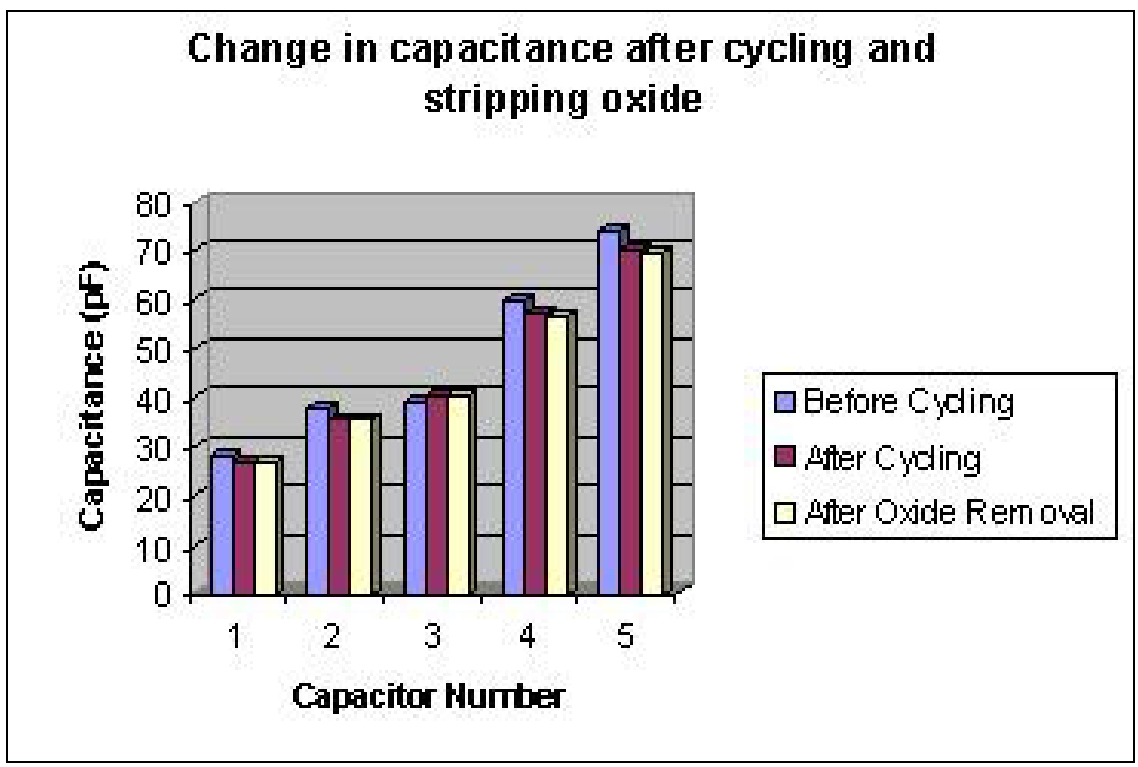

Figure 7.5. Change in capacitance after 1000 thermal cycles

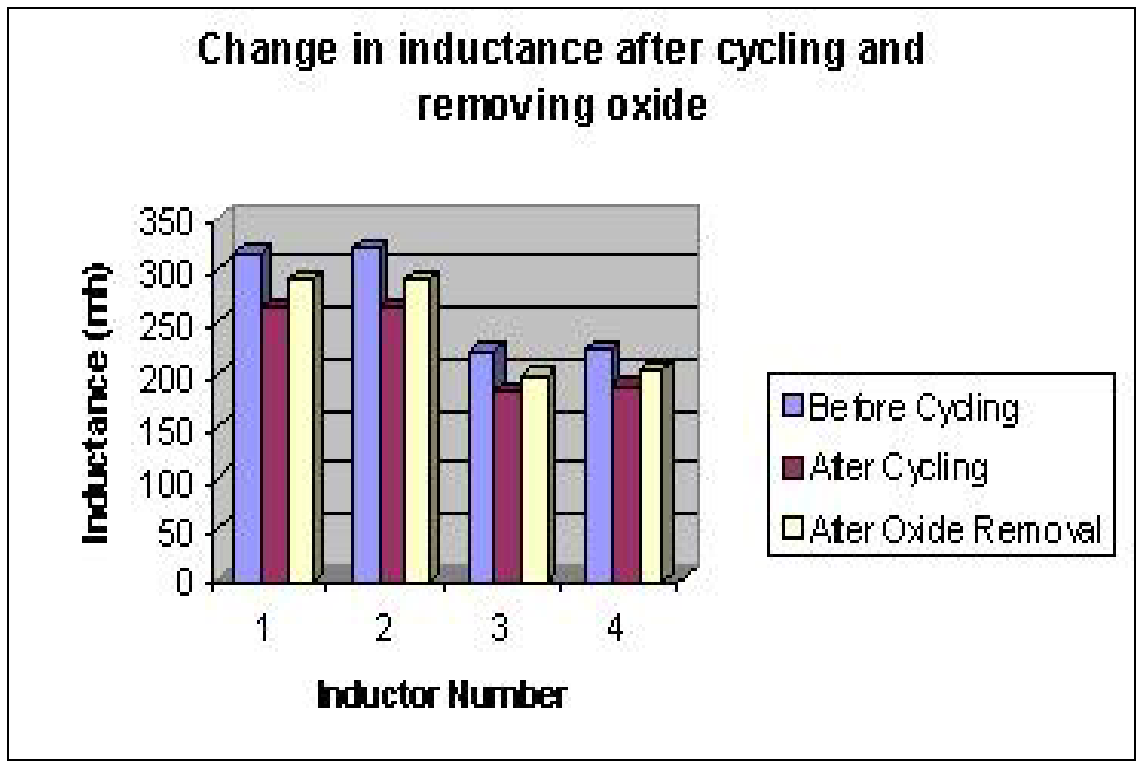

Figure 7.6. Change in inductance after 1000 thermal cycles 


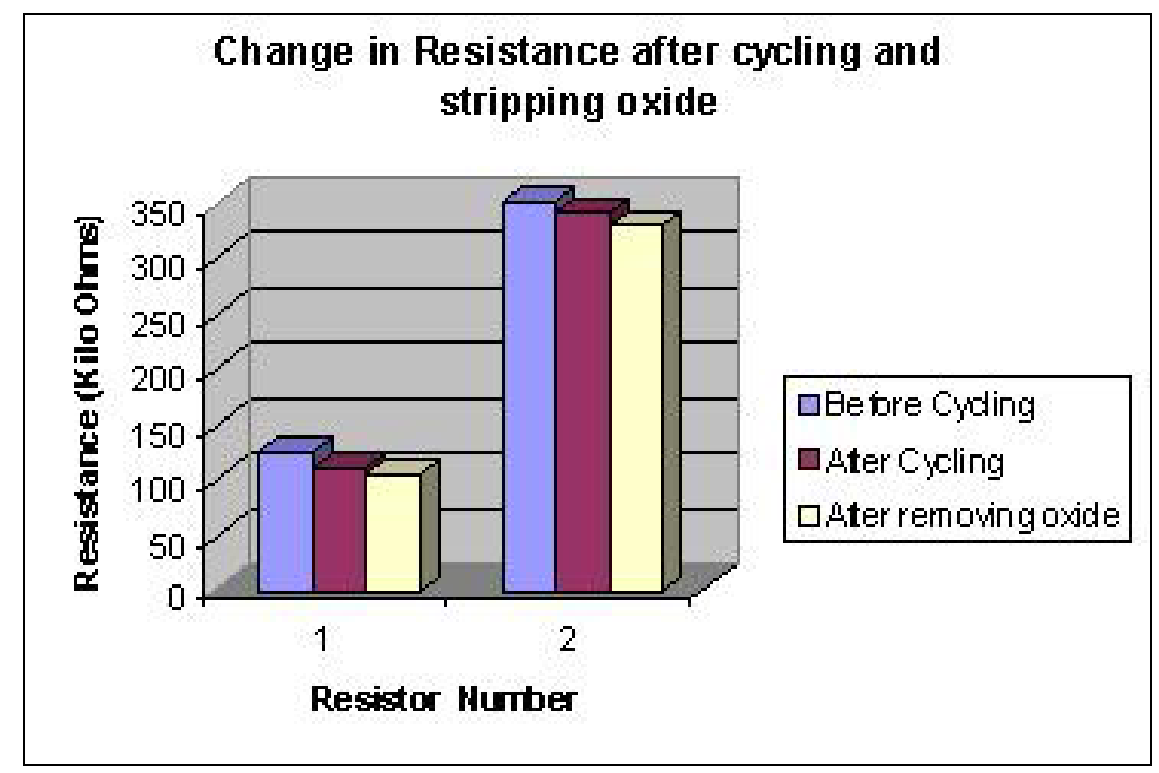

Figure 7.7. Change in resistance after 1000 thermal cycles

\section{Humidity Testing}

The other test performed on the board with passives is the humidity test. In this test, the board is subjected a temperature of $85^{\circ} \mathrm{C}$ and $85 \%$ Relative Humidity (RH). The test is performed in a Thermatron 2800 chamber as shown in Figure 7.8. The boards are kept for 100 hours initially and the electrical parameters are measured. The boards are then kept for 400 more hours for a total of 500 hours. The results are plotted in Figures 7.9, 7.10 and 7.11. As expected, the capacitance went up due to moisture absorbed by the dielectric. The average increase in capacitance was 5\% after 100 hours and 10\% after 500 hours. The inductance went up by an average of $4 \%$ after 100 hours and $8 \%$ after 500 hours. 
The resistance went down by an average of 3\% after 100 hours and 7\% after 500 hours.

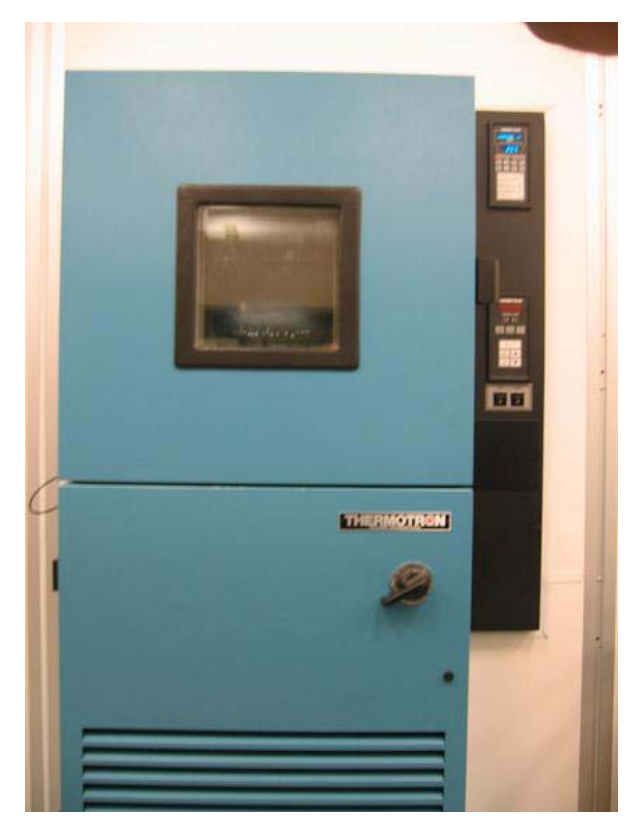

Figure 7.7. Humidity Chamber used

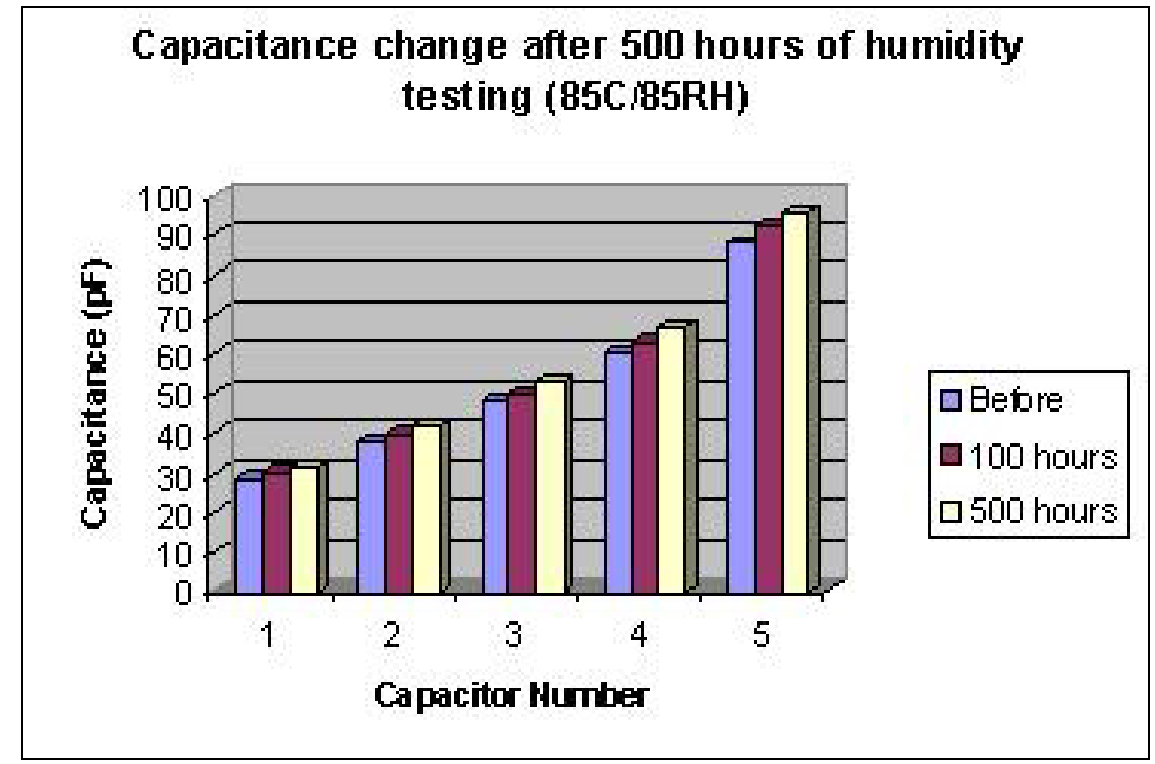

Figure 7.9. Capacitance change after humidity testing 


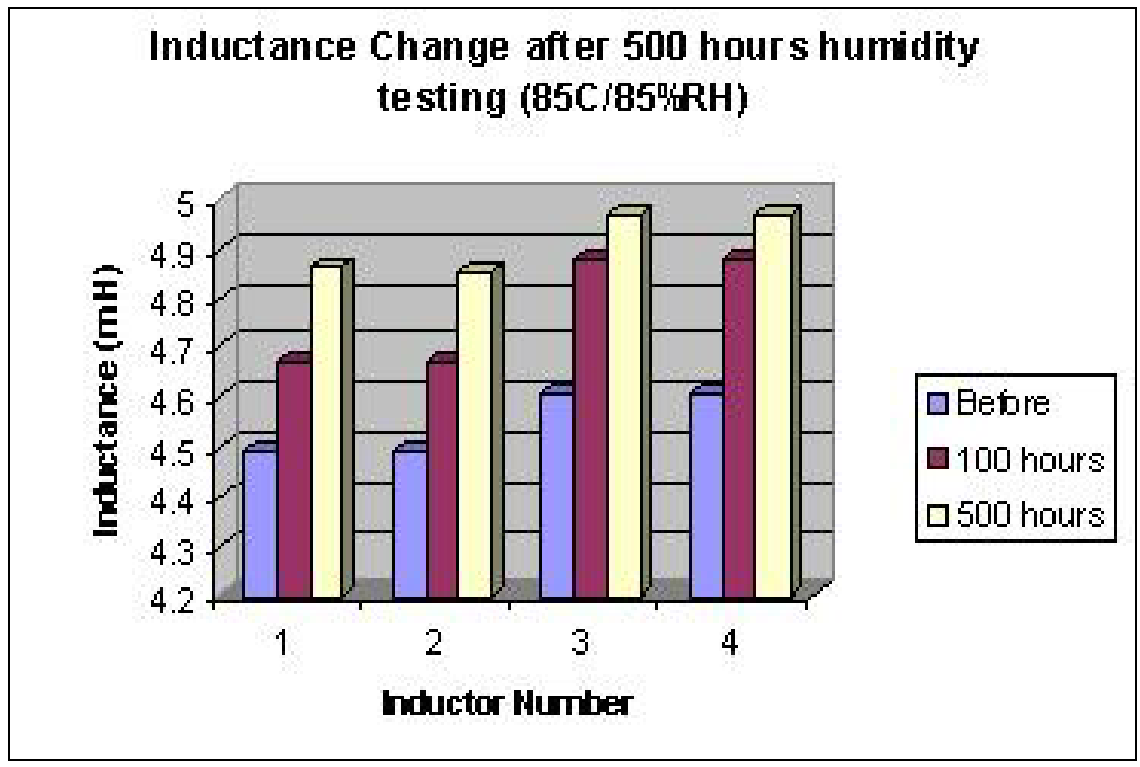

Figure 7.10. Inductance change after humidity testing

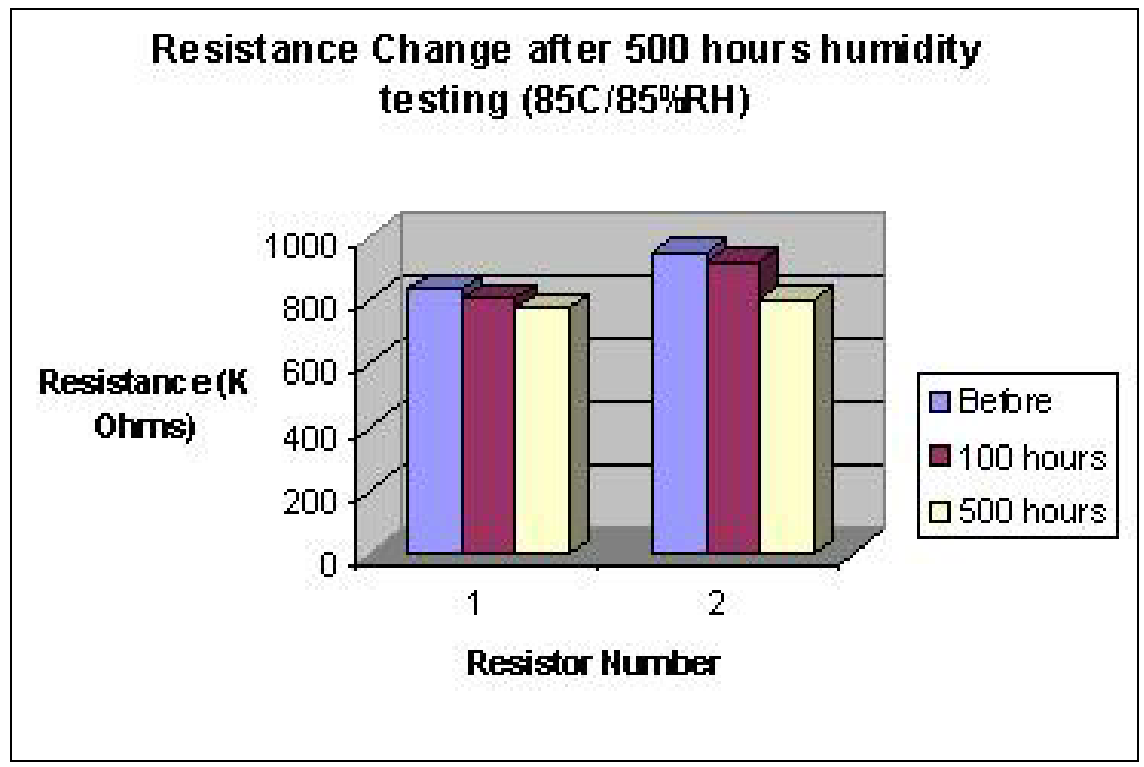

Figure 7.11. Resistance change after humidity testing 


\section{CHAPTER VIII}

\section{PERFORMANCE OF INTEGRAL PASSIVES DURING}

\section{FIELD USE}

The previous chapters have looked at the change in electrical parameters of the passives with thermal cycling and humidity. FEA models were constructed and validated against experimental data. However the effect of these changes in electrical parameters needs to be determined. In particular, the system performance needs to be evaluated at the changed electrical parameters. To this purpose, the performance of a low pass and high pass filter are evaluated. A circuit is designed with capacitors and inductors from the test board and the performance evaluated after 1000 thermal cycles and humidity testing. In addition, the results from the FEA analysis are also incorporated. This analysis helps the designers get an idea about the how reliable the passives should be on the board to get maximum performance.

\section{$\underline{\text { Low Pass Filter }}$}

Low pass filters are the filers in which frequencies above a certain range are not allowed to pass through. It consists of series inductors and shunt 
capacitors, which tend to block high frequency signals. Figure 8.1 shows a Figure of a simple low pass filter.

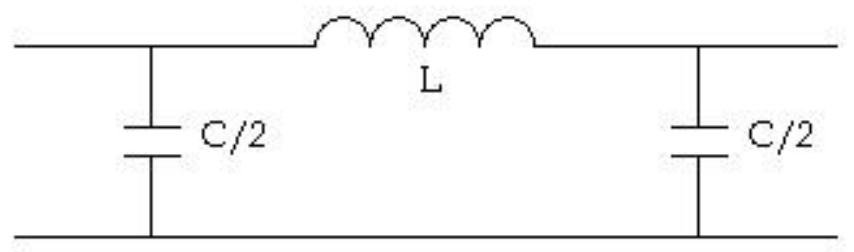

Figure 8.1. Schematic of a low pass filter

The cut off frequency is defined as the frequency above, which no signal passes through. It is denoted by $\omega_{c}$ and is given by

$$
\omega_{c}=\frac{2}{\sqrt{L C}}
$$

Above the cutoff frequency, the attenuation constant $\alpha$ increases steadily resulting in a drop in the signal propagation and finally as $\omega \rightarrow \infty, \alpha$ $\rightarrow \infty$. The attenuation constant is defined as the rate of decay with distance. The complex propagation constant $(\gamma)$ is defined by sum of the attenuation constant and the complex phase constant. In the case of the above filter, the propagation constant is given by

$$
e^{\gamma}=1-\frac{2 \omega^{2}}{\omega_{c}^{2}}+\frac{2 \omega}{\omega_{c}} \sqrt{\frac{\omega}{\omega_{c}^{2}}-1}
$$


where $\omega$ is the frequency. The real part of the propagation constant gives the attenuation constant and the complex part gives the phase constant. Figure 8.2 shows the response of the filter as a function of frequency.

A hypothetical case is now considered in which the inductance is taken to be the board value of $4.86 \mu \mathrm{H}$ (the FEA value is $4.951 \mu \mathrm{H}$ ) and the capacitance is taken to be the board value of $73.7 \mathrm{pF}$ (the FEA value is $71.18 \mathrm{pF}$ ).

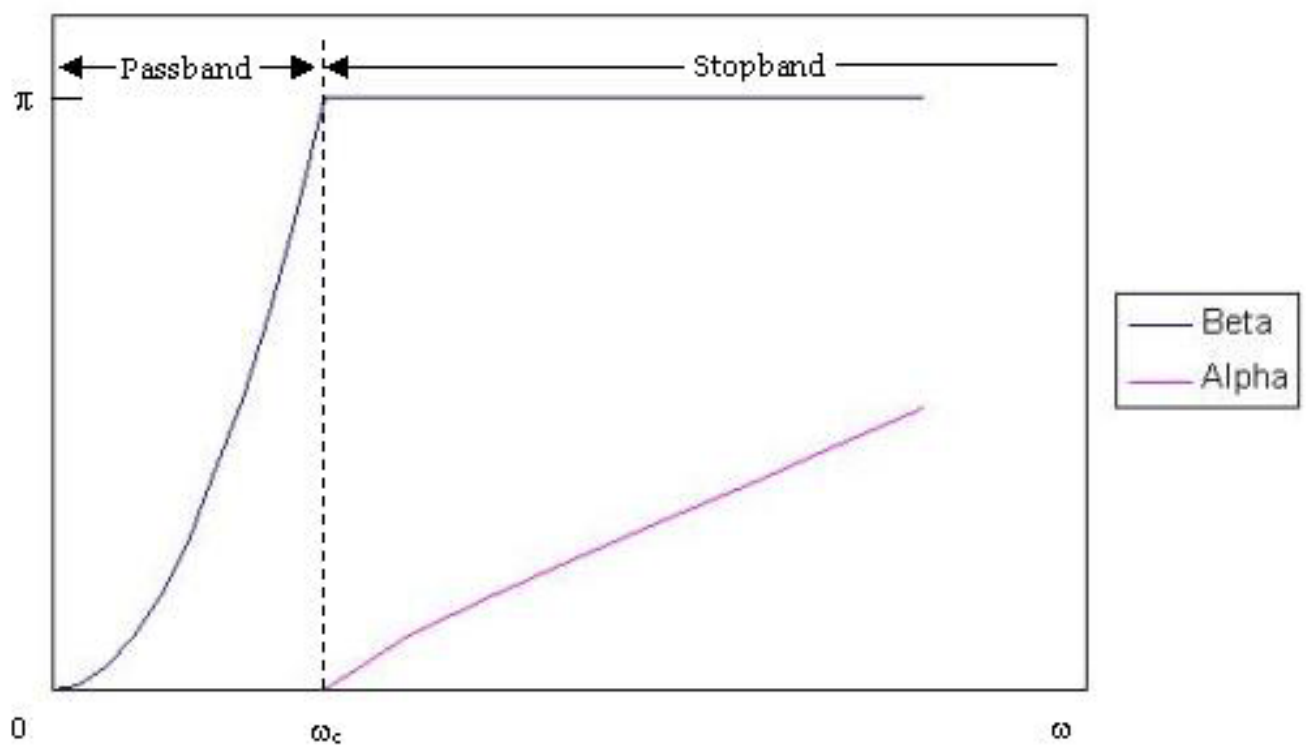

Figure 8.2. Low pass filter characteristics

\section{Experimental Results}

The cutoff frequency considering experimental results would $105.67 \mathrm{MHz}$. The experimental change thermal cycling observed in the inductance is $-4.75 \%$ and the capacitance change is $-4.8 \%$. Taking this into account, the inductance 
changes to $4.64 \mu \mathrm{H}$ and the capacitance changes to $70.14 \mathrm{pF}$. The new cutoff frequency is now $110.86 \mathrm{MHz}$ or changes by nearly $5 \%$. The filter will now allow an additional $5 \mathrm{MHz}$ of signal to pass through it. This represents a huge change in most filters and this tolerance is not acceptable for stable, noise free performance. In addition, another change is in the decay of the signal after it has passed the cutoff frequency. Figure 8.3 shows the change in the attenuation constant after the change in electrical parameters. The attenuation constant goes down, meaning the signal will decay slower after the cutoff frequency. So this in addition with the change in cutoff frequency, will hinder the performance of the filter.

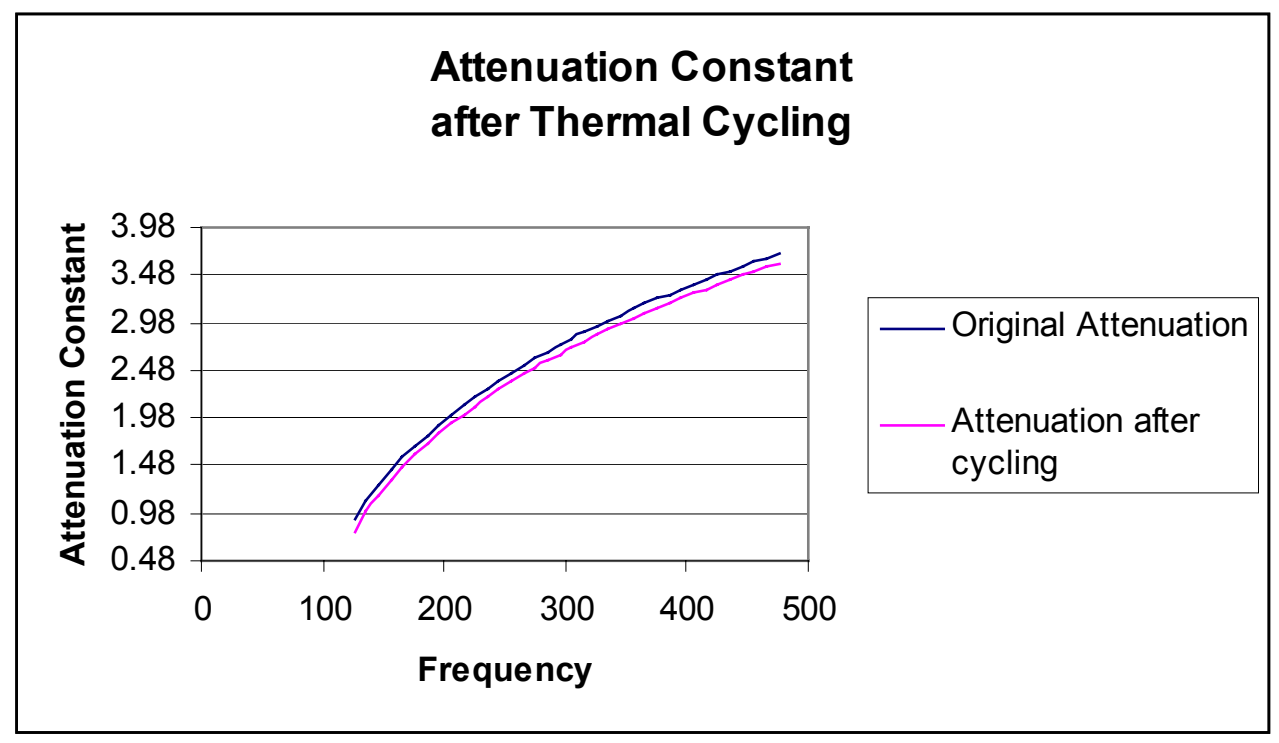

Figure 8.3. Change in Attenuation constant after thermal cycling of the filter 
After humidity testing, the capacitance increases by $10.2 \%$ and inductance increases by $8.2 \%$. Hence the changed cutoff frequency is $96.67 \mathrm{MHz}$. This massive change of $8.5 \%$ in cutoff frequency means that the filter will stop additional $9 \mathrm{MHz}$ of frequency from passing through it. Again such a big change can hamper the proper functioning of the filter. However the attenuation constant in this case goes up after the cut off frequency meaning that the signal will decay faster after the cutoff frequency. SO the change in cut off frequency is balanced off by the increase in attenuation constant.

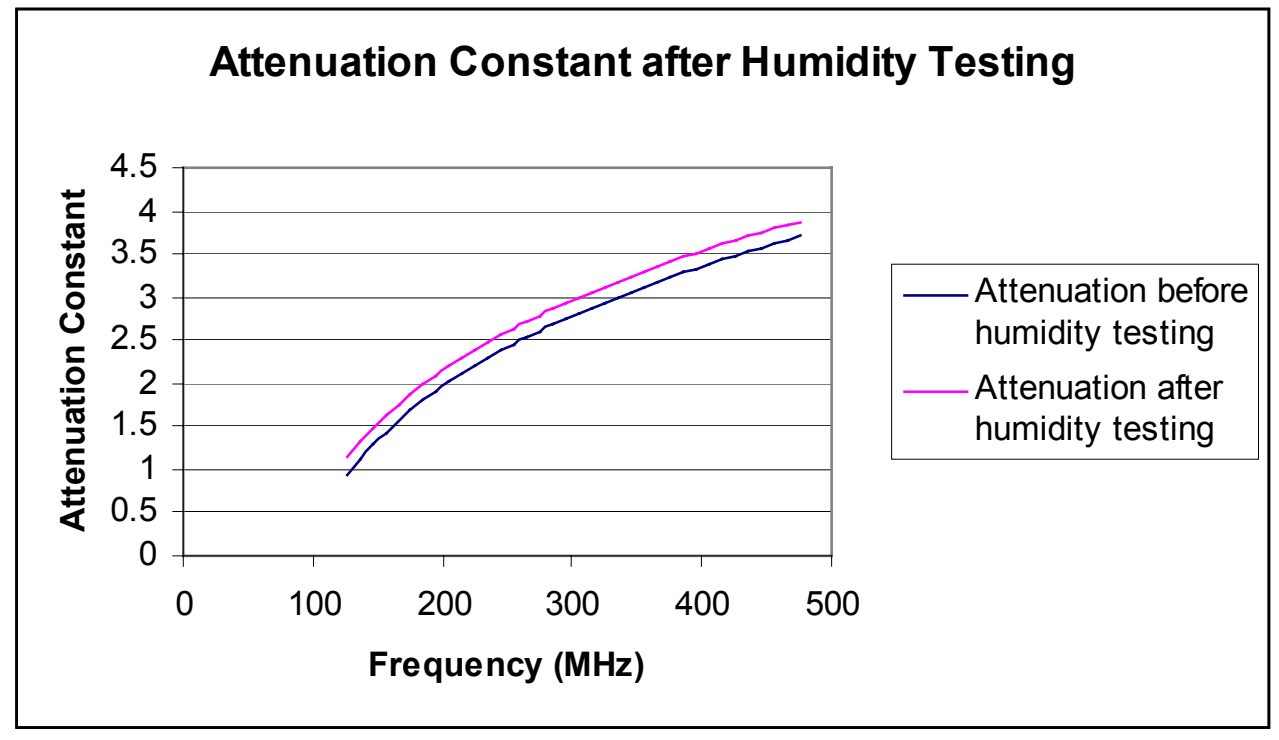

Figure 8.4. Change in Attenuation constant after humidity testing

It is important to note that both ends of the spectrum are covered in the scenarios observed above. In one case, additional frequencies are allowed to pass through and in another; some frequencies, which had been previously allowed, 
are now blocked. However, the attenuation constant in thermal cycling decreases, which aggravates the situation while in humidity testing, the attenuation constant increases balancing out the change in cutoff frequency. However, in both instances, the working of the filter is compromised.

\section{FEA Results}

The cutoff frequency in this case is $106.53 \mathrm{MHz}$. The change in the capacitance is $3.05 \%$ and the change in inductance is $1.25 \%$. Hence the cutoff frequency changes to $108.89 \mathrm{MHz}$. The change in the cutoff frequency is $2.2 \%$ and it will allow an additional $2.36 \mathrm{MHz}$ to get through.

\section{$\underline{\text { Amplifier }}$}

Another commonly used component in electrical circuits is the amplifier. In simple terms, the amplifier increases the input voltage to the output voltage. In order to determine the effect of passive change on the amplifier, a simple GaAs Field Effect Transistor (FET) is evaluated with changed passive parameters. In order to find the equivalent changes, the FET is constructed with embedded passives in the board as shown in figure 8.5. The gate to source capacitance on the FET is denoted by $\mathrm{C}_{\mathrm{gs}}$ and the gate to source capacitance on the board as an embedded passive is denoted by $\mathrm{C}_{\mathrm{GS}}$. Similarly, the drain to source resistance on the FET is denoted by $R_{d s}$ and the drain to source resistance as embedded in the board is denoted by $\mathrm{R}_{\mathrm{DS}}$. The passives embedded in the 
board are the ones that have been subjected to thermal cycling and humidity testing. The gain of the FET is given by

$$
G=\frac{g_{m}^{2} R_{D S}}{\sqrt{R_{D S}^{2} \omega^{2} C_{T}^{2}+1}}
$$

where $g_{m}$ is the transconductance (ratio of the AC output current to the input voltage), $C_{T}$ is the total capacitance of the circuit which is the sum of the gate to source capacitance on the FET and the gate to source capacitance on the circuit. Figure 8.5 shows a FET circuit for a common source configuration.

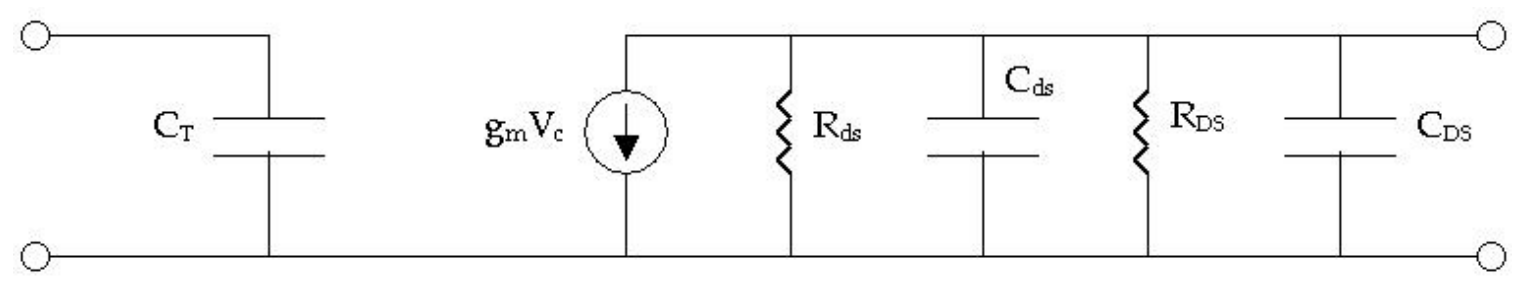

Figure 8.5. GaAs FET in the common source configuration

The values of the different parameters are:

$\mathrm{g}_{\mathrm{m}}=40 \mathrm{mS}$

$\omega=100 \mathrm{MHz}$

$\mathrm{C}_{\mathrm{GS}}=28.05 \mathrm{pF}$ (capacitor 1 on the experimental board) 


\section{Thermal Cycling}

The resistance in the thermal cycled boards (taken as $R_{D S}$ ) is $121000 \Omega$ before cycling. The gain at the above parameters is 5.69. After thermal cycling, the gate to source capacitance changes to $26.95 \mathrm{pF}$ and the drain to source resistance changes to $110000 \Omega$. The revised gain at these parameters is 5.92 . It is interesting to note that despite a change of $4 \%$ in the capacitance and $10 \%$ in the resistance, the amplifier gain changes by a very small amount of $4 \%$. This is because the change in resistance does no affect the gain of the amplifier due to the fact that $\left(R_{L} \omega C_{T}\right)^{2}$ is much bigger than 1 and the resistance terms hence cancel out each other leaving only the capacitance and the transconductance. This is supported by the fact that if only the capacitance change is considered, the new gain will be 5.92 and if only the resistance changes, the gain still is 5.69 .

\section{Humidity Testing}

The experimental board tested in humidity testing has slight different resistors and hence the resistance for the drain to source is taken to be equal to the value of $950000 \Omega$. The value of the gain is now 5.92. After being subjected to humidity conditions, the value of the capacitance rises to $31.31 \mathrm{pF}$ (9.8\% change) and the resistance drops to $795000 \Omega(-16.9 \%$ change). The value of the new gain is 5.10. The new gain undergoes a drastic change of $-14 \%$. This will result in imminent failure of the amplifier. 


\section{CHAPTER IX}

\section{CONCLUSIONS AND FUTURE WORK}

\section{Conclusions}

The study conducted in this research has given some understanding in the reliability of embedded passives. Complex thermo-mechanical-electrical models have been developed that take time and temperature dependent properties into consideration. Based on the experimental and FEA results and the field use analysis, it can be concluded that the thermo-mechanical deformation can have a significant impact on the functioning of the passive component. In addition, it was found from the parametric studies that the DNP is crucial and can result in higher changes in the electrical parameters. Finally, the fabrication process can be highly influential in the final electrical value of the passive. Based on the simulations performed and the experimental data collected, the following conclusions can be drawn:

- Capacitance, inductance and resistance change by $-4 \%,-8 \%$ and $-12 \%$ respectively after 1000 thermal cycles.

- The change in capacitance during humidity testing was 5\% after 100 hours and $10 \%$ after 500 hours. The change in inductance was $4 \%$ after 100 hours and $8 \%$ after 500 hours. The change in resistance was 3\% after 100 hours and $7 \%$ after 500 hours. 
- Moisture did not significantly affect the performance of the passives.

- Oxidation after thermal cycling does not impact the performance of a capacitor but after etching the passives, the inductance change dropped from $-18 \%$ to $-8 \%$ and the resistance change dropped from $-16 \%$ to $-12 \%$.

- The fabrication process can alter the capacitance by as much as $-3.12 \%$ from the designed theoretical value.

\section{Contributions}

- Developed an experimental and theoretical program to study the thermomechanical reliability of embedded passives.

- Developed finite element models that take into account the time, temperature and directional material properties.

- Developed finite element models that simulate a part of the fabrication process.

- Developed parametric finite element models that change the DNP of the passive.

- Fabricated experimental boards in the clean room.

- Performed reliability experiments on the fabricated test boards.

- Implemented an electro-thermo-mechanical approach to determine the effect of deformation on electrical performance.

- Validated the results from theoretical models with experimental data 


\section{Future Work}

The research in the field of embedded passives continues with respect to materials and processes and there is no standardization as of today in the field of embedded passives. While this thesis is one of the preliminary efforts to take a look at the reliability of embedded passives, a multitude of processes and material could mean new tests and analysis methods in contrast to those developed in this thesis. For example, sputtering metals can result in residual stresses in the material, which is controlled by a variety of factors. The future analysis procedures need to take all of the above into consideration. Materials such as Barium Titanate have a Curie temperature of $105{ }^{\circ} \mathrm{C}$ and so thermal cycling it between $125^{\circ} \mathrm{C}$ and $-55^{\circ} \mathrm{C}$ is not possible since exceeding $105^{\circ} \mathrm{C}$ will cause Barium Titanate to lose it ferroelectric properties and convert it to a paraelectric dielectric. Hence new qualification tests will be required to qualify the passives. In addition, there is no criterion for the failure of passives given the wide range of application of passives. Some applications like decoupling capacitors can withstand change in electrical properties but need very low leakage properties. Other applications such as filter or amplifiers, as considered in chapter 8 , requires strict tolerances as small changes can cause malfunctioning of the passive. With increase in the number of layers in a HDW package, the potential for delamination and other mechanical failures can increase as well. 
The effect of mechanical failure on electrical functioning needs to be evaluated as well.

The models constructed in the thesis above do not take other components of the passives that are essential for the functioning of it into consideration. Pads, via and traces can also have an impact on the reliability of the passive and future thermo-mechanical-electro models needs to take the entire functioning passive as a single component. 


\section{REFERENCES}

1) R.R. Tummala, G.E. White, V. Sundaram, S.K. Bhattacharya, "SOP: the microelectronics for the $21^{\text {st }}$ century with Integral passive integration", Adv. Microelectronics, Jan./Feb. 2000, Pages: 13-19.

2) E.J. Reardon, R.W. Carpenter, "Novel, Practical Materials for Embedded Capacitors and Resistors - an Update", 2000 International Conference on High-Density Interconnect and Systems Packaging, Volume 19, 1996, pp.483489.

3) R.K. Ulrich, L.W. Schaper, Integrated Passive Component Technology, IEEE Components, Packaging \& Manufacturing Technology Society.

4) R.R. Tummala, Fundamentals of Microsystems Packaging, McGraw-Hill, pp.440.

5) J. Rector Jr., J. Dougherty, V. Brown, J. Galvagni, J. Prymak, “Integrated and Integral Passive Components: A Technology Roadmap" 1997 ECTC Electronic Components and Technology Conference.

6) R.R. Tummala, J. Laskar, “Gigabit Wireless: System-on-a-Package Technology" February 2004, Proceedings of the IEEE, Volume 92, No. 2, Pages: 376-377.

7) R.R. Tummala, 2000, Packaging Research Center, Georgia Institute of Technology, Atlanta, GA, Personal Communication. 
8) R.R. Tummala, Fundamentals of Microsystems Packaging, McGraw-Hill, Pages 727.

9) E. Itoh, K. Maki, K. Miyairi, “Effect of annealing on dielectric dispersion of tantalum oxide films prepared by RF sputtering", Annual Report Conference on Electrical Insulation and Dielectric Phenomena, October 17-20 1999, Volume 1, Pages: 62-65.

10) R.K. Ulrich, L.W. Schaper, Integrated Passive Component Technology, IEEE Components, Packaging \& Manufacturing Technology Society, Pages: 114 123.

11) G. Morcan, S.S. Ang, T. Lenihan, L.W. Schaper, W.D. Brown, "Characterization of thin film tantalum oxide capacitors on polyimide substrates", IEEE Transactions on Advanced Packaging, August 1999, Volume 22, Issue 3, Pages: 499-509.

12) K. Chen; M. Nielsen, S. Soss, E.J. Rymaszewski, Lu Toh-Ming, C.T. Wan, "Study of tantalum oxide thin film capacitors on metallized polymer sheets for advanced packaging applications", IEEE Transactions on Components, Packaging, and Manufacturing Technology, Part B: Advanced Packaging, May 1997, Volume 20, Issue 2, Pages: 117-122.

13) W.T. Liu, S. Cochrane, S.T. Lakshmikumar, D.B. Knorr, E.J. Rymaszewski, J.M. Borrego, T.-M. Lu, “Low-temperature fabrication of amorphous $\mathrm{BaTiO}_{3}$ thin-film bypass capacitors", IEEE Electron Device Letters, July 1993, Volume 14 , Issue: 7 , Pages: 320- 322. 
14) K. Baba, R. Hatada, S. Nakao, S. Miyagawa, Y. Miyagawa, "Formation of diamond like carbon films by plasma source ion implantation from $\mathrm{CH}_{4}$, $\mathrm{C}_{2} \mathrm{H}_{2}$ and $\mathrm{C}_{6} \mathrm{H}_{6}{ }^{\prime \prime}$, International Conference on Ion Implantation Technology Proceedings, June 22-26 1998, Volume 2, Pages: 1214-1217

15) A.C. King, S.S. Shoup, M.K. White, S.L. Krebs, D.M. Mattox, T. Polley, N. Darnell, K.R. Marken, Seung Hong; B. Czabaj, “The progress made using the combustion chemical vapor deposition (CCVD) technique to fabricate $\mathrm{YBa} / \mathrm{sub} 2 / \mathrm{Cu} / \mathrm{sub} 3 / \mathrm{O} / \mathrm{sub} 7-\mathrm{x} /$ coated conductors", IEEE Transactions on Applied Superconductivity, June 2003, Volume 13, Issue 2, Pages: 2643-2645

16) S.S. Shoup, S. Shanmugham, D. Cousins, A.T. Hunt, M. Paranthaman, A. Goyal, P. Martin, D.M. Kroeger, "Low-cost combustion chemical vapor deposition of epitaxial buffer layers and superconductors" IEEE Transactions on Applied Superconductivity, June 1999, Volume 9, Issue 2, Pages: 24262429.

17) P. Bendale, S. Venigalla, J. Ambrose, E. Verink Jr., and J. Adair, "Preparation of Barium Titanate Films at $55^{\circ} \mathrm{C}$ by an Electrochemical Method," Journal of the American Ceramic Society.

18) D. Nelms, R. Ulrich, L. Schaper, S. Reeder, "Anodization for forming embedded capacitors in MCM-D and MCM-L substrates," 48 th Proceedings of the Electronic Components and Technology Conference, 1998, Pages: 247-251. 
19) L. Matay, "Studies of dielectric characteristics of spin-coated polyimide films" The Fourth International Conference on Advanced Semiconductor Devices and Microsystems, 14-16 October 2002, Pages: 83- 86.

20) S.K. Bhattacharya, K.S. Moon, R.R. Tummala, G.S. May, “Meniscus Coating: A Low-Cost Polymer Deposition Method for System-on-Package Substrates" IEEE Transactions on Electronics Packaging Manufacturing, April 2003, Volume 26, No. 2.

21) S. Lahiry, V. Gupta, K. Sreenivas, A. Mansingh, "Dielectric Properties of SolGel Derived Barium-Strontium-Titanate $\left(\mathrm{Ba}_{0.4} \mathrm{Sr}_{0.6} \mathrm{TiO}_{3}\right)$ Thin Films" IEEE Transactions on Ultrasonics, Ferroelectrics and Frequency Control, July 2000, Volume 47, No. 4.

22) W. Borland, J. J. Felten, “Thick Film Ceramic Capacitors and Resistors inside Printed Circuit Boards" International Symposium on Microelectronics, October 2001, Pages: 452 - 457.

23) E. Diaz-Alvarez, J.P. Krusius, F. Kroeger, “Modeling and simulation of integrated capacitors for high frequency chip power decoupling" IEEE Transactions on Components and Packaging Technologies, December 2000, Volume 23 , Issue 4 , Pages: 611- 619.

24) D.J. Hayes, M.E. Grove, W.R. Cox, “Development and Application by Ink-Jet printing of Advanced Packaging Materials" 1999 International Symposium on Advanced Packaging Materials, 14-17 March 1999, Pages: 88-93. 
25) P. Chinoy, M. Langlois, "Thin-film embedded resistor and capacitor technologies", Circuit World, 2004, Volume 30, Number 1, Pages: 16-19

26) D. Schatzel, “Development Of Reliable Electronic Packaging Solutions For Spacecraft Avionics Miniaturization Using Embedded Passives Devices" Proceedings of International Electronic Packaging Technical Conference and Exhibition, July 2003, Pages: 797-800.

27) W. Borland, J.J. Felton, L.E. Dellis, S. Ferguson, D. Majumdar, A. B. Jones, M.S. Lux, R.R. Traylor, M.Doyle, "Ceramic Resistors and Capacitors Embedded In Organic Printed Wiring Boards" Proceedings of International Electronic Packaging Technical Conference and Exhibition, July 2003, Pages: 797-800.

28) J.T. Strydom, J.D.V. Wyk, "Investigation of Thermally Induced Failure Mechanisms in Integrated Spiral Planar Power Passives" 37th IAS Annual Meeting. Conference Record of the Industry Applications Conference, Volume 3, 13-18 October 2002 Pages: 1781-1786.

29) K. Fairchild, G. Morcan, T. Lenihan, W. Brown, L. Schaper, S. Ang, W. Sommers, J. Parkerson, M. Glover, "Reliability of Flexible Thin-Film Embedded Resistors and Electrical Characterization of Thin-Film Embedded Capacitors and Inductors" 47th Proceedings of the Electronic Components and Technology Conference, 1997, 18-21 May 1997, Pages: 730-738. 
30) J. Zhou, J.D. Myers, J.J. Felten, “Embedded Passives Technology for PCBs: Materials, Design and Process" International Microelectronics and Packaaging Society, 2002

31) S.Y. Lee, W.G. Odendaal, J.D. van Wyk, “Thermo-Mechanical Stress Analysis for an Integrated Passive Resonant Module" IEEE Transactions on Industry Applications, Volume 40, No. 1, Jan - Feb 2004, Pages: 94 - 102.

32) Iannuzzelli, R., "Predicting Plated-Through-Hole Reliability in High Temperature Manufacturing Process" Proceedings of the $41^{\text {st }}$ Electronics and Technology Conf., 1991, pp 410-442

33) H. Murai, Y. Takeda, N. Takano, "Halogen-free materials for PWB and advanced packaging substrate" International Symposium on Advanced Packaging Materials, 2000, Pages: 221-226.

34) R.C. Dunne, "An Integrated Process Modeling Methodology and Module for Sequential Multi-layered high-density substrate fabrication for microelectronic packages" Ph.D. Thesis in Mechanical Engineering, Georgia Institute of Technology, 2000.

35) Ramakrishna, G, et al, "Role of Dielectric Material and Geometry on the ThermoMechanical Reliability of Microvias" $52^{\text {nd }}$ Electronic Compoenents and Technology Conference. 